\title{
Experimental Evaluation of a Triple-State Sorption Chiller
}

\author{
by \\ Daniel Bowie, B.A.Sc., Mechanical Engineering \\ University of New Brunswick
}

A thesis submitted to the Faculty of Graduate and Postdoctoral Affairs in partial fulfilment of the requirements for the degree of

Master of Applied Science

in

Sustainable Energy

Carleton University

Ottawa, Ontario

(C) 2016, Daniel Bowie 


\section{Abstract}

Globally, residential electricity consumption for space cooling is projected to increase by a factor of 40 over the course of the $21^{\text {st }}$ century. Given that $66.8 \%$ of worldwide electricity is generated from the combustion of fossil fuels, a surge in air conditioning of this magnitude would add millions of tonnes of carbon dioxide to the atmosphere annually. The extent of these emissions can be reduced by upgrading the energy efficiency of the existing air conditioner stock, by employing more stringent building energy codes, and by implementing energy conservation programs. However, the most effective mitigation strategy may be the widespread adoption of alternative cooling technologies that consume considerably less electrical energy. One such technology is the sorption chiller, which can be driven by lowgrade heat provided by solar thermal collectors. Although residential solar-driven sorption chillers have gained popularity during the past decade, there exist approximately only 1000 worldwide installations today. The unique nature of each system (i.e., local climate, solar collector size/type/orientation, utilization of thermal storage, operating strategy) makes it difficult to extend the performance of existing installations to future projects. Therefore, before widespread implementation of this technology can occur, more work is required to adequately model the performance of the current generation of commercially available sorption chillers over their full range of operating conditions. This thesis presents the experimental testing results of a novel triple-state sorption chiller with integrated cold storage. The performance of the chiller was measured for hot water inlet temperatures between $65^{\circ} \mathrm{C}$ and $95^{\circ} \mathrm{C}$, heat rejection inlet temperatures between $15^{\circ} \mathrm{C}$ and $35^{\circ} \mathrm{C}$, and chilled water inlet temperatures between $10^{\circ} \mathrm{C}$ and $25^{\circ} \mathrm{C}$. The performance data collected 
during these tests were then used to develop a Microsoft Excel-based model for implementation in the TRNSYS simulation software. The output of the model was then compared to the results of a five hour experimental charge test in which the inlet temperatures were varied throughout the experiment, resulting in a $0.7 \%$ error in the heat input energy and a $1.3 \%$ error in the heat rejection energy. 


\section{Acknowledgements}

I would like to thank my supervisor, Dr. Cynthia Cruickshank, for the guidance, patience, and unwavering encouragement she has provided over the past two years.

I would also like to thank my colleagues within the Solar Energy Systems Laboratory including Chris Baldwin, Dylan Bardy, Jayson Bursill, Jenny Chu, Brock Conley, Nina Dmytrenko, Darcy Gray, Kevin Khalaf, Jacek Khan, David Ouellette, Patrick Smith, Sarah Wert, and Adam Wills for your friendship, support, and assistance over the past two years.

I would like to acknowledge the financial support received from the Natural Sciences and Engineering Research Council of Canada's Smart Net-Zero Energy Buildings Strategic Research Network.

Finally, I would like to acknowledge the support and encouragement of my family throughout my academic career. 


\section{Table of Contents}

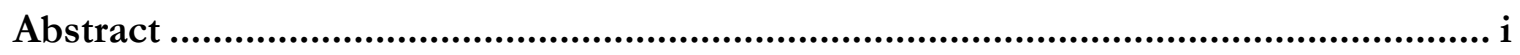

Acknowledgements ........................................................................................ iii

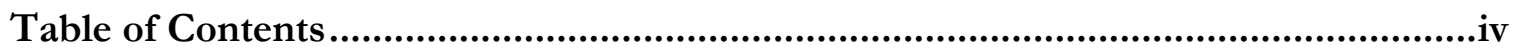

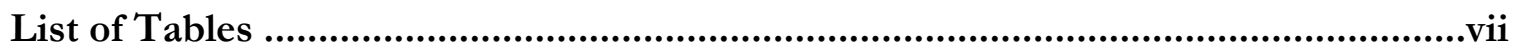

List of Figures .......................................................................................... viii

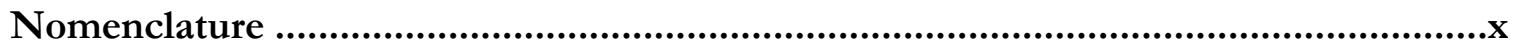

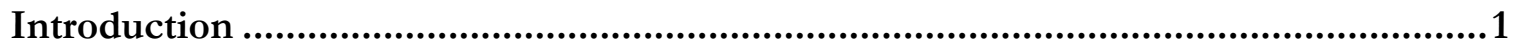

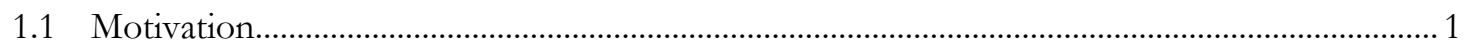

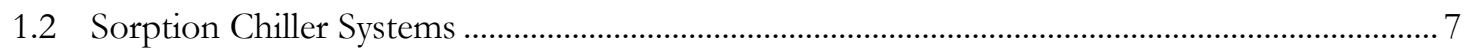

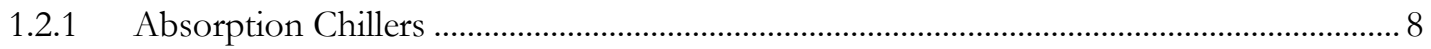

1.2.2 Adsorption Chillers....................................................................................................... 11

1.2.3 Triple-State Sorption Chiller ......................................................................................... 13

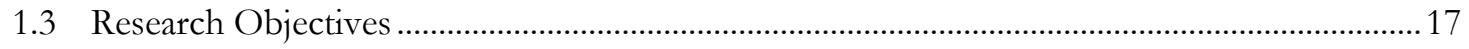

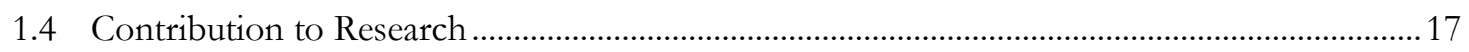

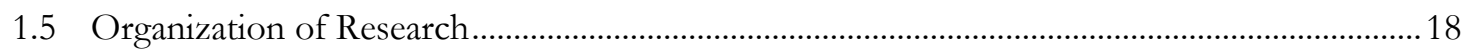

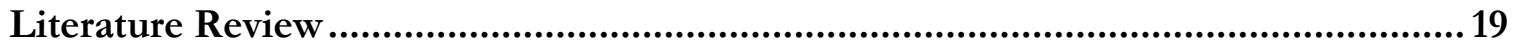

2.1 Sorption Chiller Performance Metrics ........................................................................................ 19

2.2 New Developments in Sorption Chillers ................................................................................21

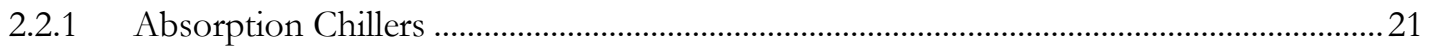

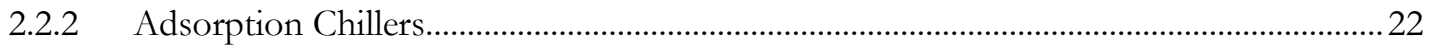

2.3 Comparison of Results from Recent Experimental Studies .....................................................24

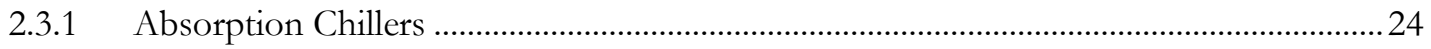

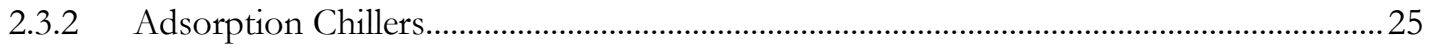


2.4 Existing ClimateWell Studies ...................................................................................................2

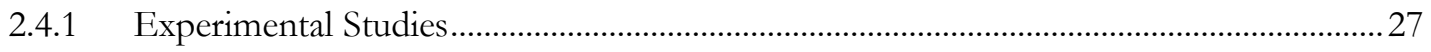

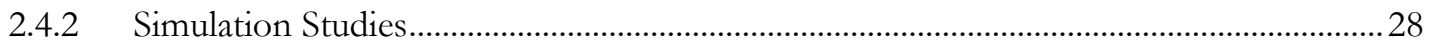

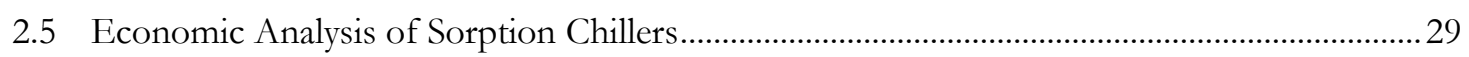

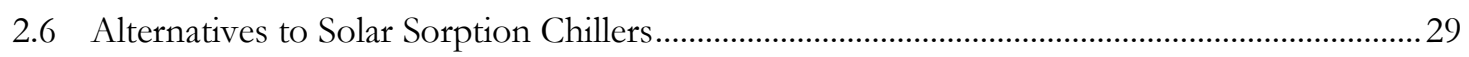

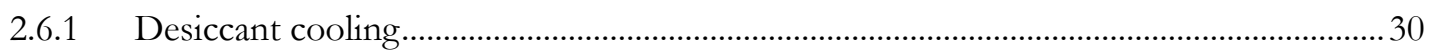

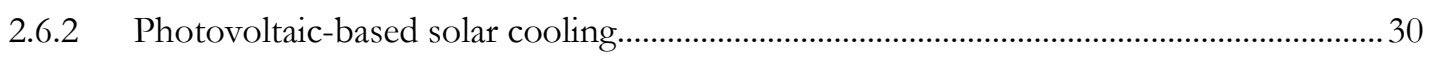

Experimental Design and Commissioning ……………….........................................32

3.1 Overview of Experimental Set-Up .......................................................................................... 32

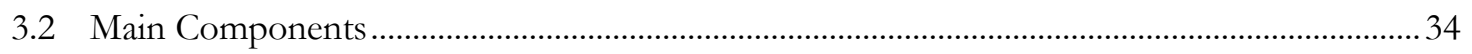

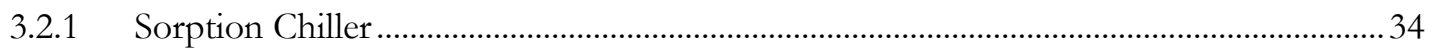

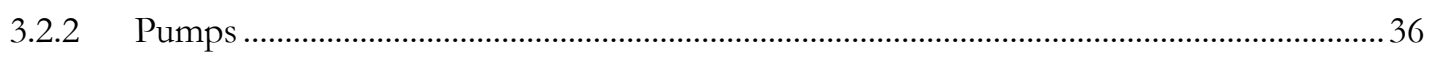

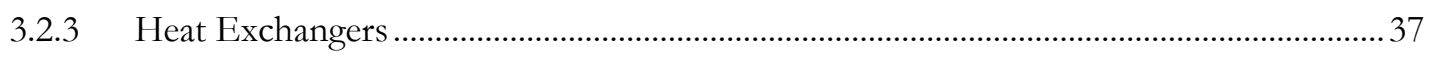

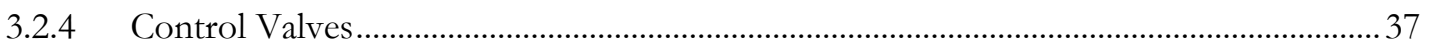

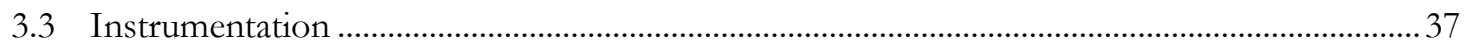

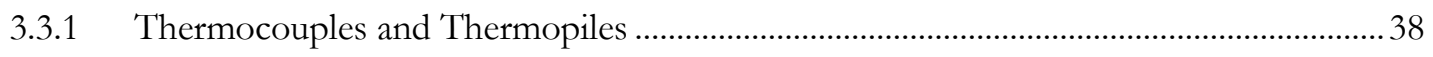

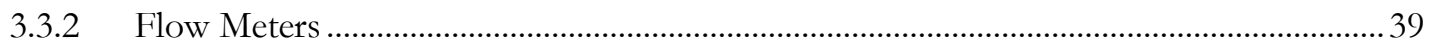

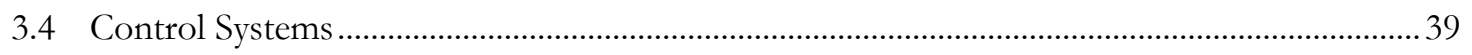

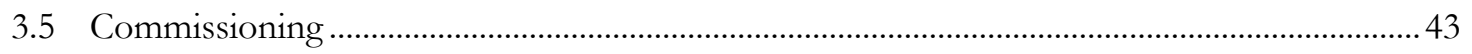

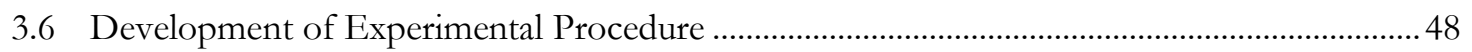

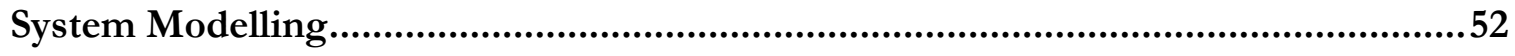

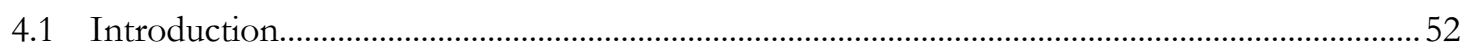

4.2 Existing TRNSYS Sorption Chiller Models .............................................................................. 52

4.2.1 Single-effect absorption chiller - Type 107 …................................................................... 53

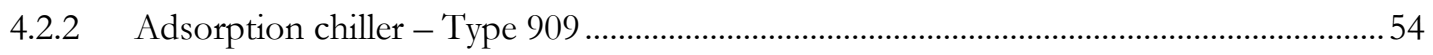


4.2.3 Limitations of existing TRNSYS Types ............................................................................ 55

4.3 Modelling Approach ............................................................................................................... 57

4.3.1 Charging - Condenser................................................................................................ 57

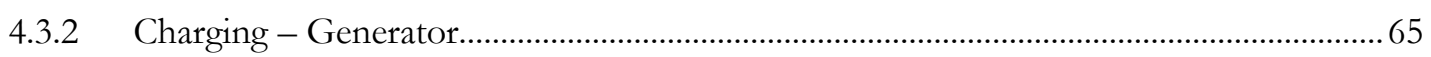

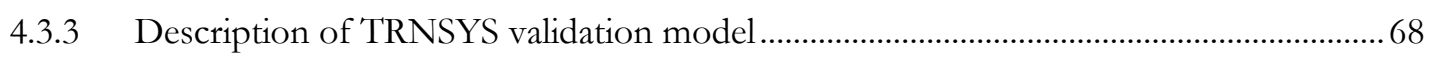

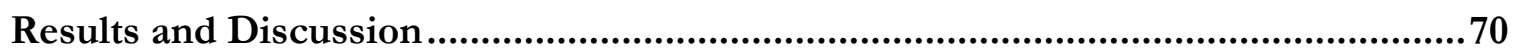

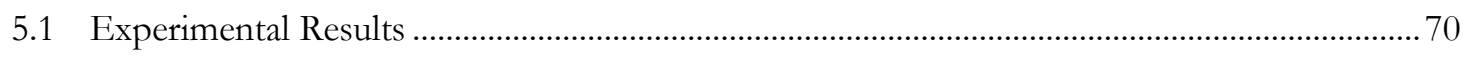

5.1.1 Charge Cycle .................................................................................................................. 70

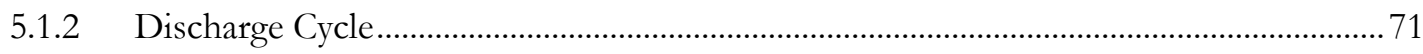

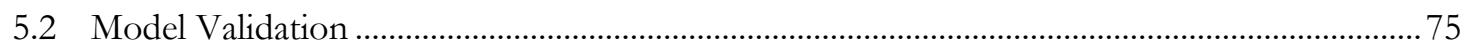

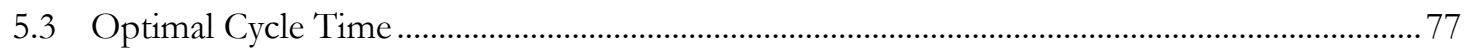

Conclusions and Future Work ....................................................................... 81

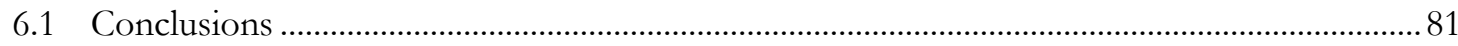

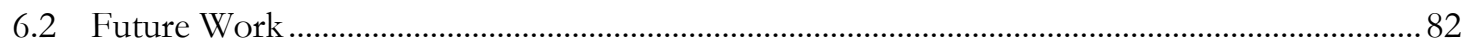

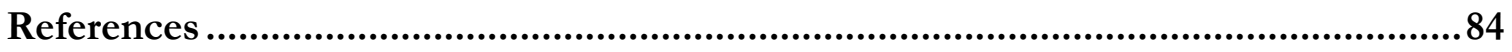

Appendix A Detailed System Schematic ............................................................................................... 90

Appendix B TRNSYS Deck File ……………………................................................................... 91

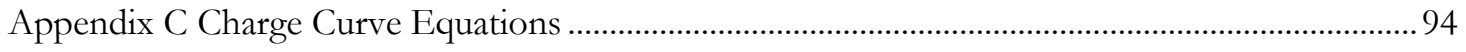




\section{List of Tables}

Table 2-1: Comparison of recent experimental findings for sorption chillers ..........................27

Table 3-1: Design temperatures, flow rates, and heat transfer rates ...........................................32

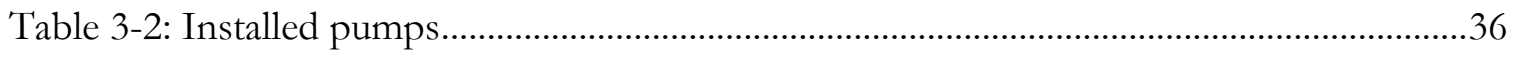

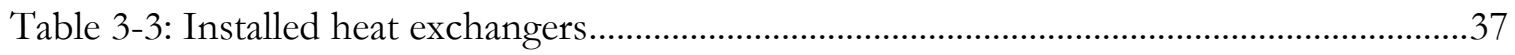

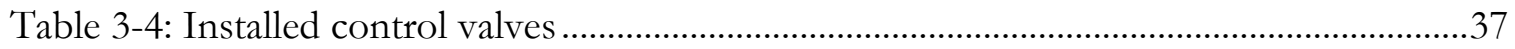

Table 3-5: Mean and standard deviation of the inlet temperatures during first three hours of

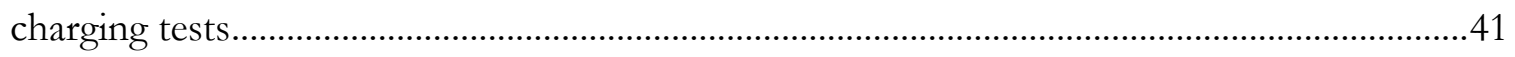

Table 4-1: Inputs and outputs for the Type 62 triple-state sorption chiller model..................69

Table 5-1: Comparison of model and experimental results .......................................................76

Table C-1: Steady state temperature differences for generator during charge cycle................. 96

Table C-2: Steady state temperature differences for condenser during charge cycle.................96 


\section{List of Figures}

Figure 1-1: Comparison of cooled floor space to total floor space and space cooling energy use in the Canadian residential sector .3

Figure 1-2: Comparison of outdoor temperature to electricity demand in Ottawa, and to the percentage of generation supplied by gas in Ontario from June 1, 2015 to August 31, $2015 . .5$

Figure 1-3: Correlation between outdoor temperature and electricity demand in Ottawa; between outdoor temperature and fraction of generation supplied by gas in Ontario..............6

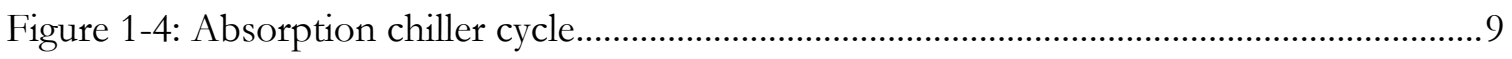

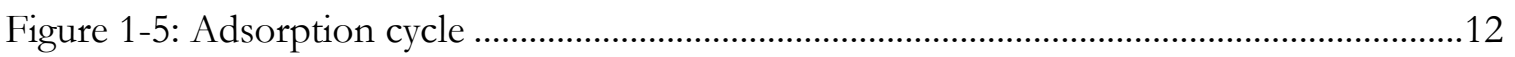

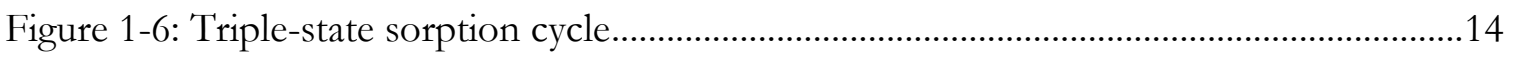

Figure 1-7: LiCl Dühring diagram illustrating the charge cycle ................................................15

Figure 1-8: LiCl Dühring diagram illustrating the discharge cycle ..........................................16

Figure 3-1: High-level schematic of experimental set-up ........................................................34

Figure 3-2: ClimateWell sorption chiller installed within the lab .............................................35

Figure 3-3: Driving circuit inlet temperatures during first three hours of charging tests ........41

Figure 3-4: Heat rejection inlet temperatures during first three hours of charging tests.........42

Figure 3-5: Adapter tool used for evacuation of sorption chiller and condenser plug ............44

Figure 3-6: Modified evacuation set-up ……….........................................................................46

Figure 3-7: Post-evacuation vacuum retention (Barrel A).........................................................48

Figure 3-8: Comparison of charge cycle for evacuated and non-evacuated starting condition

Figure 3-9: Sensitivity of charging rate for different initial condenser pressures.......................50 
Figure 4-1: Fractional cooling capacity throughout the discharge cycle of a triple-state sorption chiller with constant boundary conditions .56

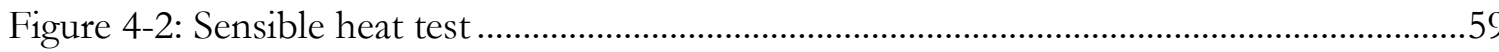

Figure 4-3: Determining the dimensionless heat transfer coefficient A ...................................60

Figure 4-4: Comparison of methodologies for determining SOC .........................................63

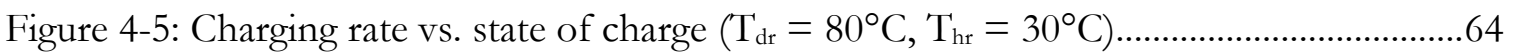

Figure 4-6: Charging rate vs. state of charge, with decay function $\left(\mathrm{T}_{\mathrm{dr}}=80^{\circ} \mathrm{C}, \mathrm{T}_{\mathrm{hr}}=30^{\circ} \mathrm{C}\right) .64$

Figure 4-7: Relationship between charging rate and temperature increase in the heat rejection circuit due to the cooling and condensing of the refrigerant in the condenser

Figure 4-8: Relationship between charging rate and temperature increase in the driving circuit due to the desorption of the refrigerant in the generator .67

Figure 4-9: TRNSYS validation model .68

Figure 5-1: Characteristic charge curves for varying heat rejection temperatures and constant driving temperatures of $65^{\circ} \mathrm{C}, 75^{\circ} \mathrm{C}, 85^{\circ} \mathrm{C}$, and $95^{\circ} \mathrm{C}$ 72

Figure 5-2: Characteristic charge curves for varying driving temperatures and constant heat rejection temperatures of $35^{\circ} \mathrm{C}, 25^{\circ} \mathrm{C}$, and $15^{\circ} \mathrm{C}$

Figure 5-3: Comparison of experimental and simulated outlet temperatures for validation test .78

Figure 5-4: Cumulative energy allocation for driving circuit during charging cycle

Figure 5-5: Optimal charging cycle time for an initial SOC of $0 \%, 25 \%$, and $50 \%$ .80

Figure 6-1: Recently acquired SorTech eCoo 2.0 adsorption chiller .82 


\section{Nomenclature}

$\begin{array}{ll}\text { Abbreviations } & \\ \text { CPC } & \text { Compound Parabolic Concentrator } \\ \text { CPVT } & \text { Concentrating Photovoltaic/Thermal } \\ \text { CV } & \text { Control Valve } \\ \text { HE } & \text { Heat Exchanger } \\ \text { MOF } & \text { Petal Organic Framework } \\ \text { P } & \text { Parabolic Trough Collector } \\ \text { PTC } & \text { Thermal Energy System Specialists }\end{array}$

Variables

$\begin{array}{lll}\mathrm{c}_{\mathrm{p}} & \text { Specific Heat Capacity } & \mathrm{kJ} / \mathrm{kg}{ }^{\circ} \mathrm{C} \\ \text { cap } & \text { Cooling Capacity } & \mathrm{kW} \\ \mathrm{COP} & \text { Coefficient of Performance } & - \\ \mathrm{H} & \text { Enthalpy } & \mathrm{kJ} / \mathrm{kg} \\ \dot{\mathrm{m}} & \text { Mass Flow Rate } & \mathrm{kg} / \mathrm{s} \\ \mathrm{Q} & \text { Heat Energy } & \mathrm{kJ} \\ \dot{\mathrm{Q}} & \text { Heat Transfer Rate } & \mathrm{kW} \\ \mathrm{SCP} & \text { Specific Cooling Power } & \mathrm{W} / \mathrm{kg} \\ \mathrm{SF} & \text { Solar Fraction } & - \\ \mathrm{SOC} & \text { State of Charge } & - \\ \mathrm{T} & \text { Temperature } & { }^{\circ} \mathrm{C} \\ \mathrm{t} & \text { Time } & \mathrm{s}\end{array}$




\section{Subscripts}

\begin{tabular}{|c|c|}
\hline$\Delta \mathrm{t}$ & Time-step \\
\hline $\mathrm{C} / \mathrm{E}$ & Condenser/evaporator \\
\hline cap & Capacity \\
\hline col & Collector \\
\hline cond & Condenser \\
\hline $\mathrm{cw}$ & Chilled Water Circuit \\
\hline cycle & Cycle time \\
\hline des & Desorption \\
\hline $\mathrm{dr}$ & Driving Circuit \\
\hline el & Electrical \\
\hline evap & Evaporator \\
\hline $\mathrm{G} / \mathrm{A}$ & Generator/adsorber \\
\hline gen & Generator \\
\hline hr & Heat Rejection Circuit \\
\hline $\mathrm{HX}$ & Heat Exchanger \\
\hline in & Inlet \\
\hline load & Cooling Load \\
\hline loss & Heat Loss \\
\hline $\max$ & Maximum \\
\hline nom & Nominal \\
\hline out & Outlet \\
\hline ref & Refrigerant \\
\hline req & Required \\
\hline
\end{tabular}


set

sol

sor
Set-point

Solar

Sorbent 


\section{Chapter 1}

\section{Introduction}

This introductory chapter begins by discussing the implications of growing cooling energy demand, first on a global scale and then within the Canadian context. Solar-driven sorption chillers are then presented as a potential solution to the anticipated stress that will be placed on electricity grids due to an increased demand for cooling energy. The chapter concludes with a summary of the reseach objectives and contributions of this thesis, as well as a brief outline of its remaining contents.

\subsection{Motivation}

Energy demand for space cooling is expected to increase significantly in the coming decades as global temperatures increase and developing countries with warm climates and large populations continue to gain affluence. This assertion is supported by a 2015 study by Davis and Gertler, which used household survey data from more than 27,000 respondents to show that, in warm municipalities, air conditioning ownership in Mexico increases by 27 percentage points for each $\$ 10,000$ increase in household income [1]. This strong correlation between household income and air conditioner ownership is expected to play a significant role when considering future demand for space cooling on a global scale. According to a 2013 study by Sivak, 22 of the 25 countries with the highest potential for space cooling demand (based on cooling degree days and population) are below the World Bank income limit for developed countries [2]. Sivak noted that if the rest of the world had the means and desire to use air conditioning to the same extent as the United States, worldwide energy 
consumption for space cooling would exceed current levels in the U.S. by a factor of 50, a significant finding considering the U.S. currently uses more energy for space cooling than the rest of the world combined. A similar study by Isaac and van Vuuren predicted that, under current climate conditions, global electricity demand for space cooling would increase by a factor of 30 between the years 2000 and 2100, and by a factor of 40 when accounting for climate change [3].

The challenges presented by the forecasted increase in cooling energy consumption will differ regionally based on local climatic and economic conditions. In warm developing countries, where air conditioning ownership is currently low, the projected increase in electricity demand for space cooling will present enormous financial and environmental challenges; new generation and transmission infrastructure will need to be implemented to support the increased demand, and since $66.8 \%$ of electricity worldwide is currently generated from fossil fuels, a surge in air conditioning use would indirectly add millions of tons of carbon dioxide to the atmosphere annually [4]. In warm developed countries, where air conditioning ownership is nearly saturated, increased energy consumption for space cooling will be driven by increased cooling loads induced by climate change, population growth, and increasing floor space per capita [3]. The major challenge in these countries will be to meet peak electricity demand on particularly hot days, signifying an increased reliance on fossil-fuelled peaking power plants.

Developed countries with heating dominated climates are also expected to experience large increases in energy consumption for space cooling due to increased adoption of air conditioning in non-traditional markets. The rapid uptake of air conditioning is already apparent in Canada, where cooled floor space in the residential sector more than 
tripled between 1990 and 2012. As shown in Figure 1-1, cooled floor space has increased at nearly the same pace as total floor space during this time, with $86 \%$ of new floor space being cooled. The added cooled floor space has resulted in a $71 \%$ increase in electricity consumption for space cooling ${ }^{1}$ [4]. Moreover, without efficiency improvements to the air conditioner stock, the increase in electricity consumption for space cooling would have been 65 percentage points greater.

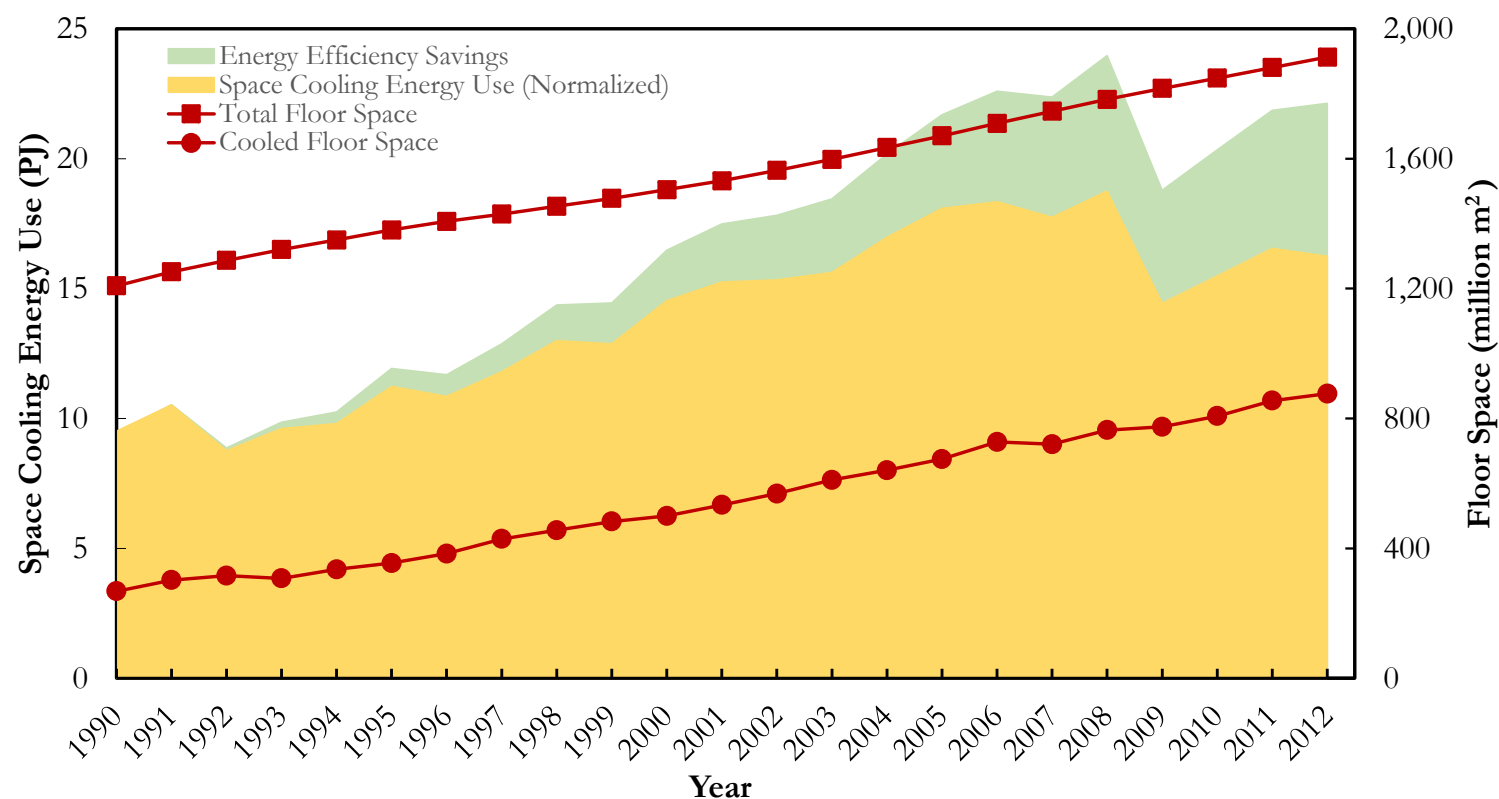

Figure 1-1: Comparison of cooled floor space to total floor space and space cooling energy use in the Canadian residential sector

Since electricity is often not required to meet heating loads (e.g., only $25 \%$ of secondary energy use for space heating in the Canadian residential sector is sourced from electricity), warmer regions of the country may see peak electricity demand shift from winter to summer. This shift has already taken place in Ontario, which accounted for $68 \%$ of national space cooling energy consumption in 2012. Ontario has experienced peak electricity demand during the summer in nine of the past ten years, and each of the province's ten

${ }^{1}$ Yearly cooling energy was normalized by dividing actual energy consumption by the cooling degree day index provided by Natural Resources Canada [4] 
record demand days have occurred during the months of June, July, or August. Furthermore, the province has seen its peak demand grow by $0.7 \%$ from 2003 to 2013 even though annual electricity consumption has decreased by $7.2 \%$ over that span [5]. The widening gap between the peak demand and base load demand has negative implications on greenhouse gas emissions since most peaking power plants in Ontario are fuelled by natural gas, whereas base loads are usually met by low emission sources like nuclear and hydro. Figure 1-2 shows the clear relationship between summertime outdoor temperature and electricity demand in Ottawa, as well as the relationship between outdoor temperature and the fraction of total generation sourced from natural gas.

The "U" shaped curves of gas supply show that it is the ramping up of demand in the late morning/early afternoon that predominantly brings peaking power plants online. Figure 1-3 shows that, by averaging the demand and gas supply within each temperature bin from Figure 1-2, each variable correlates strongly with outdoor temperature. Specifically, it was found that electricity demand in Ottawa increases by approximately 39 MW for each degree Celsius above $16^{\circ} \mathrm{C}$, while the share of generation supplied by gas increases by approximately $1 \%$ for each degree Celsius above $16^{\circ} \mathrm{C}$.

Regardless of the economic status of the country, the impacts of the expected surge in space cooling energy can be mitigated by continued improvements in energy efficiency, energy conservation programs, or the development of alternative cooling technologies. One promising alternative technology is that of sorption chillers driven by solar thermal energy. Solar thermal energy is a logical choice for the driving source since peak cooling loads usually coincide with peak solar irradiance. 

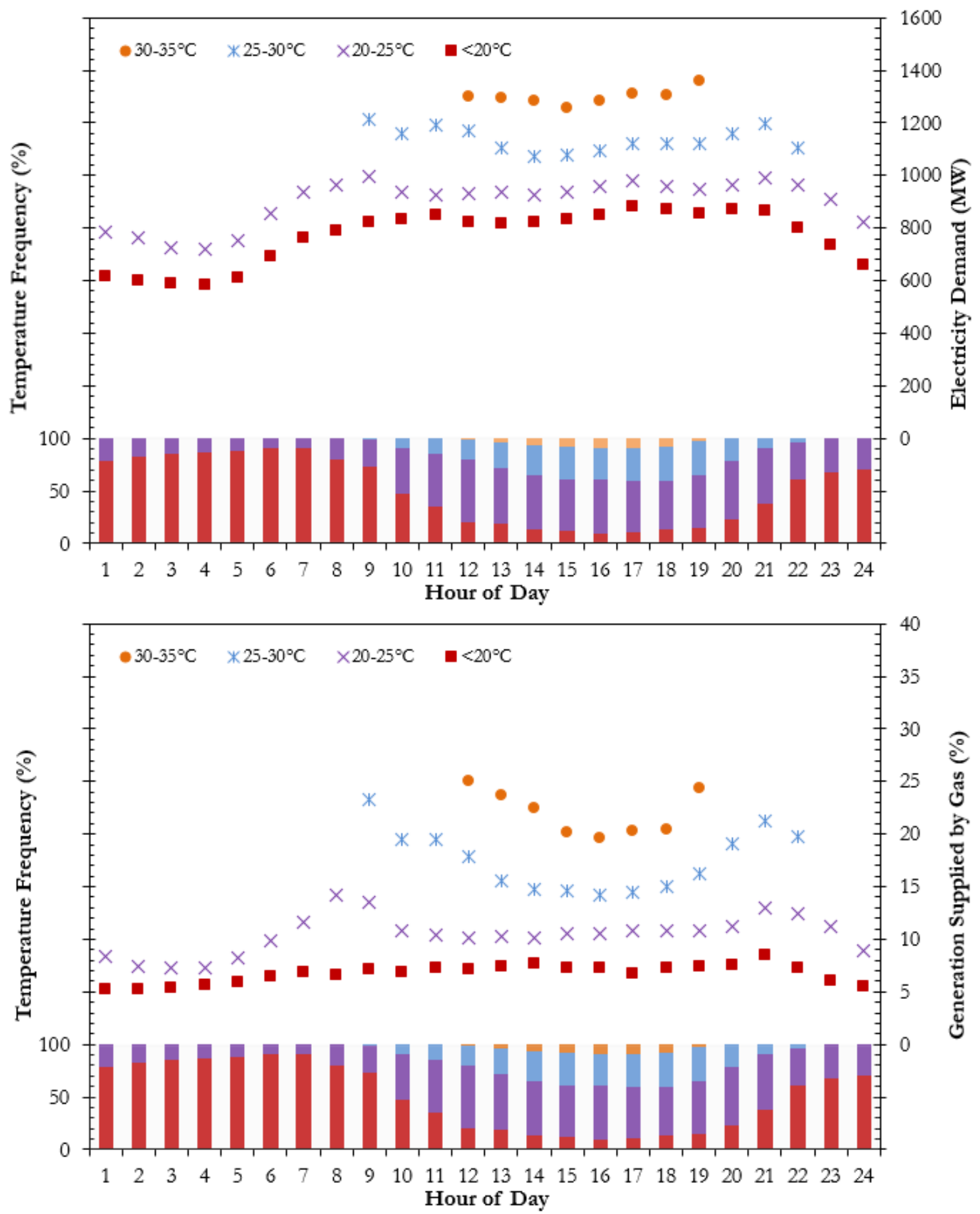

Figure 1-2: Comparison of outdoor temperature to electricity demand in Ottawa (top), and to the percentage of generation supplied by gas in Ontario (bottom) from June 1, 2015 to August 31, 2015 [5] 


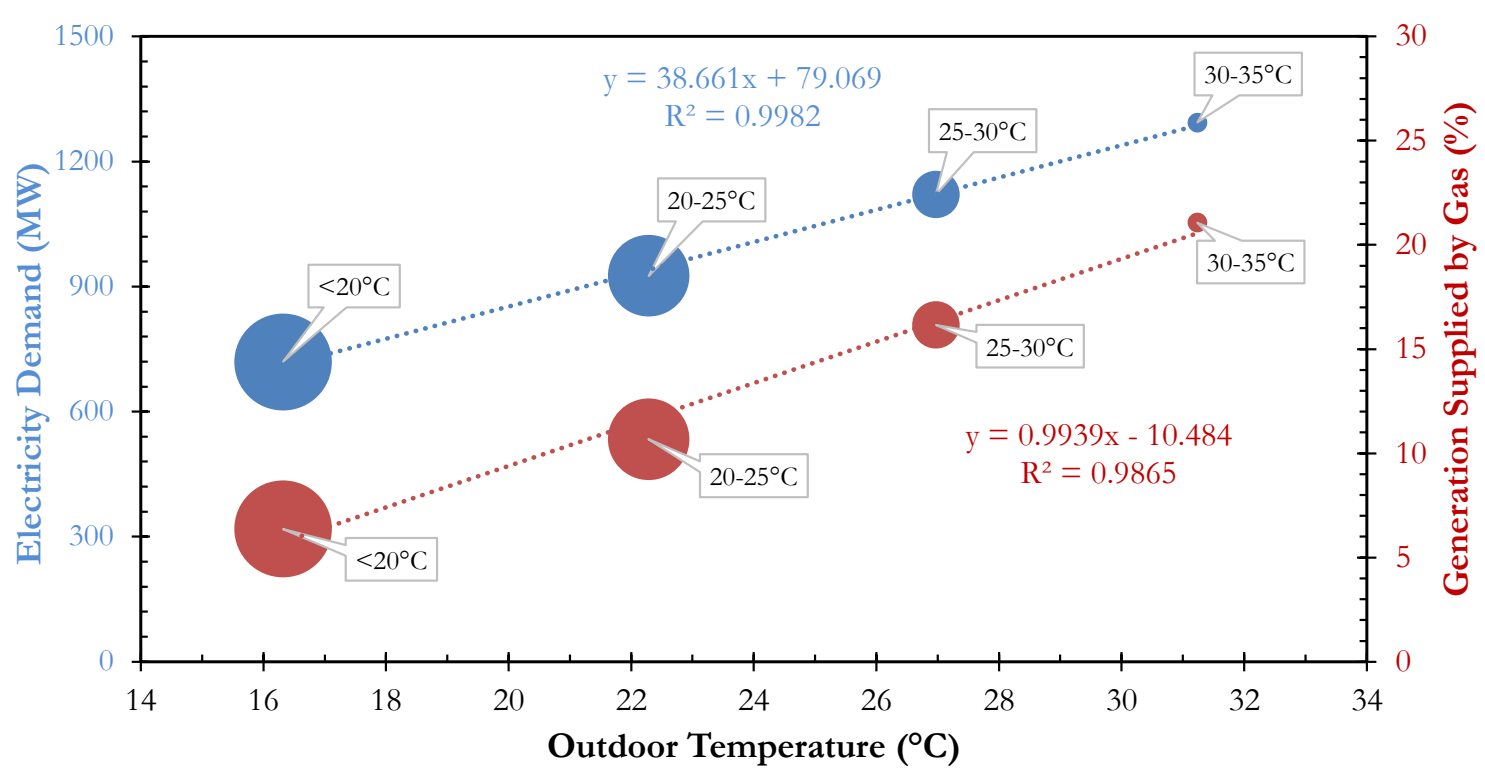

Figure 1-3: Correlation between outdoor temperature and electricity demand in Ottawa; between outdoor temperature and fraction of generation supplied by gas in Ontario

Within the past 10 years, sorption chillers have returned to the forefront of many research institutions due to their high electrical coefficient of performance $\left(\mathrm{COP}_{\mathrm{el}}\right)$, and thus their potential to reduce peak loads placed on the electricity grid on hot summer days. While Zamora et al. showed that the $\mathrm{COP}_{\mathrm{el}}$ of thermally driven chillers varies considerably based on whether a wet cooling tower or dry cooler is used for heat rejection purposes, the authors also showed that an air-cooled absorption chiller was still been able to achieve an impressive $\mathrm{COP}_{\mathrm{el}}$ of 6.5 [6]. In addition to minimizing electricity consumption, solar sorption chillers offer many other benefits compared to conventional vapour compression systems, including the use of an environmentally benign refrigerant (water), lower operating costs, and system versatility whereby the sorption chiller can be operated as a low-grade heat pump during the heating season. Moreover, sorption chillers benefit from the fact that their cold production comes in the form of chilled water, which can be used by a wide range of equipment and for a variety of cooling applications. 
Although solar sorption chillers remain a niche market, the number of worldwide installations has been estimated to have increased from less than 100 in 2004 to over 1000 in 2013 [7]. While the recent growth of the market bodes well for future developments of the technology, most installations to date have been concentrated in Western Europe, and very few systems have been installed in Canada [8]. Furthermore, the unique nature of each system (i.e., local climate, solar collector size/type, utilization of thermal storage, operating strategy) makes it difficult to extend the performance of existing installations to future projects. Therefore, more work is necessary to characterize and model the performance of these systems throughout their entire operating range to allow for the design and optimization of future projects, regardless of climate or system configuration.

\subsection{Sorption Chiller Systems}

Although the study of solar driven sorption chillers has mostly been limited to the past few decades, absorption chillers have been commercially available since the 1920s [9]. However, due to their low coefficient of performance compared to vapour compression refrigeration cycles, the use of sorption chillers has historically been limited to industrial applications where waste heat is readily available or off-grid applications such as recreational vehicles where gas-fired absorption chillers have commonly been employed [9].

There are two main types of sorption chillers: absorption and adsorption. An adsorption chiller uses a solid sorbent (typically silica gel or zeolite), whereas an absorption chiller uses a liquid sorbent (most commonly a lithium bromide-water solution). Absorption and adsorption chillers each have their respective advantages and disadvantages, which will be outlined in the sections below. Additionally, a hybrid sorption chiller (often referred to as 
a triple-state sorption chiller), which is the subject of this research, is introduced and its advantages and disadvantages are discussed.

\subsubsection{Absorption Chillers}

Of the two main sorption chiller types, absorption chillers are the more mature technology and as such have dominated the first generation of solar sorption systems. For example, of the 54 projects in the Solar Air Conditioning in Europe (SACE) project, which took place between 2002 and 2004 and aimed to assess the potential of various solar thermal driven air conditioning technologies, $70 \%$ employed absorption chillers, while only $10 \%$ consisted of adsorption chillers [10].

The operation of a typical single-effect absorption chiller is depicted in Figure 1-4. Hot water enters the generator heat exchanger where it transfers heat to a dilute solution (typically lithium bromide). Due to the low pressure in the generator, water boils from the solution and the resulting water vapour fills the condenser, where the heat of condensation is removed by the cooling water of a heat rejection circuit. The pressure of the accumulated condensate is reduced as it passes through a narrow channel before being sprayed onto the evaporator coils. Because the pressure in the evaporator is near vacuum, the condensate easily boils on the surface of the evaporator coils, even at temperatures as low as $10^{\circ} \mathrm{C}$. During this process, the latent heat of vaporization is sourced from the chilled water circulating through the evaporator heat exchanger. The water vapour produced in the evaporator is then absorbed by the concentrated solution returning from the generator, while the heat of condensation is removed by the heat rejection circuit. After absorbing the water vapour, the solution is once again dilute and is pumped back to the generator to complete the cycle. This constant exchange of refrigerant-rich and refrigerant-depleted 
solution between absorber and generator allows the absorption chiller to operate in a continuous cycle. To improve the efficiency of the absorption cycle, the dilute solution passes through a heat exchanger where it is pre-heated by the concentrated solution returning to the absorber. Single-effect absorption chillers typically achieve a thermal coefficient of performance $\left(\mathrm{COP}_{\mathrm{th}}\right)$ of 0.7 [11].

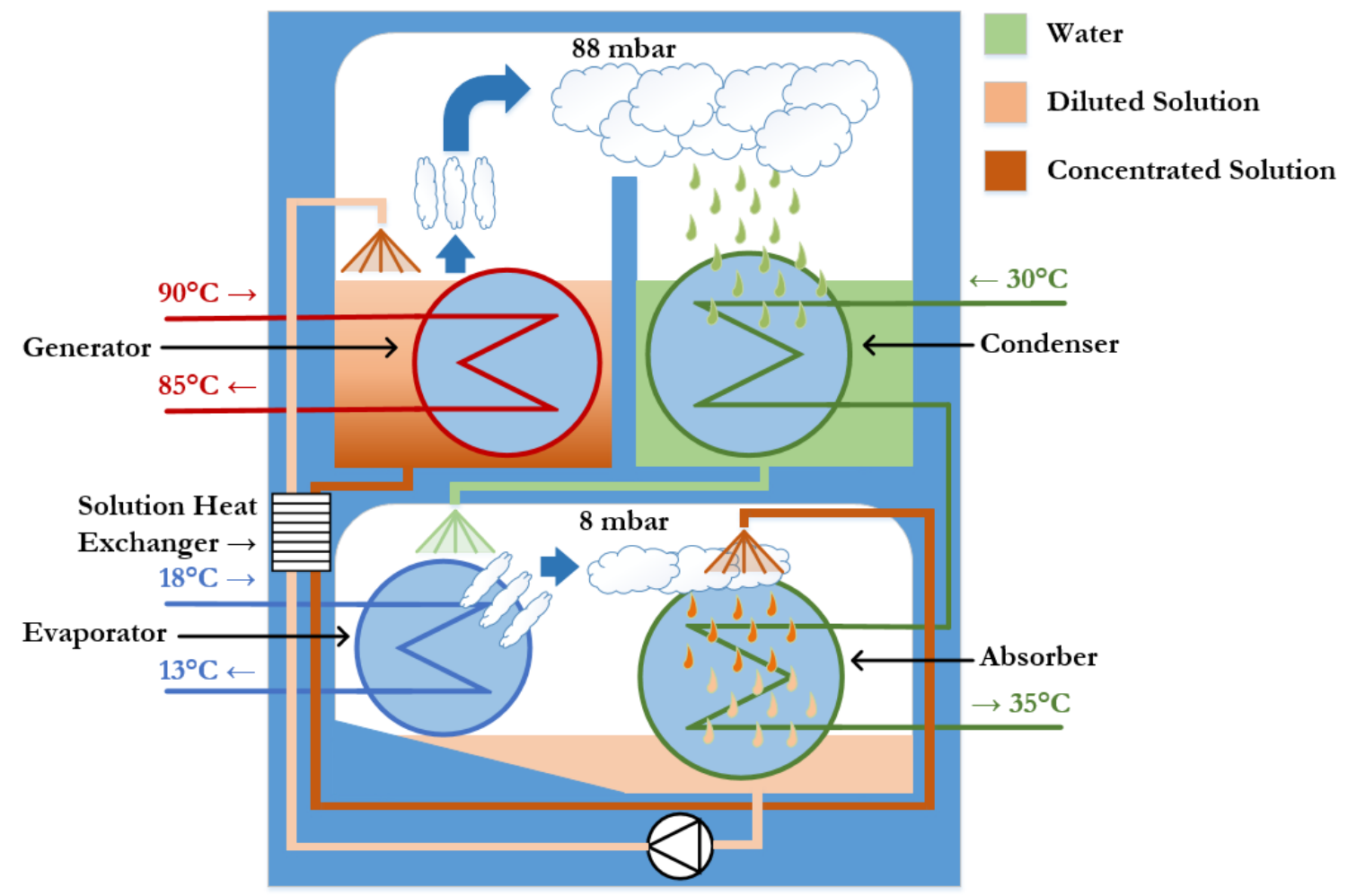

Figure 1-4: Absorption chiller cycle

The main strength of the absorption cycle is that it is able to provide continuous cooling. However, there is also an inherent disadvantage to the continuous cycle of an absorption chiller; the cycle requires equal absorption and desorption rates so as to avoid unwanted crystallization of the sorbent. Crystallization occurs when the solution becomes super-saturated with the sorbent salt and may be caused by one of three mechanisms: (a) excessive temperatures in the generator can cause super-saturation of the absorbent 
solution; (b) a sudden drop in heat rejection temperature can cause the temperature of the concentrated absorbent solution to fall below the crystallization point in the solution heat exchanger; (c) air leaks into the system can lead to corrosion and the generation of noncondensable gases, which in turn reduces the solution's ability to absorb the refrigerant water vapour, eventually leading to the super-saturation of the absorbent solution [12]. Crystallization should be avoided because it could cause damage to the solution pump or even result in complete blockage of flow through the solution heat exchanger. To avoid unwanted crystallization, absorption chillers must operate within a narrow range of acceptable hot water and heat rejection inlet temperatures. This narrow operating range presents challenges for integration with solar thermal energy, as the available driving heat source is prone to vary throughout the day with changes in cloud cover. As a result, solar absorption chillers tend to require an auxiliary heat source to ensure steady operation, a factor that leads to additional system costs.

The use of a liquid sorbent and solution pump allows the solution to be sprayed onto the coils of the absorption chiller's internal heat exchangers. This important design aspect of the absorption chiller facilitates heat transfer between the external circuits and the liquid sorbent, and as a result absorption chillers typically have a slightly higher $\mathrm{COP}_{\text {th }}(0.7)$ than adsorption chillers (0.6). However, to achieve this higher $\mathrm{COP}_{\text {th }}$, absorption chillers require driving temperatures between 80 and $100^{\circ} \mathrm{C}$. These temperatures can be difficult to produce consistently with conventional flat plate solar collectors [11]. If a double-effect absorption chiller is employed, even greater driving temperatures of $140-160^{\circ} \mathrm{C}$ are required and a more complex and expensive set of solar collectors (e.g., concentrating, two-axis tracking) is needed to produce the necessary driving heat. However, double-effect absorption chillers, 
which consist of a high pressure and low pressure generator in series, typically achieve a thermal coefficient of performance between 1.1 and 1.2 [11].

\subsubsection{Adsorption Chillers}

The market availability of residential scale adsorption chillers has been mostly limited to the past decade [7]. Unlike absorption chillers, adsorption chillers use a solid sorbent (typically silica gel or zeolite), and therefore the sorbent material cannot be pumped from the adsorber to the generator. Instead, adsorption chillers consist of two compartments containing the sorbent material, as shown in Figure 1-5. The adsorption chiller provides quasi-continuous cooling by allowing the two adsorbent filled compartments to intermittently switch between roles of generator and adsorber. Initially, compartment A acts as the generator while compartment $\mathrm{B}$ acts as the adsorber. During the regeneration process, the external heat source warms the sorbent material in compartment A. As the temperature within compartment A rises, water vapour is desorbed from the sorbent and the pressure increases and forces the one way valve separating the generator and condenser to open. At the same time, the pressure in the evaporator is less than the pressure in compartment $\mathrm{A}$, and as a result the valve separating these two compartments remains closed. Similarly, a negative pressure differential between compartment B and the condenser keeps the valve separating these two compartments closed, while a positive pressure differential between compartment $\mathrm{B}$ and the evaporator forces the valve connecting these two compartments to open. As the sorbent in compartment B becomes loaded with water vapour, the cooling capacity of the evaporator diminishes. At this point the external circuits are switched such that the heat source is redirected to compartment $\mathrm{B}$ and the heat rejection circuit is redirected to 
compartment A. After the brief switching period, compartment A now acts as the adsorber while compartment B acts as the generator and the cooling capacity of the chiller is restored.

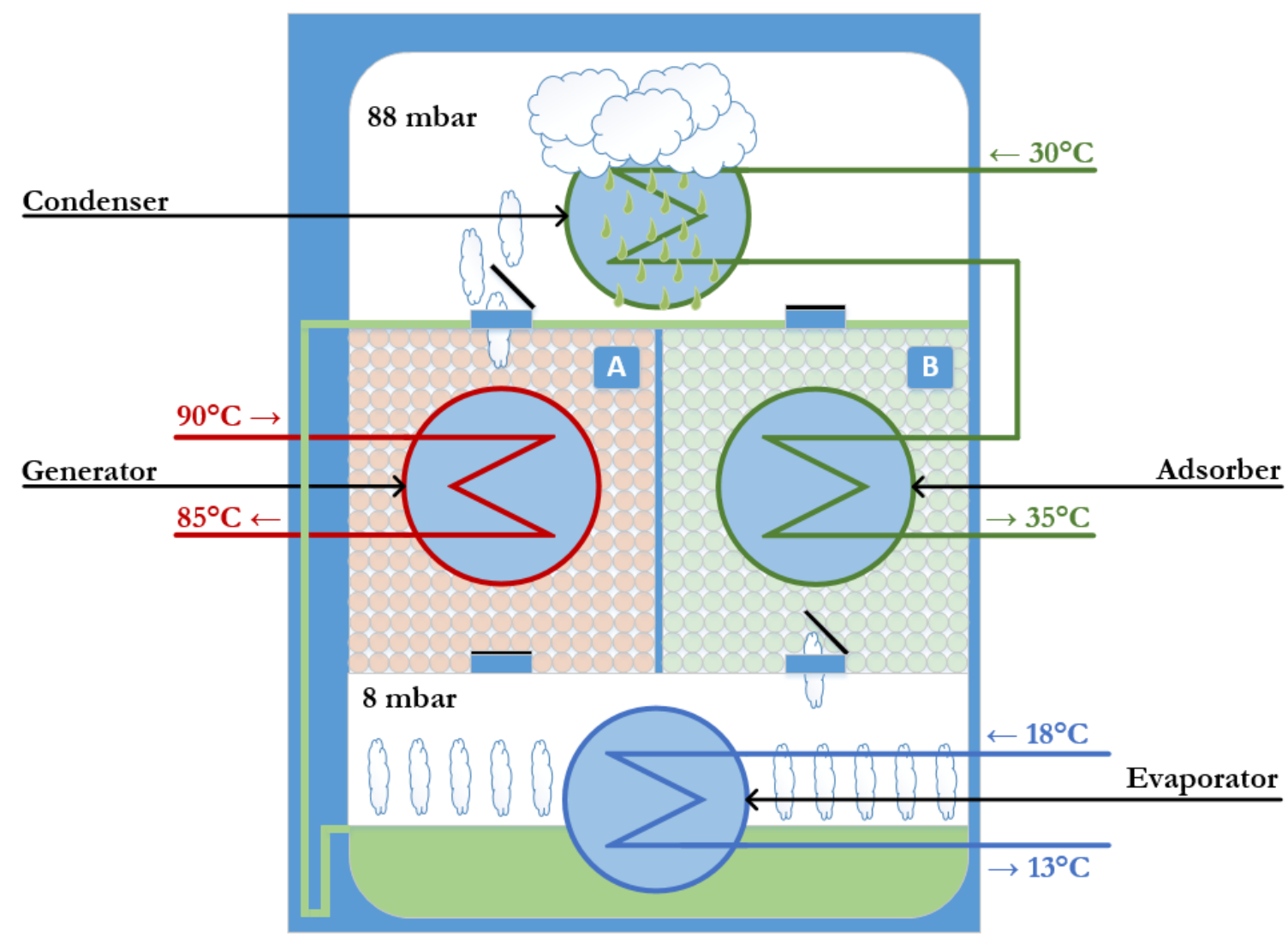

Figure 1-5: Adsorption cycle

Although adsorption chillers typically have a lower $\mathrm{COP}_{\text {th }}$ than absorption chillers, there are many comparative advantages to the adsorption cycle. First, the lack of a solution pump tends to give adsorption chillers a higher electrical coefficient of performance $\left(C O \mathrm{P}_{\mathrm{el}}\right)$ than absorption chillers. Second, if silica gel is used as the adsorbent, full desorption can occur for generator temperatures as low as $60^{\circ} \mathrm{C}$. This low regeneration temperature is more easily attainable for conventional solar thermal collectors compared to the minimum $80^{\circ} \mathrm{C}$ required by absorption chillers. Third, the independent operation of the sorption and desorption processes makes the cycle more accommodating to temperature variations in the driving and heat rejection circuits. Finally, if control valves are placed between the 
evaporator and sorbent-filled compartments, cooling potential can be stored indefinitely following the regeneration process.

There are also a few comparative disadvantages to the adsorption cycle. First, the cooling capacity of the chiller declines throughout each adsorption cycle as the sorbent becomes loaded with water vapour. Second, the solid sorbent used in adsorption chillers typically has a low thermal conductivity which limits the heat transfer to and from the external hydraulic circuits. To compensate for the low thermal conductivity of the sorbent material, the surface area of the internal heat exchangers is increased and more sorbent is added. This extra material adds significant cost to the upfront cost of the unit.

\subsubsection{Triple-State Sorption Chiller}

A triple-state sorption chiller was conceived and designed by ClimateWell in an attempt to capture the strengths of both absorption and adsorption cycles. The triple-state sorption chiller is represented by Figure 1-6 and consists of two independent generator/adsorbercondenser/evaporator pairs (here labelled as Barrel A and Barrel B). In this design, the sorbent material (lithium chloride) is impregnated in a porous host matrix that is wrapped around the inner surface of the generator/adsorber. The porous matrix is made from aluminium oxide and serves three main functions: (i) to act as a good thermal conductor between the external heat source and the sorbent material; (ii) to increase the effective heat

exchanger surface area by maximizing the amount of sorbent material in thermal contact with the external heat source; (iii) to confine the sorbent material within the porous matrix. 


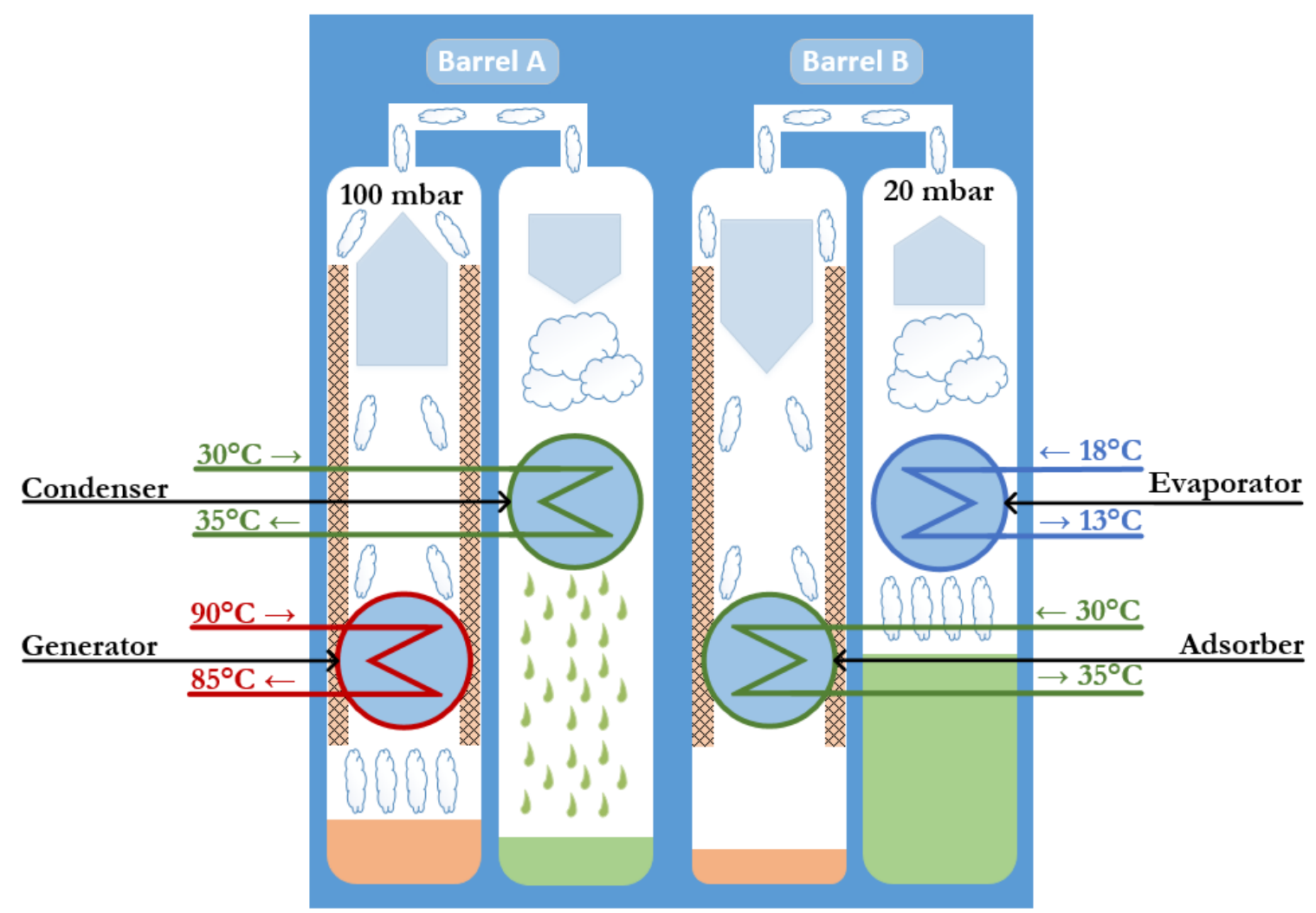

Figure 1-6: Triple-state sorption cycle

Similar to the adsorption chiller cycle, the triple-state sorption chiller provides quasicontinuous cooling. Figure 1-6 shows Barrel A operating in charging mode, wherein the sorbent-filled compartment acts as the generator while the other compartment acts as the condenser. At the same time, Barrel B is shown operating in discharging mode, wherein the sorbent-filled compartment acts as the adsorber while the other compartment acts as the evaporator. Once the cooling power falls below a set threshold, Barrel A and Barrel B switch roles (i.e., Barrel A enters discharging mode while Barrel B enters charging mode).

During the charge cycle, the mass transfer of the vapour refrigerant is driven by a pressure gradient that is created by heating the $\mathrm{LiCl}$ solution in the generator. This process is illustrated in the Dühring diagram of Figure 1-7, which shows that the dilute LiCl solution in the generator is initially heated from room temperature (point a) to a temperature just below 
that of the fluid in the driving circuit (point b). The sensible heat added to the $\mathrm{LiCl}$ solution causes its vapour pressure to increase significantly, leading to the desorption of the refrigerant water and subsequent transport to the condenser. As the charge cycle progresses, the $\mathrm{LiCl}$ solution becomes more concentrated (moving from point b toward point $\mathrm{c}$ ), and the pressure gradient between the generator and condenser is reduced, causing the charging rate to slow.

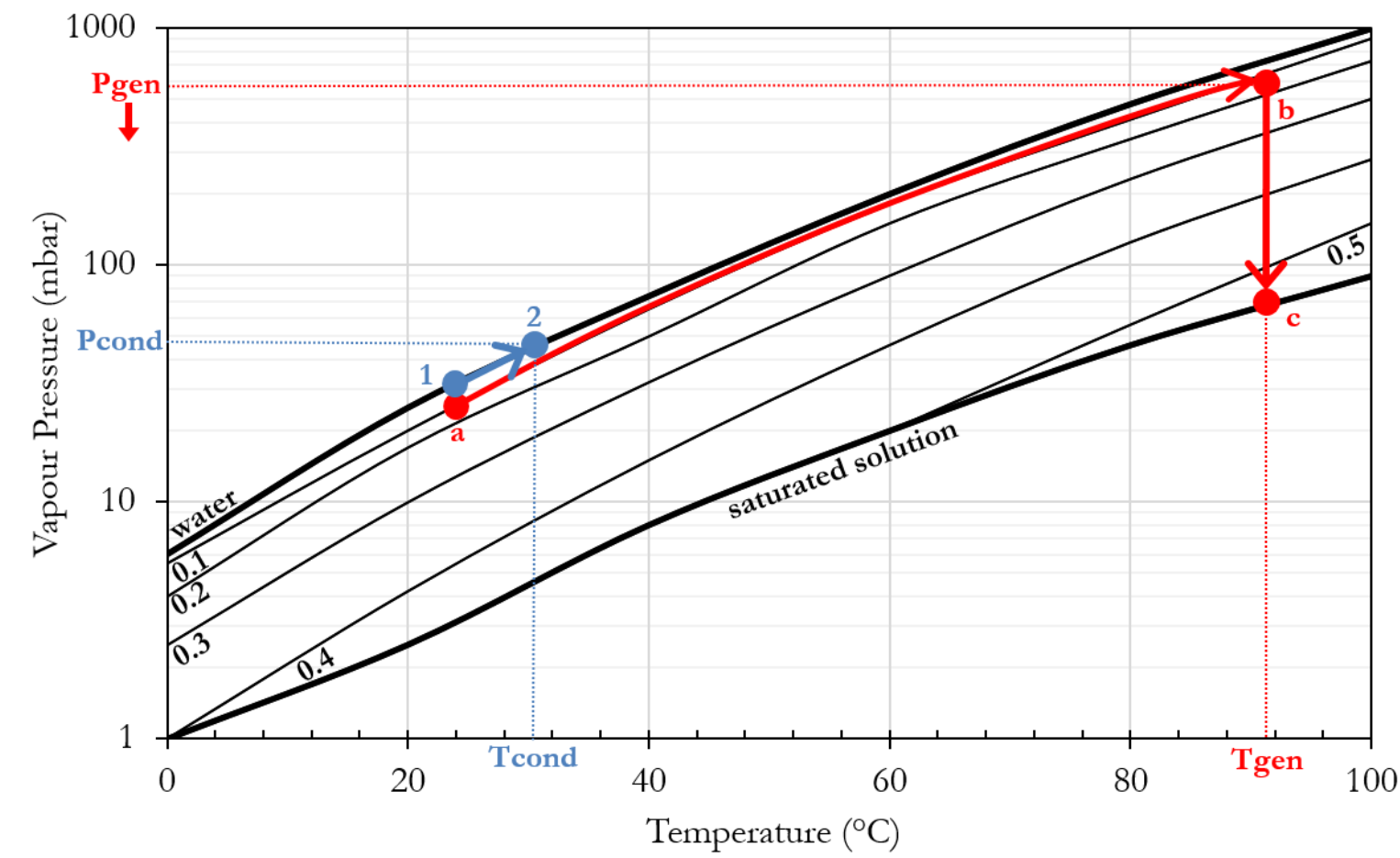

Figure 1-7: LiCl Dühring diagram illustrating the charge cycle (adapted from [13])

During the discharge cycle, the now saturated $\mathrm{LiCl}$ solution is cooled to a temperature just above that of the fluid in the heat rejection circuit. This sensible heat removal is illustrated in Figure 1-8 (point c to point d). Once cooled, the vapour pressure of the saturated $\mathrm{LiCl}$ solution drops below the vapour pressure of the liquid refrigerant in the evaporator and as a result the flow of vapour refrigerant reverses and begins to move from the evaporator to the adsorber. As the vapour refrigerant is absorbed in the $\mathrm{LiCl}$ solution, the vapour pressure of 
the solution increases from point $d$ to point $e$, where it reaches equilibrium with the vapour pressure of the evaporator and the discharge cycle terminates.

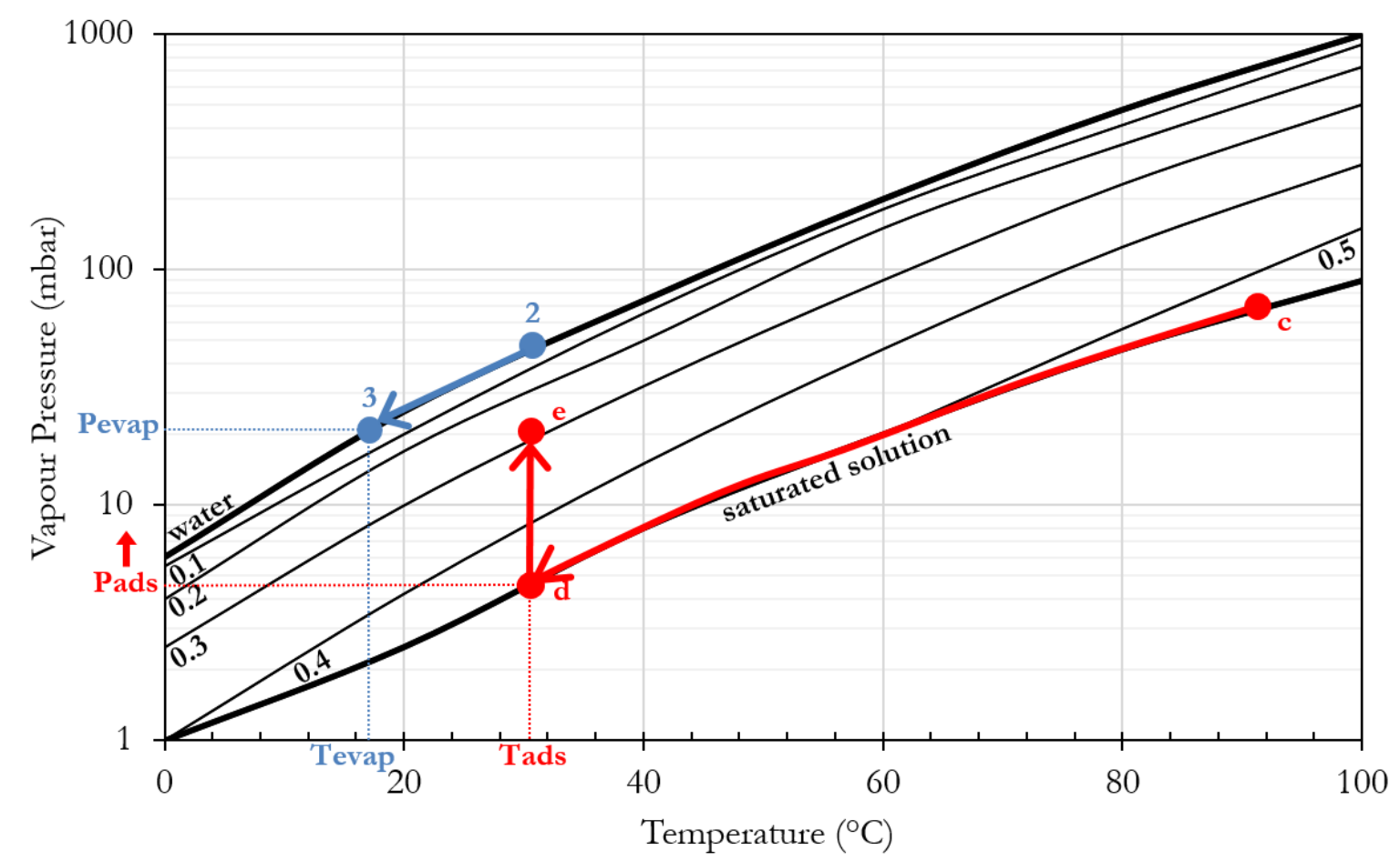

Figure 1-8: LiCl Dühring diagram illustrating the discharge cycle (adapted from [13])

It is important to note that Figure 1-6 depicts the $5^{\text {th }}$ generation of the triple-state sorption chiller, which was the final version manufactured by ClimateWell and also serves as the subject of this research. The most significant difference between the $5^{\text {th }}$ generation and its predecessor was the removal of internal solution pumps, which served to pump the $\mathrm{LiCl}$ water solution to the top of each generator/adsorber and condenser/evaporator where it could be sprayed onto the internal heat exchangers in order to increase the rate of heat transfer [14]. The decision to remove the solution pumps was based on the presumption that a higher electrical coefficient of performance $\left(\mathrm{COP}_{\mathrm{el}}\right)$ could be obtained without significantly compromising the cooling capacity or thermal coefficient of performance $\left(\mathrm{COP}_{\mathrm{th}}\right)$. However, tests have shown that 2-3 times more heat exchanger surface area is required to achieve the same cooling capacity as the $4^{\text {th }}$ generation chiller [15]. 


\subsection{Research Objectives}

The work presented in this thesis represents the second phase of a multi-year project to determine the feasibility of solar sorption cooling in Canada. In the first phase of the project, an experimental set-up was designed and constructed within the Solar Energy Systems Laboratory at Carleton University to test a sorption chiller with a cooling capacity of $10 \mathrm{~kW}$. The objectives of the second phase of the research are listed below.

- Provide an updated literature review documenting the recent advances in residential scale sorption chiller technology.

- Commission the experimental set-up, including the evacuation and calibration of the sorption chiller, and the development of experimental control systems.

- Develop an experimental test procedure to effectively characterize the performance of the sorption chiller over a wide range of operating conditions.

- Develop and validate a TRNSYS compatible model for future system optimization through simulation.

\subsection{Contribution to Research}

This work included the:

i. investigation on the relationship between summer outdoor temperatures and gasfired electricity generation in Ontario;

ii. development of system controls for the experimental testing of a triple-state sorption chiller;

iii. characterization of the vacuum retention of a triple-state sorption chiller and the effects of internal pressure on system performance; 
iv. experimental evaluation of the performance of a $10 \mathrm{~kW}$ triple-state sorption chiller; and

v. development of a TRNSYS model to characterize the performance of the charging cycle of a triple-state sorption chiller;

\subsection{Organization of Research}

The contents of this thesis are organized as follows:

Chapter 2 - Literature Review: A review of literature pertaining to the state-of-the art of sorption chiller technology

Chapter 3 - Experimental Design and Commissioning: A description of the experimental set-up and control systems, as well as a summary of the commissioning process

Chapter 4 - System Modelling: An overview of existing models and their limitations, followed by a detailed description of the development of a new model

Chapter 5 - Results and Discussion: A summary of the experimental results and a discussion pertaining to the validation of the model

Chapter 6 - Conclusion and Future Work: A summary of the conclusions drawn from this thesis and an outline of future work 


\section{Chapter 2}

\section{Literature Review}

This chapter begins by outlining some of the key performance metrics that are used to assess the performance of sorption chillers. Next, the state-of-the-art in sorption chiller technology is discussed briefly, followed by a comparison of absorption and adsorption chillers based on some of the most recent experimental results found in the literature. The following section describes studies pertaining specifically to the ClimateWell sorption chiller and highlights the need for further research. The chapter concludes with an economic assessment of sorption chillers and a brief introduction to competing technologies.

\subsection{Sorption Chiller Performance Metrics}

The most commonly reported metric for evaluating the performance of sorption chillers is the thermal coefficient of performance $\left(\mathrm{COP}_{\mathrm{th}}\right)$. The $\mathrm{COP}_{\text {th }}$ is calculated by dividing the cooling energy produced in the evaporator by the heat input delivered to the generator [11]:

$$
\mathrm{COP}_{\text {th }}=\frac{\mathrm{Q}_{\text {evap }}}{\mathrm{Q}_{\mathrm{gen}}}
$$

When configured as part of a solar cooling system, the solar thermal coefficient of performance $\left(\mathrm{COP}_{\text {sol }}\right)$ may be used as a more comprehensive metric for evaluating the sorption chiller. The $\mathrm{COP}_{\text {sol }}$ is calculated by dividing the cooling energy produced in the evaporator by the total solar energy incident on the collectors:

$$
\mathrm{COP}_{\text {sol }}=\frac{\mathrm{Q}_{\mathrm{evap}}}{\mathrm{Q}_{\mathrm{sol}}}
$$


Alternatively, the $\mathrm{COP}_{\text {sol }}$ may be calculated by multiplying the efficiency of the solar collectors by the $\mathrm{COP}_{\text {th }}$ of the sorption chiller:

$$
\mathrm{COP}_{\text {sol }}=\eta_{\mathrm{col}} \mathrm{COP}_{\mathrm{th}}
$$

While the $\mathrm{COP}_{\text {th }}$ is a good indicator of how efficiently a sorption chiller is at producing cooling energy, since sorption chillers are primarily being considered as an alternative to electrically driven vapour compression air conditioners, it is also important to measure the electrical coefficient of performance $\left(\mathrm{COP}_{\mathrm{el}}\right)$. The $\mathrm{COP}_{\mathrm{el}}$ is defined as the cooling energy produced divided by the electrical energy consumed by the sorption chiller system, including control systems, internal pumps, circulation pumps, and heat rejection fans:

$$
\mathrm{COP}_{\mathrm{el}}=\frac{\mathrm{Q}_{\mathrm{evap}}}{\mathrm{Q}_{\mathrm{el}}}
$$

Another important metric for sorption chillers is specific cooling power (SCP). For an adsorption chiller, the SCP is calculated by dividing the total cooling energy produced during the discharge cycle by the length of the cycle and the sorbent mass [16]:

$$
\mathrm{SCP}=\frac{\mathrm{Q}_{\text {evap }}}{\mathrm{t}_{\text {cycle }} \mathrm{m}_{\text {sor }}}
$$

For an absorption chiller, the SCP is calculated by dividing the average cooling power by the mass of the sorbent material. The SCP evaluates the effectiveness of the chiller from the perspective of efficient material use. Therefore, improving the SCP of a sorption chiller has the potential to reduce system size and costs.

For solar-driven sorption chillers, the solar fraction (SF) is also an important performance metric. The SF is defined as the fraction of cooling energy derived from solar energy to the total cooling energy demand of the building [17]. 


\subsection{New Developments in Sorption Chillers}

\subsubsection{Absorption Chillers}

Small scale absorption chillers (those with a rated capacity less than $20 \mathrm{~kW}$ ) were commercialized many years before adsorption chillers came to market, and have therefore historically been the most popular technology for residential solar cooling installations. In 2005, Balaras et al. [18] reported that of the 54 solar cooling installations in the Solar Air Conditioning in Europe project, $70 \%$ employed absorption chillers, while only $10 \%$ had adsorption chillers. Due to the relative maturity of absorption chillers, the majority of recent research on the technology has been focused on optimizing the solar cooling system as a whole rather than modifying the design of the chiller itself. However, absorption chillers continue to struggle with many of the same problems faced by adsorption chillers (e.g., poor heat transfer, high capital costs), and as a result a number of research groups continue to explore possible design modifications that can be made to address these issues. One such modification is the implementation of nanoparticles into the heat transfer fluid. The incorporation of nanofluids into absorption chillers has been shown to improve both the heat transfer rate and absorption rate [19].

Many researchers have taken advantage of the recent developments in advanced solar collectors, especially those designed for high temperature applications. For example, the development of low cost, lightweight, modular parabolic trough collectors (PTC) has made the use of double-effect absorption chillers possible in residential solar cooling systems [20]. Similar systems have been developed using other high temperature solar collectors such as concentrating photovoltaic/thermal (CPVT) hybrid collectors [21] and compound parabolic concentrator (CPC) collectors [22]. 
One recent trend in the development of solar cooling systems employing absorption chillers has been the use of air cooling as the heat rejection method. To improve the effectiveness of air cooling mechanisms, a new generation of efficient absorbers are being developed. One such development is that of an adiabatic flat-fan sheet absorber which has the added benefit of reducing the size of the absorption chiller due to its compact design [23]. Solar cooling systems that are air cooled have a significantly lower overall system cost, as this method eliminates the need for a cooling tower. The removal of the cooling tower reduces the system complexity and cost as cooling towers require a significant amount of maintenance and regulatory oversight [24]. Furthermore, it is known that cooling towers have the potential risk of developing legionella and are especially undesirable for solar cooling installations in Canada and other countries with cold winters due to the risk of freezing.

\subsubsection{Adsorption Chillers}

In order to improve the $\mathrm{COP}_{\text {th }}$ and $\mathrm{SCP}$ of adsorption chillers, many researchers have experimented with new refrigerant-adsorbent pairs. Conventional working pairs for adsorption chillers have typically been restricted to water-zeolite, water-silica gel, methanolactivated carbon, and ammonia-activated carbon [25]. However, of these pairs, only watersilica gel and water-zeolite are suitable for air conditioning applications as methanol-activated carbon and ammonia-activated carbon have lower evaporator temperatures and are geared more towards refrigeration applications. While most commercially available adsorption chillers use either silica gel [26] or zeolite [27] as the adsorbent, there has been a growing interest in the research community for the use of metal-organic frameworks (MOF) in adsorption chillers [28]. There are several qualities that make MOFs more attractive options 
as chiller adsorbents compared to zeolites and silica gel. First, MOFs are not as hydrophilic as zeolites, and therefore do not require such high heat input temperatures for desorption. Second, unlike silica gel, MOFs are able to desorb water even at low temperature lifts (the temperature difference between the desorber and condenser), and thus their application in an adsorption chiller would reduce the dependency on the availability of a low temperature source for heat rejection. Finally, MOFs have a significantly higher water uptake than both zeolites and silica gel, and therefore show promise for both improving the SCP and reducing the overall size of adsorption chillers.

In addition to the research that has been done on new adsorbents such as MOFs, other studies have focused on improving the thermal conductivity of existing adsorbents to improve internal heat transfer in adsorption chillers. This has mainly been accomplished through the use of consolidated adsorbents, which consist of compounds made from mixtures of adsorbents and expanded graphite or metal foams [29]. Consolidated adsorbents are able to improve the SCP by increasing the rate of heat transfer from the external heat source to the adsorbent, which allows for a more complete desorption of the refrigerant. However, the gains in SCP usually come at the expense of the $\mathrm{COP}_{\text {th }}$ because the consolidated adsorbent adds considerable thermal mass to the internal heat exchanger of the chiller. This causes a significant amount of additional sensible heat to be added and removed to the chiller at the beginning of the charging and discharging cycles, respectively. Therefore, the decision to implement consolidated adsorbents depends on which performance metric, $\mathrm{COP}_{\text {th }}$ or SCP, is more pertinent to the specific application. 


\subsection{Comparison of Results from Recent Experimental Studies}

Many experimental studies have been conducted in recent years to investigate the effects of different system designs on the performance of various sorption chillers. A few of these studies are highlighted below and the main results are summarized in Table 2.1.

\subsubsection{Absorption Chillers}

Monné et al. [30] monitored the performance of a $4.5 \mathrm{~kW}$ solar powered LiBr absorption chiller over the course of two years. The absorption chiller was a commercial unit and was powered by $35 \mathrm{~m}^{2}$ of flat plate solar collectors. During the first year, the average cooling power and $\mathrm{COP}_{\text {th }}$ of the chiller were $5.7 \mathrm{~kW}$ and 0.57 , respectively, for average heat input, evaporator, and outdoor dry-bulb temperatures of $91.0^{\circ} \mathrm{C}, 11.5^{\circ} \mathrm{C}$, and $27.7^{\circ} \mathrm{C}$, respectively. During the second year, the average cooling power and $\mathrm{COP}_{\text {th }}$ of the chiller were $4.4 \mathrm{~kW}$ and 0.51 , respectively, for average heat input, evaporator, and outdoor dry-bulb temperatures of $92.5^{\circ} \mathrm{C}, 11.5^{\circ} \mathrm{C}$, and $31.2^{\circ} \mathrm{C}$, respectively. Despite an increase in the average heat input temperature during the second year, the average cooling power of the chiller decreased by $23 \%$ relative to the first year due to the increase in the outdoor temperature. The authors predicted that the replacement of the dry cooler with a ground-coupled heat exchanger would improve the $\mathrm{COP}_{\text {th }}$ by $42 \%$. This study highlights the significant influence of the heat rejection temperature on the performance of the chiller.

Zamora et al. [6] developed two identical ammonia-lithium nitrate $\left(\mathrm{NH}_{3}-\mathrm{LiNO}_{3}\right)$ prototype absorption chillers and compared their performance when one was air-cooled and the other was water-cooled. It was found that the water-cooled chiller had a cooling capacity and $\mathrm{COP}_{\mathrm{el}}$ of $12.9 \mathrm{~kW}$ and 19.3, respectively, for heat input, chilled water, and heat rejection temperatures of $90^{\circ} \mathrm{C}, 15^{\circ} \mathrm{C}$, and $35^{\circ} \mathrm{C}$. The air-cooled chiller had a cooling capacity and 
$\mathrm{COP}_{\mathrm{el}}$ of $9.3 \mathrm{~kW}$ and 6.5, respectively, for heat input, chilled water, and ambient air temperatures of $90^{\circ} \mathrm{C}, 15^{\circ} \mathrm{C}$, and $35^{\circ} \mathrm{C}$. Interestingly, although the cooling capacity of the aircooled unit was only $28 \%$ lower than that of the water-cooled unit, the $\mathrm{COP}_{\mathrm{el}}$ experienced a significant $66 \%$ reduction. The steep reduction in the $\mathrm{COP}_{\mathrm{el}}$ was due to the large power consumption of the fan used for air-cooling.

Izquierdo et al. [31] built and experimentally tested an innovative air-cooled LiBrwater absorption prototype that can operate either as a single-effect chiller or as a doubleeffect unit. When operating as a single-effect system, the chiller is driven by hot water from flat plate collectors, and when operating in a double-effect configuration, the heat input from the solar collectors is boosted by an auxiliary source. During a five day test period, the prototype chiller had an average cooling capacity and $\mathrm{COP}_{\text {th }}$ of $3.4 \mathrm{~kW}$ and 0.54 , respectively, when configured as a single-effect system. A separate three day test was also conducted on the prototype using the double-effect configuration, yielding average an average cooling capacity and $\mathrm{COP}_{\text {th }}$ of $4.5 \mathrm{~kW}$ and 1.0 , respectively.

\subsubsection{Adsorption Chillers}

Sapienza et al. [32] created a lab-scale adsorption chiller by embedding an aluminum finned flat tube heat exchanger with the adsorbent AQSOA®-FAM-Z02 (zeolite). The performance of this mini-type adsorption chiller was then monitored while varying the cycle time and the relative duration of the adsorption and desorption phases. For heat input, evaporator, and heat rejection temperatures of $90^{\circ} \mathrm{C}, 15^{\circ} \mathrm{C}$, and $35^{\circ} \mathrm{C}$, respectively, it was found that the optimal SCP occurred when the cycle consisted of a 5 minute adsorption phase and a 2 minute desorption phase. Testing at these conditions yielded a SCP of 394 $\mathrm{W} / \mathrm{kg}$ and a $\mathrm{COP}_{\text {th }}$ of 0.60 . For the same heat input, evaporator, and heat rejection 
temperatures of $90^{\circ} \mathrm{C}, 15^{\circ} \mathrm{C}$, and $35^{\circ} \mathrm{C}$, respectively, it was found that the optimal $\mathrm{COP}_{\text {th }}$ occurred when the adsorption and desorption phases were each 10 minutes long. These test conditions yielded a SCP of $204 \mathrm{~W} / \mathrm{kg}$ and a COP th of 0.69.

Lu et al. [33] designed and experimentally tested two nearly identical prototype adsorption chillers with built in vacuum valves for heat and mass recovery. The only difference between the two prototype chillers was that one used the composite adsorbent $\mathrm{LiCl} /$ silica gel-methanol while the other used the more conventional working pair of silica gel/water. It was found that the mass recovery process was able to improve the cooling capacity of the chiller by $36.4 \%$, while the heat recovery process only improved the cooling capacity by $6.3 \%$. It was also found that for heat input, evaporator, and heat rejection temperatures of $85^{\circ} \mathrm{C}, 15^{\circ} \mathrm{C}$, and $31^{\circ} \mathrm{C}$, respectively, the SCP of the $\mathrm{LiCl} /$ silica gel-methanol chiller was $59.5 \%$ higher than that of the silica gel/water chiller.

Li et al. [34] developed an adsorption chiller employing the novel zeolite adsorbent FAM Z01, which was strategically coated onto the surface of a fin-tube heat exchanger in order to improve heat and mass transfer. The cooling capacity and $\mathrm{COP}_{\text {th }}$ were tested for a variety of heat input temperatures and adsorption/desorption cycle times, while the evaporator and heat rejection temperatures were held constant at $12^{\circ} \mathrm{C}$, and $27^{\circ} \mathrm{C}$, respectively. It was found that the highest cooling capacity $(12.13 \mathrm{~kW})$ occurred at heat input temperatures of $85^{\circ} \mathrm{C}$, while the highest $\mathrm{COP}_{\text {th }}(0.44)$ coincided with a much lower heat input temperature of $65^{\circ} \mathrm{C}$, respectively. 
Table 2-1: Comparison of recent experimental findings for sorption chillers

\begin{tabular}{|c|c|c|c|c|c|c|}
\hline $\begin{array}{c}\text { System } \\
\text { Description }\end{array}$ & $\begin{array}{l}\text { Refrigerant- } \\
\text { sorbent pair }\end{array}$ & $\begin{array}{c}\text { Cooling } \\
\text { Capacity }(\mathbf{k W})\end{array}$ & $\begin{array}{c}\text { Input } \\
\text { Temperatures }\left({ }^{\circ} \mathrm{C}\right)\end{array}$ & $\mathrm{COP}_{\mathrm{th}}$ & $\begin{array}{c}\text { SCP } \\
(\mathrm{W} / \mathrm{kg})\end{array}$ & Source \\
\hline Adsorption & Water-zeolite & 1 & $90 / 35 / 15$ & 0.60 & 394 & {$[32]$} \\
\hline Adsorption & Water-zeolite & 1 & $90 / 35 / 15$ & 0.69 & 204 & {$[32]$} \\
\hline Adsorption & Water-silica gel & 4.9 & $86 / 32 / 15$ & 0.42 & 153 & [33] \\
\hline Adsorption & $\begin{array}{l}\text { Methanol- } \\
\text { silica gel/LiCl }\end{array}$ & 4.9 & $85 / 31 / 15$ & 0.41 & 244 & [33] \\
\hline Adsorption & Water-zeolite & 12.13 & $85 / 27 / 12$ & $\sim 0.34$ & - & {$[34]$} \\
\hline Adsorption & Water- zeolite & $\sim 8$ & $65 / 27 / 12$ & 0.44 & - & {$[34]$} \\
\hline $\begin{array}{l}\text { Absorption } \\
\text { (single-effect, } \\
\text { water-cooled) }\end{array}$ & Water-LiBr & 5.7 & $91.0 / 11.5 / 27.7$ & 0.57 & - & {$[30]$} \\
\hline $\begin{array}{l}\text { Absorption } \\
\text { (single-effect, } \\
\text { water-cooled) }\end{array}$ & Water-LiBr & 4.4 & $92.5 / 11.5 / 31.2$ & 0.51 & - & {$[30]$} \\
\hline $\begin{array}{c}\text { Absorption } \\
\text { (single-effect, } \\
\text { water-cooled) }\end{array}$ & $\begin{array}{l}\text { Ammonia- } \\
\mathrm{LiNO}_{3}\end{array}$ & 12.9 & $90 / 15 / 35$ & 0.61 & - & [6] \\
\hline $\begin{array}{l}\text { Absorption } \\
\text { (single-effect, } \\
\text { air-cooled) }\end{array}$ & $\begin{array}{l}\text { Ammonia- } \\
\mathrm{LiNO}_{3}\end{array}$ & 9.3 & $90 / 15 / 35$ & 0.60 & - & [6] \\
\hline $\begin{array}{l}\text { Absorption } \\
\text { (single-effect, } \\
\text { air-cooled) }\end{array}$ & Water-LiBr & $\sim 3.4$ & $80-95 / 16 / 36$ & 0.54 & - & {$[31]$} \\
\hline $\begin{array}{c}\text { Absorption } \\
\text { (double-effect, } \\
\text { air-cooled) }\end{array}$ & Water-LiBr & $\sim 4.5$ & $180-190 / 12 / 35.5$ & $\sim 1.0$ & - & {$[31]$} \\
\hline
\end{tabular}

\subsection{Existing ClimateWell Studies}

A few studies can be found in the literature which investigate the performance of the ClimateWell sorption chiller.

\subsubsection{Experimental Studies}

Angrisini et al. experimentally tested a ClimateWell sorption chiller as part of a microtrigeneration system [35]. The sorption chiller was tested for a two hour period during which 
the average outdoor temperature was $35^{\circ} \mathrm{C}$ and the driving temperature varied between 80 $85^{\circ} \mathrm{C}$. Under these conditions, it was found that the ClimateWell produced an average cooling power of about $3 \mathrm{~kW}$, while the $\mathrm{COP}_{\text {th }}$ varied between 0.25 and 0.45 . However, the chilled water temperature, cycle time, and state of charge (SOC) are not reported by the study. It is also unclear which version of the ClimateWell was being tested.

Borge-Diaz et al. monitored the performance of solar-driven ClimateWell chiller over the course of an entire year [24]. The ClimateWell chiller served to cool a single detached house in Spain, and was driven by $35.54 \mathrm{~m}^{2}$ of flat plate solar collectors while using a swimming pool as a heat sink for the heat rejection circuit. On a typical hot day (maximum outdoor temperature of $35^{\circ} \mathrm{C}$ ), the sorption chiller produced a maximum cooling power of approximately $5 \mathrm{~kW}$, while on a typical warm day (maximum outdoor temperature of $25^{\circ} \mathrm{C}$ ) the maximum cooling power achieved was approximately $5.5 \mathrm{~kW}$. It is important to note that the ClimateWell chilller under investigation for this study was the 4th generation which contains the internal solution pump.

\subsubsection{Simulation Studies}

Sanjuan et al. performed an optimization study aiming to maximize the solar fraction achieved by a system consisting of four ClimateWell sorption chillers [36]. It was determined that a maximum solar fraction of $91 \%$ could be achieved with $170 \mathrm{~m}^{2}$ of flat plate solar collectors. The performance of each sorption chiller was modelled based on experimental performance curves provided by ClimateWell, wherein the charging capacity is determined from the inlet temperatures of the driving and heat rejection circuits while discharging capacity is determined from the inlet temperatures of the chilled water and heat rejection temperatures. A major limitation of the provided performance curves is that they do no 
account for the variations in charging or discharging capacities that occur throughout the charging and discharging cycles. Furthermore, the performance curves were limited to a temperature resolution of $10^{\circ} \mathrm{C}$ for the heat rejection circuit.

Bales and Ayadi developed a "grey box" model of the $4^{\text {th }}$ generation ClimateWell sorption chiller for use in the TRNSYS (TRaNsient SYstem Simulation) software [37]. The model simplifies the physical principles of the sorption chiller cycle so that it may be calibrated with the use of experimental data. This model was then used in a subsequent study where it was able to predict the energy performance of a ClimateWell sorption chiller to within 4\% [38].

\subsection{Economic Analysis of Sorption Chillers}

It is estimated that the cost of solar cooling systems has decreased by $40-50 \%$ from 2007 to 2012 [7]. However, these systems are still not economically viable despite having lower maintenance and operating costs than their vapour compression counterparts. The high cost of solar sorption systems is largely due to the expensive nature of the solar collectors that are required to produce the necessary driving energy. While it can be argued that the future success of solar sorption systems will depend on the cost reductions and efficiency improvements of solar thermal collectors, it is also important to note that significant savings can be accrued by improving the performance of the sorption chiller itself. This is because a more efficient sorption chiller does not require as many solar collectors to provide the necessary heat input.

\subsection{Alternatives to Solar Sorption Chillers}

In addition to solar sorption chillers, there are a number of competing technologies that may also be used to reduce the impact of space cooling on the electricity grid. These technologies 
are discussed below and include dessicant cooling systems as well as conventional vapour compression units driven directly by electricity generated by photovolataic (PV) modules.

\subsubsection{Desiccant cooling}

Rather than produce chilled water, desiccant based cooling systems typically dehumidify a building's incoming air and therefore only provide a cooling effect through the removal of latent heat. These types of systems are therefore best suited for humid climates and for buildings requiring high ventilation rates [11].

\subsubsection{Photovoltaic-based solar cooling}

The reduced cost of photovoltaic (PV) modules has led to the recent emergence of PVbased solar cooling systems as the main competitor to solar-driven sorption chillers. The increased role of PV-based solar cooling systems is reflected by its inclusion in the International Energy Agency's (IEA) most recent Task 53 - New Generation Solar Cooling and Heating, which commence in March of 2014. The IEA Solar Heating and Cooling Programme has investigated solar-driven sorption chillers since 1999 when Task 25 - Solar Assisted Air Conditioning of Buildings was initiated. However, Task 53 marks the first instance of research for PV-based cooling systems by the Solar Heating and Cooling Programme.

A few studies have appeared in the literature in the past few years comparing thermally driven sorption chillers to photovoltaic-based solar cooling systems. For the European cities of Palermo, Madrid, and Stuttgart, Eicker et al. compared the primary energy savings of both PV-based solar cooling systems and solar-driven sorption chiller systems to a conventional vapour-compression system powered by electricity from the local grid [39]. It was found that, in the case of PV-based solar cooling systems, relative primary energy savings (i.e., primary energy savings as a percentage of the reference primary energy consumption) 
increased as the cooling load of the city decreased. In the case of solar-driven sorption chiller systems, relative primary energy savings increased as the cooling load of the city increased. In all cases, the relative primary energy savings were greatest for the PV-based solar cooling systems $(\sim 50 \%)$ compared to the solar-driven sorption chiller systems (29-37\%).

In a separate study, Lazzarin compared water-cooled (i.e., heat rejection via wet cooling tower) sorption chillers to PV-driven vapour compression chillers in terms of the collector area required to produce $1 \mathrm{kWh}$ of cooling and in terms of capital costs [40]. The sorption chillers considered by the study were found to be most effectively driven by evacuated tube collectors and included an adsorption chiller, a single-effect absorption chiller, and a double-effect absorption chiller. It was found that, for a sunny day (i.e., clearness index of 0.65 ) in Venice, the double-effect absorption chiller required the smallest collector area $\left(0.24 \mathrm{~m}^{2} \mathrm{kWh}^{-1}\right)$, followed by the PV-based system at $0.27 \mathrm{~m}^{2} \mathrm{kWh}^{-1}$, the singleeffect absorption chiller at $0.29 \mathrm{~m}^{2} \mathrm{kWh}^{-1}$, and finally the adsorption chiller at approximately $0.55 \mathrm{~m}^{2} \mathrm{kWh}^{-1}$. 


\section{Chapter 3}

\section{Experimental Design and Commissioning}

The design and construction of an experimental apparatus for testing small scale sorption chillers was completed in December of 2013 by Baldwin and serves as the basis for the experimental work conducted in this thesis [41]. This chapter begins with a brief overview of the experimental set-up completed by Baldwin, including a description of its components, the measurement uncertainty of the installed instrumentation, and the design and testing of system controls. Next, the steps taken to commission the sorption chiller are outlined and discussed. Finally, the development of an experimental test procedure is detailed.

\subsection{Overview of Experimental Set-Up}

The primary goal of the experimental set-up is to allow for extensive testing of residential scale sorption chillers (i.e., sorption chillers having a cooling capacity between 5 and $15 \mathrm{~kW}$ ) under a variety of controlled boundary conditions (i.e., inlet temperatures and flow rates) so as to characterize the performance of the chiller over its full operational range. Table 3-1 shows the range of temperatures and flow rates that can be accommodated by the experimental apparatus, as well as the maximum heat transfer rates required by each of the three hydraulic loops.

Table 3-1: Design temperatures, flow rates, and heat transfer rates

\begin{tabular}{c|cccc}
\hline Hydraulic Loop & $\mathrm{T}_{\text {in, } \min }\left({ }^{\circ} \mathrm{C}\right)$ & $\mathrm{T}_{\text {in, } \max }\left({ }^{\circ} \mathrm{C}\right)$ & Flow Rate $(\mathrm{L} / \mathrm{min})$ & Maximum Heat Transfer Rate $(\mathrm{kW})$ \\
\hline Driving Circuit & 50 & 95 & $20-30$ & 30 \\
Air Conditioning & 10 & 25 & $15-25$ & 15 \\
Heat Rejection & 10 & 40 & $45-70$ & 60 \\
\hline
\end{tabular}


To effectively characterize the performance of a sorption chiller, the experimental apparatus must be able to quickly adapt to changing heat transfer rates in order to maintain the desired boundary conditions for the duration of the testing period. Once sufficient performance data are obtained, a comprehensive performance-based model of the sorption chiller can be developed for use in simulation. The newly developed model can then be paired with existing validated models of other system-level components such as solar thermal collectors, storage tanks, and a variety of different HVAC distribution systems. The use of simulation software allows for the flexible design and optimization of proposed solar cooling systems for various climates and cooling loads.

A high-level representation of the experimental system is shown in Figure 3-1. For the interested reader, a detailed schematic of the system is available in Appendix A. The system consists of seven hydraulic loops, including three primary loops that are connected directly to the sorption chiller and four secondary loops which serve to add or remove heat from the three main loops. In the driving circuit, heat can be added to the system by modulating a control valve on the condensate side of a steam-to-water shell and tube heat exchanger. In the chilled water loop, a 279 litre hot water tank equipped with two $4.5 \mathrm{~kW}$ heating elements is used to provide a cooling load for the sorption chiller. In the case of the heat rejection loop, heat can be dissipated through any one of three different flat plate heat exchangers. First, the flow can be directed through a flat plate exchanger that interfaces with the chilled water loop, thus simultaneously providing an additional cooling load for the chiller. Second, heat can be rejected to a glycol loop, which is in turn cooled by a $30 \mathrm{~kW}$ dry cooler on the roof of the Canal Building at Carleton. Third, during the summer, when high outdoor temperatures might prohibit the effective use of the dry cooler, the water in the heat 
rejection line can be redirected to pass through a flat plate heat exchanger that interfaces with the Canal Building's chilled water line, which is used to air condition the building. The inclusion of several heat rejection options was purposely incorporated into the design of the system to allow for year-round testing capability.

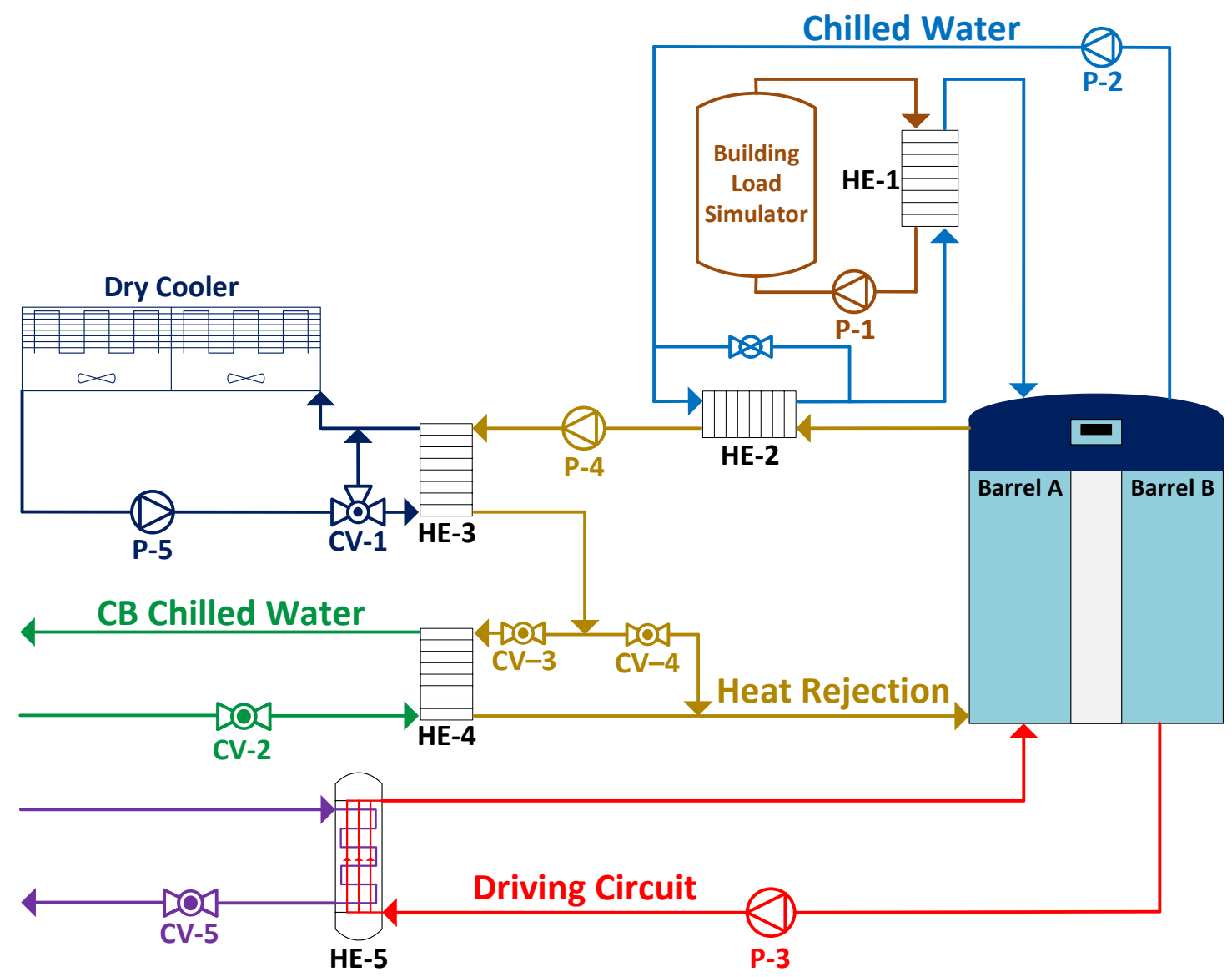

Figure 3-1: High-level schematic of experimental set-up

\subsection{Main Components}

This section will discuss the major components needed to operate the experimental set-up, including the sorption chiller, pumps, heat exchangers, and the control valves.

\subsubsection{Sorption Chiller}

In order to carry out the necessary experiments, a $10 \mathrm{~kW}$ ClimateWell triple-state sorption chiller was procured and installed within the Solar Energy Systems Laboratory. As detailed in 
Section 1.2.3, the sorption chiller consists of two independent generator/adsorbercondenser/evaporator pairs. The two pairs are labelled as Barrel A and Barrel B in Figure 3-2. Each of the two generator/adsorbers and two condenser/evaporators are enveloped by a wrap-around heat exchanger, meaning the sorption chiller contains a total of four internal heat exchangers. The incoming heat transfer fluid enters from the connection point at the top left of the chiller, where it is redirected to the appropriate heat exchanger by a switching unit before exiting from the connection point at the top right of the chiller. The switching unit consists of ten control valves which can either be controlled manually by the operator or autonomously using the unit's predefined switching algorithm. Four of the control valves correspond to the heat rejection circuit (one for each wrap-around heat exchanger). Similarly, another set of four control valves regulate flow to the internal heat exchangers for the chilled water circuit, while the final two control valves designate flow to the two generator heat exchangers for the driving circuit.

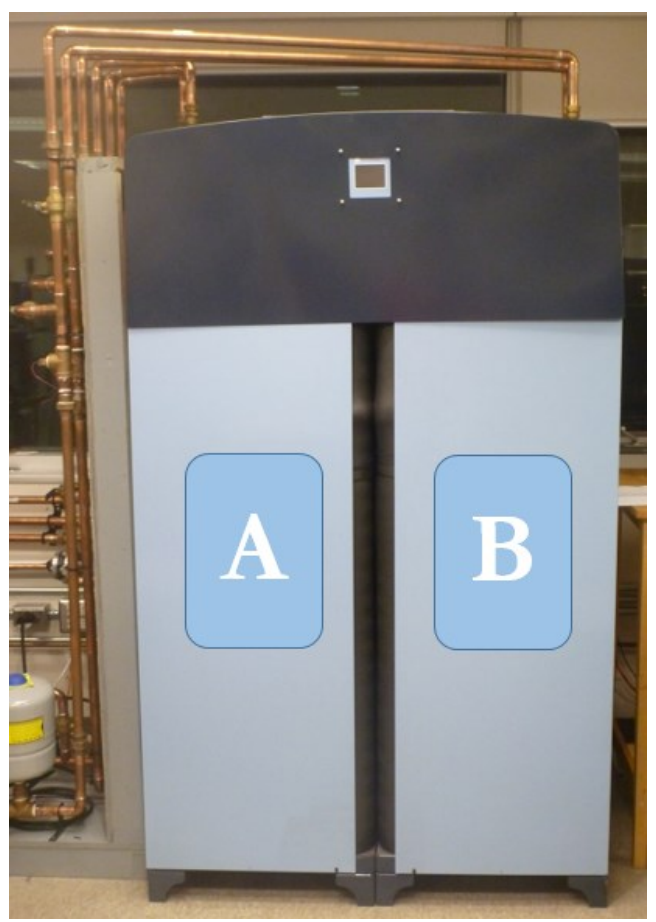

Figure 3-2: ClimateWell sorption chiller installed within the lab 
The ClimateWell sorption chiller is equipped with two load cells to measure the weight of each condenser/evaporator. Since the weight of the condenser/evaporator is directly proportional to the mass of condensed refrigerant, the load cell measurements can be used to determine the SOC of the chiller. However, the output signals of the load cells are unprocessed and must be calibrated such that the maximum value corresponds to a SOC of $100 \%$ (fully charged) while the minimum value corresponds to a SOC of $0 \%$ (fully discharged). Once calibrated, the sorption chiller's control system is able to determine the SOC at any given time by performing a linear interpolation between these two prescribed values. The chiller was calibrated such that a SOC of $100 \%$ corresponded to the maximum condenser weight achieved for a charging cycle having a driving temperature of $95^{\circ} \mathrm{C}$ and a heat rejection temperature of $15^{\circ} \mathrm{C}$.

\subsubsection{Pumps}

As shown in Figure 3-1, the experimental set-up consists of five circulation pumps, labelled P-1 through P-5. Each variable speed pump is governed by a 0-10 V control signal, which permits testing of the sorption chiller using various flow rates. The variable speed pumps in the secondary hydraulic loops can be used to control the rate of heat transfer to the primary hydraulic loops. The specifications of the five circulation pumps are provided in Table 3-2.

Table 3-2: Installed pumps

\begin{tabular}{|c|c|c|c|c|}
\hline Pump & Model & Hydraulic Loop & Design Flow Rate (L/min) & Power (W) \\
\hline P-1 & Grundfos UP 26-96F/VS & Building Load & 15 & 62 \\
\hline P-2 & Grundfos Magna 32-100 & Chilled Water & 25 & 180 \\
\hline P-3 & Grundfos CR 3-2 & Driving Circuit & 25 & 373 \\
\hline P-4 & Grundfos CR 5-4 & Heat Rejection & 60 & 1119 \\
\hline P-5 & Grundfos CR 5-4 & Dry Cooler & 75 & 1119 \\
\hline
\end{tabular}




\subsubsection{Heat Exchangers}

In addition to the five circulation pumps, five heat exchangers are found within the hydraulic network, the details of which are outlined in Table 3-3.

Table 3-3: Installed heat exchangers

\begin{tabular}{c|lllc}
\hline $\begin{array}{c}\text { Heat } \\
\text { Exchanger }\end{array}$ & \multicolumn{1}{|c}{ Model } & Hot Side & \multicolumn{1}{c}{ Cold Side } & $\begin{array}{c}\text { Capacity } \\
(\mathrm{kW})\end{array}$ \\
\hline HE-1 & HEX BL14-30H & Building Load & Air Conditioning & 3.5 \\
HE-2 & HEX BL26C-30H & Heat Rejection & Air Conditioning & 5 \\
HE-3 & Alfa Laval CB30-70H & Heat Rejection & Dry Cooler & 42.8 \\
HE-4 & Alfa LavalCB27-34L & Heat Rejection & CB Chilled Water & 46.5 \\
HE-5 & Preston Phipps PPSCF-300-11W & Steam Line & Driving Circuit & 30 \\
\hline
\end{tabular}

\subsubsection{Control Valves}

In addition to the five circulation pumps and five heat exchangers, the hydraulic network consists of five automated control valves which govern the flow within the experimental setup. The location and function of each of the five control valves is outlined in Table 3-4.

Table 3-4: Installed control valves

\begin{tabular}{|c|c|c|}
\hline Control Valve & Hydraulic Loop & Function \\
\hline $\mathrm{CV}-1$ & Dry Cooler & $\begin{array}{l}\text { Bypasses the glycol/heat rejection heat exchanger when outdoor } \\
\text { temperatures fall below }-25^{\circ} \mathrm{C} \text { in order to protect water in the } \\
\text { heat rejection line from freezing }\end{array}$ \\
\hline $\mathrm{CV}-2$ & CB Chilled Water & $\begin{array}{l}\text { Proportional control valve used to modulate the flow of the } \\
\text { water in the Canal Building chilled water circuit }\end{array}$ \\
\hline $\mathrm{CV}-3$ & Heat Rejection & $\begin{array}{l}\text { Opens to redirect flow in the heat rejection circuit through the } \\
\text { Canal Building chilled water heat exchanger }\end{array}$ \\
\hline $\mathrm{CV}-4$ & Heat Rejection & $\begin{array}{l}\text { Opens to allow the flow in the heat rejection circuit to bypass } \\
\text { the Canal Building chilled water heat exchanger }\end{array}$ \\
\hline $\mathrm{CV}-5$ & Steam Line & $\begin{array}{l}\text { Proportional control valve used to modulate the release of } \\
\text { condensate through the steam line/driving circuit shell and tube } \\
\text { heat exchanger }\end{array}$ \\
\hline
\end{tabular}

\subsection{Instrumentation}

This section will discuss the instrumentation used to measure the performance of the sorption chiller, including the uncertainty associated with each measurement. 


\subsubsection{Thermocouples and Thermopiles}

The temperatures of the fluid streams as they enter and exit the sorption chiller are measured with Type-T thermocouples. As part of the work completed by Baldwin in the first phase of this project, the thermocouple wire was calibrated using a Fluke 7102 uniform temperature bath. During the calibration process, the temperature of the bath was measured with a platinum resistant temperature detector, having a factory calibrated accuracy of $\pm 0.02^{\circ} \mathrm{C}$, while the temperature of the cold junction was measured with the built-in thermistor of the data acquisition system and had an accuracy of $\pm 0.25^{\circ} \mathrm{C}$. The temperature of the bath was varied between $5^{\circ} \mathrm{C}$ and $95^{\circ} \mathrm{C}$ at temperature intervals of $2^{\circ} \mathrm{C}$, and the thermocouple voltage was measured at each set-point. The temperature of the bath was held constant for three minutes at each set-point, during which time the thermocouple voltage was measured every five seconds. A sixth order polynomial was fit to the measured data to produce Equation 3.1, which calculates the measured temperature based on the thermocouple voltage and cold junction temperature,

$$
\mathrm{T}=0.00109 \mathrm{~V}^{6}+0.00615 \mathrm{~V}^{5}-0.0799 \mathrm{~V}^{4}+0.212 \mathrm{~V}^{3}-0.708 \mathrm{~V}^{2}+24.65 \mathrm{~V}-0.186+\mathrm{CJC}
$$

where $\mathrm{T}$ is the temperature in degrees Celsius, $\mathrm{V}$ is the thermocouple voltage in $\mathrm{mV}$, and CJC is the cold junction temperature in degrees Celsius. Through the calibration experiment, the total uncertainty of the temperature measurements was found to be $\pm 0.49^{\circ} \mathrm{C}$ [41].

In addition to the use of thermocouples to measure the inlet and outlet temperatures of the fluid streams, thermopiles are used to measure the temperature difference across the inlet and outlet of each of the three hydraulic circuits. A thermopile is simply a set of thermocouples placed in series, whereby the outlet temperature acts as the cold junction and the thermocouple voltage is indicative of the temperature of the fluid at the inlet relative to 
its temperature at the outlet. While the main benefit of a thermopile is the removal of the cold junction compensation error, the use of several thermocouples in series also serves to amplify the thermocouple voltage produced, thereby reducing the error associated with the voltage measurement. With the use of a five-junction thermopile, the measurement error associated with the temperature difference across the inlet and outlet of a hydraulic loop is reduced to $\pm 0.15^{\circ} \mathrm{C}[41]$.

\subsubsection{Flow Meters}

The flow rate of the heat transfer fluid in each of the three chiller-connected hydraulic circuits was measured using oval gear positive displacement flow meters, each having a factory calibrated measurement uncertainty of $\pm 1 \%$ reading [42]. The movement of the heat transfer fluid through the flow meter causes a set of internal gears to rotate, with each rotation of the gears allowing a fixed volume of fluid to pass through the flow meter. Each rotation of the oval gears also causes a reed switch to temporarily switch off a $24 \mathrm{~V}$ signal that is continuously supplied to the flow meter. The data acquisition system counts the number of pulses generated by the flow meter over a given period of time and in turn calculates the volumetric flow rate. For the design flow rate of $25 \mathrm{~L} / \mathrm{min}$ and an averaging period of 30 seconds, the overall uncertainty of the volumetric flow rate was found to be $\pm 0.26 \mathrm{~L} / \mathrm{min}$ for the driving circuit and $\pm 0.25 \mathrm{~L} / \mathrm{min}$ for each of the heat rejection and air conditioning circuits, or an accuracy of $\pm 1 \%$ [41].

\subsection{Control Systems}

A Delta controller was selected to control all of the control valves and pumps of the experimental set-up with the exception of the pump belonging to the building load simulator loop, which was controlled by the data acquisition system and LabVIEW software. The 
Delta controller was selected due to its robustness, ability to operate autonomously when programmed, and its ability to provide continuous monitoring in the absence of active testing. This final feature ensures that no safety limits are reached, thereby protecting against the chance of steam generation in the driving circuit or freezing in the heat rejection circuit.

The chiller inlet temperatures of the driving and heat rejection circuits were initially governed by proportional-integral-derivative (PID) control loops. However, due to the slow response time of the Delta controller and control valves, it was found that the fluid temperature was optimally controlled with a simple proportional control algorithm. In the case of the driving circuit, the Delta controller measures the temperature of the fluid upstream of the steam-to-water shell and tube heat exchanger, and modulates the position of the steam line control valve accordingly to meet the set-point temperature. Similarly, during the summer, the upstream temperature of the heat rejection fluid is used as the control parameter to modulate the position of the Canal Building chilled water control valve. In each case, measuring the upstream temperature provides enough time for the control valves to respond to the heat transfer needs of the system. The relatively constant temperatures of both the Canal Building's steam and chilled water lines allow the position of the control valves to be proportionally controlled.

The chiller inlet temperatures of the driving circuit are plotted in Figure 3-3 for the first three hours of two different test runs. The set-point temperatures of $65^{\circ} \mathrm{C}$ and $95^{\circ} \mathrm{C}$ were chosen because these temperatures represent the upper and lower bounds of the desired testing range for the driving circuit. The first three hours were selected as this is the period during which the system is not at steady state and the controller must adapt to changing thermal requirements. 
The chiller inlet temperatures of the heat rejection circuit are plotted in Figure 3-4 for the first three hours of two different test runs. As was the case for the driving circuit, setpoint temperatures of $15^{\circ} \mathrm{C}$ and $35^{\circ} \mathrm{C}$ represent the upper and lower bounds of the desired testing range for the heat rejection circuit. The mean and standard deviation of the heat rejection and driving circuit inlet temperature for each test run are provided in Table 3-5.

Table 3-5: Mean and standard deviation of the inlet temperatures during first three hours of charging tests

\begin{tabular}{c|ccc}
\hline Hydraulic Loop & Set-Point $\left({ }^{\circ} \mathrm{C}\right)$ & Mean $\left({ }^{\circ} \mathrm{C}\right)$ & Standard Deviation $\left({ }^{\circ} \mathrm{C}\right)$ \\
\hline Heat Rejection Circuit & 15 & 15.2 & 0.4 \\
Heat Rejection Circuit & 35 & 35.1 & 0.5 \\
Driving Circuit & 65 & 64.9 & 1.7 \\
Driving Circuit & 95 & 95.0 & 2.5 \\
\hline
\end{tabular}

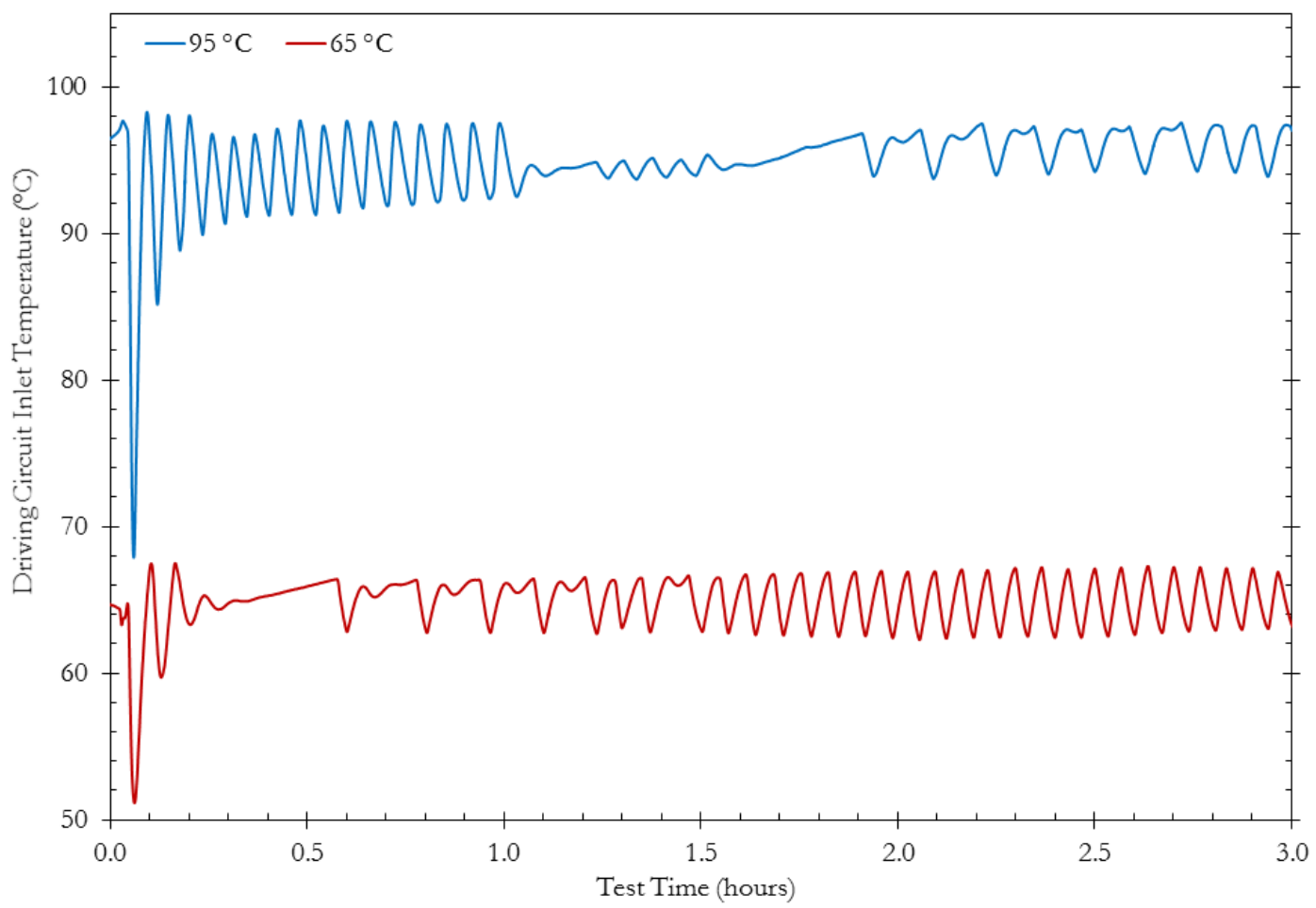

Figure 3-3: Driving circuit inlet temperatures during first three hours of charging tests 


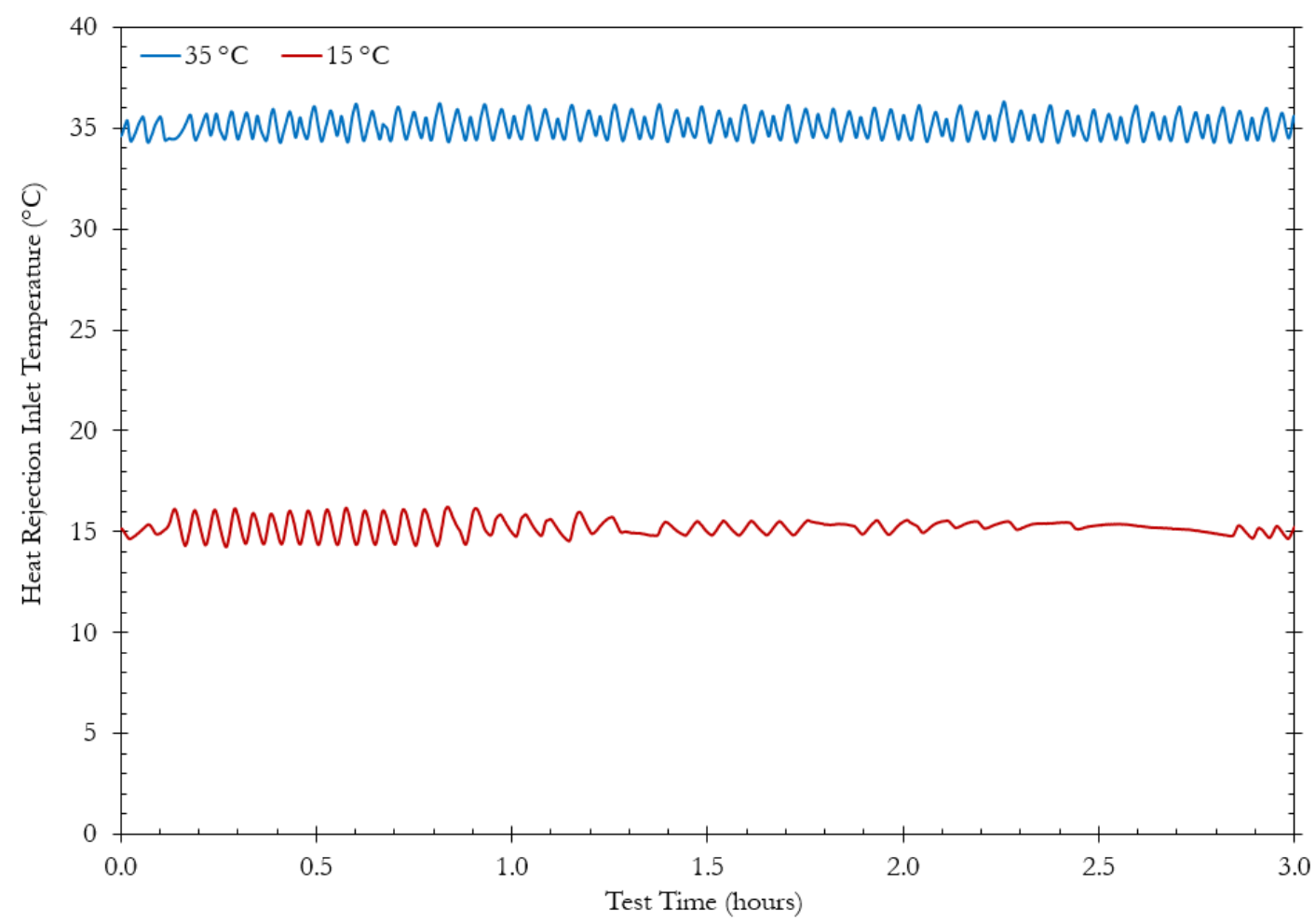

Figure 3-4: Heat rejection inlet temperatures during first three hours of charging tests

From these results, it can be noted that the greatest deviation from the set-point occurs in the driving circuit, and particularly at the beginning of each test run. This is as a result of the room-temperature fluid leaving the sorption chiller at the beginning of the test. Although the line is pre-heated to the desired set-point before the testing begins, the fluid sitting in the chiller is at room temperature and as it makes its way through the loop, it creates a significant decrease in temperature during its first pass through, and the fluids' second and third pass can also be noted. This is caused by the system not having a high enough response time to meet these, short, very significant demands, due to the thermal lag of the system, as well as the time the steam-to-water heat exchanger takes to adapt to the different heat transfer rate required. This is predominantly caused by the control valve opening time (90 seconds to go from completely closed to completely open), which allows the cold fluid to pass through the heat exchanger more quickly than the control valve is able 
to fully respond to the increased heating demand. Even after recovering from the initial large temperature drop of the fluid, the temperature continues to oscillate about the set-point due to the slow opening and closing of the control valve.

In addition to controlling the heat input, two separate PID loops were implemented into the cold side to control the returning heat rejection temperature. One control program has been built for the summer mode, which proportionally controls the flow rate of chilled water that enters the heat exchanger, and a second for the winter mode that regulates the amount of glycol passing through the heat exchanger. The heat rejection return temperatures are shown in Figure 3-4 for two summer-mode tests with set-points of $35^{\circ} \mathrm{C}$ and $15^{\circ} \mathrm{C}$, which represent the approximate upper and lower testing bounds for the chiller. The mean and standard deviations from these tests are indicated in Table 3-5.

From these results, it can be noted that the control system developed for the heat rejection system is able to provide a more constant input temperature over the entire designed temperature range of the system. However, it can be noted that the temperature of the heat rejection line also oscillates about the set-point due to the opening and closing of the control valve, but the magnitude of the oscillations are much smaller compared to the heat input line.

\subsection{Commissioning}

Following the construction of the experimental set-up, all instrumentation was tested before filling the sorption chiller. This was done to ensure that all control systems were operating and responding to system changes as intended, as well as to confirm the proper functioning of the data acquisition system. To fill the sorption chiller, the switching unit was manually operated to open each of the four control valves corresponding to the heat rejection circuit, 
thereby allowing the water to circulate through each of the sorption chiller's four wraparound heat exchangers until the circuit was fully pressurized and all of the air was purged from the system. The four heat rejection control valves were then closed, and the process was repeated for the chilled water circuit, and then a final time for the driving circuit.

In order to commission the sorption chiller, each barrel must undergo an evacuation process to ensure that the system is operating at a suitable pressure. Because water is used as the refrigerant, the system must operate under a partial vacuum if the evaporator is to produce chilled water at temperatures as low as $15^{\circ} \mathrm{C}$ (the vapour pressure of water is approximately 17 mbar at $15^{\circ} \mathrm{C}$ ). A special tool, shown in Figure 3-5, was required to temporarily pull the vacuum plug from the condenser of each barrel during the evacuation. This tool consists of a threaded rod enveloped by standard vacuum fittings. The threaded rod securely fastens to the matching threads of the vacuum plug, allowing the plug to be easily removed at the beginning of the evacuation and replaced after a satisfactory vacuum has been drawn. The vacuum tool is fitted with a tee for connections to a vacuum hose as well as a vacuum gauge to monitor the pressure of the condenser throughout the evacuation process.

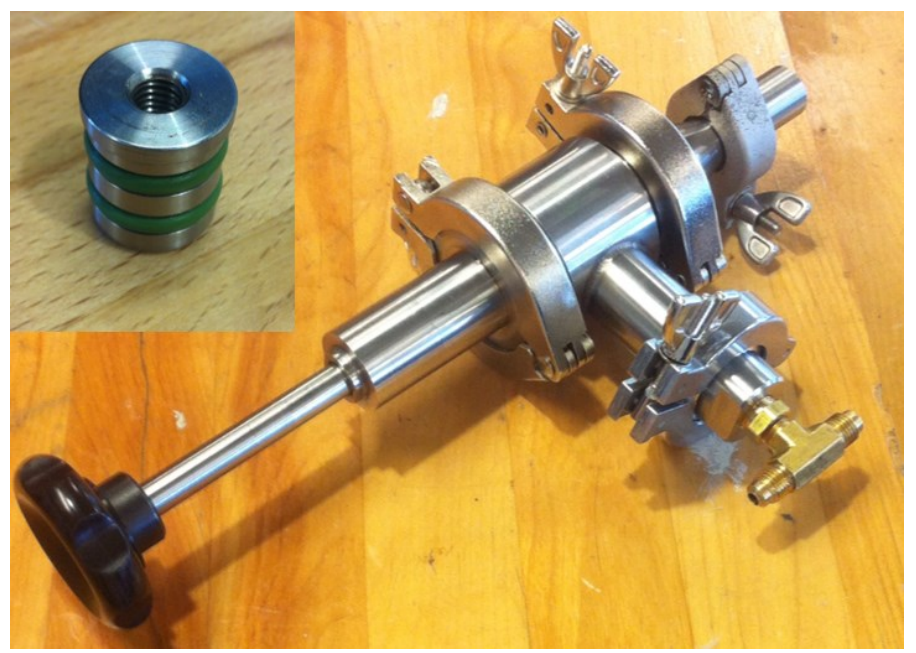

Figure 3-5: Adapter tool used for evacuation of sorption chiller and condenser plug (top left) 
In accordance with the installation manual, the evacuation process was executed at the end of the charging cycle (i.e., when all of the water has been desorbed from the $\mathrm{LiCl}$ sorbent). Since it is not possible to calibrate the load cells prior to commissioning, the installation manual defines the end of the charging cycle as the point when the temperature difference across the inlet and outlet of the driving circuit remains steadily below $3^{\circ} \mathrm{C}$ for an inlet temperature of at least $90^{\circ} \mathrm{C}$ [43]. During the initial commissioning, this criteria was met after approximately 3 hours of charging time. At this point, the first evacuation of each barrel was completed using a Yellow Jacket SuperEvac vacuum pump and a Robinair thermistor vacuum gauge, resulting in a final pressure of $2.2 \mathrm{mbar}$ and $1.7 \mathrm{mbar}$ in Barrel A and Barrel B, respectively. Following the evacuation, each barrel continued to charge until the weight of each condenser was observed to reach its maximum, as indicated by the load cell. In total, the complete charging process lasted approximately 20 hours, demonstrating that the initial evacuation did not take place at the end of the charge cycle as planned. Therefore, as a measure of assurance, each barrel was evacuated a second time, achieving a final pressure of 1.2 mbar in each barrel.

After completing the commissioning process, Barrel A was set to discharge from its fully charged state. During a 2 hour discharge period with a favourable average chilled water inlet temperature of $27.7^{\circ} \mathrm{C}$ and average heat rejection inlet temperature of $17.5^{\circ} \mathrm{C}$, Barrel A was only able to produce an average cooling power of approximately $1 \mathrm{~kW}$. Based on the performance curves provided by ClimateWell, the chiller was expected to produce in excess of $8 \mathrm{~kW}$ of cooling power under these conditions [44].

The poor performance of the chiller raised concerns as to the proper execution of the evacuation process. The accuracy of the Robinair vacuum gauge was questioned due to a 
calibration limitation that caused measurement readings to be offset. Prior to evacuation, the vacuum gauge must be calibrated to atmospheric pressure by adjusting a dial until the correct analogue output is displayed. However, after adjusting the dial to its full extent, the analogue output of the vacuum gauge continued to show a pressure of less than one atmosphere, resulting in unreliable measurements a particularly low pressures. To address this issue, a CPS VG200 Digital Vacrometer having an accuracy of $\pm 10 \%$ reading was acquired to replace the Robinair thermistor vacuum gauge. Additionally, in order to facilitate the evacuation process and allow the pressure to be monitored on an ongoing basis, an alternative means of evacuating the sorption chiller was required. To accomplish this task, the two condenser plugs were permanently removed and replaced with two vacuum ball valves. Figure 3-6 shows the vacuum valve and new pressure gauge attached to the condenser of Barrel B. Unlike the special evacuation tool, which was vulnerable to leaks due to the clearance required between the vacuum fittings and moveable rod, the air-tight seal of the vacuum valves allowed the condenser pressure to be monitored during operation of the sorption chiller.

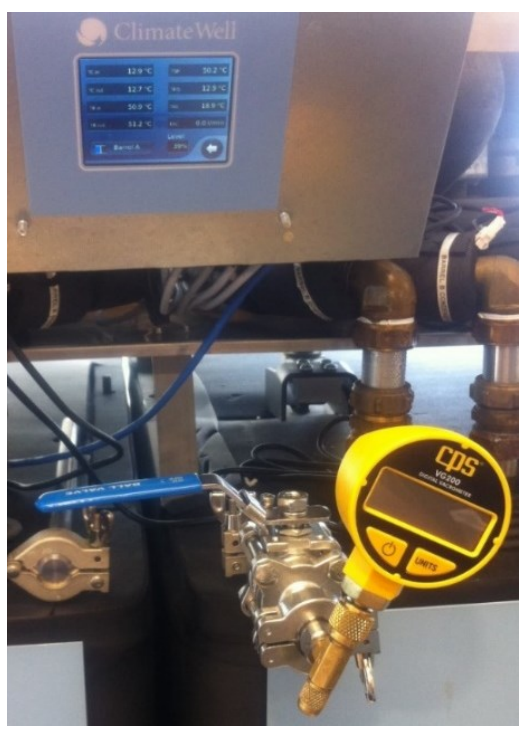

Figure 3-6: Modified evacuation set-up 
The evacuation procedure was repeated using the modified evacuation set-up, achieving a final pressure of 2 mbar. It was noted that the evacuation time required to reach a final pressure of 2 mbar was 50\% longer than with the previous evacuation set-up, suggesting that the Robinair thermistor vacuum gauge may have provided erroneous measurements. After completing the evacuation, Barrel B was discharged from a fully charged state, producing an average cooling power of $1.9 \mathrm{~kW}$ over a 2 hour period for an average chilled water temperature of $21.1^{\circ} \mathrm{C}$ and average heat rejection inlet temperature of $17.2^{\circ} \mathrm{C}$. While the average cooling power was nearly double what had been achieved in the previous discharge test, the cooling output remained less than $25 \%$ of the expected output [44]. Therefore, an inadequate evacuation process was ruled out as the primary cause for the underperformance of the chiller.

In addition to proving the vacuum during the commissioning process, the new evacuation set-up was beneficial for its ability to monitor the pressure of the system over long periods of time. This capability was used to determine if the chiller was underperforming due to a gradual increase in pressure that could be caused by a small leak or off-gassing within the system. After reaching an evacuation pressure of 2 mbar in Barrel A, the vacuum ball valve was closed before powering off the vacuum pump. The vacuum hose was then disconnected and the connection point was capped before reopening the vacuum ball valve to measure the system pressure. With the hydraulic connections to Barrel A closed, the pressure of the system was then monitored over the course of the following eight days. As shown in Figure 3-7, the pressure was observed to gradually increase at a rate of approximately $19 \mathrm{mbar} /$ day. While the early increase in pressure could be explained by the system reaching its equilibrium pressure, the continued rise in pressure suggests the presence 
of a small leak or a corrosion problem resulting in the production of non-condensable gases. The same test was conducted on Barrel B, yielding similar results.

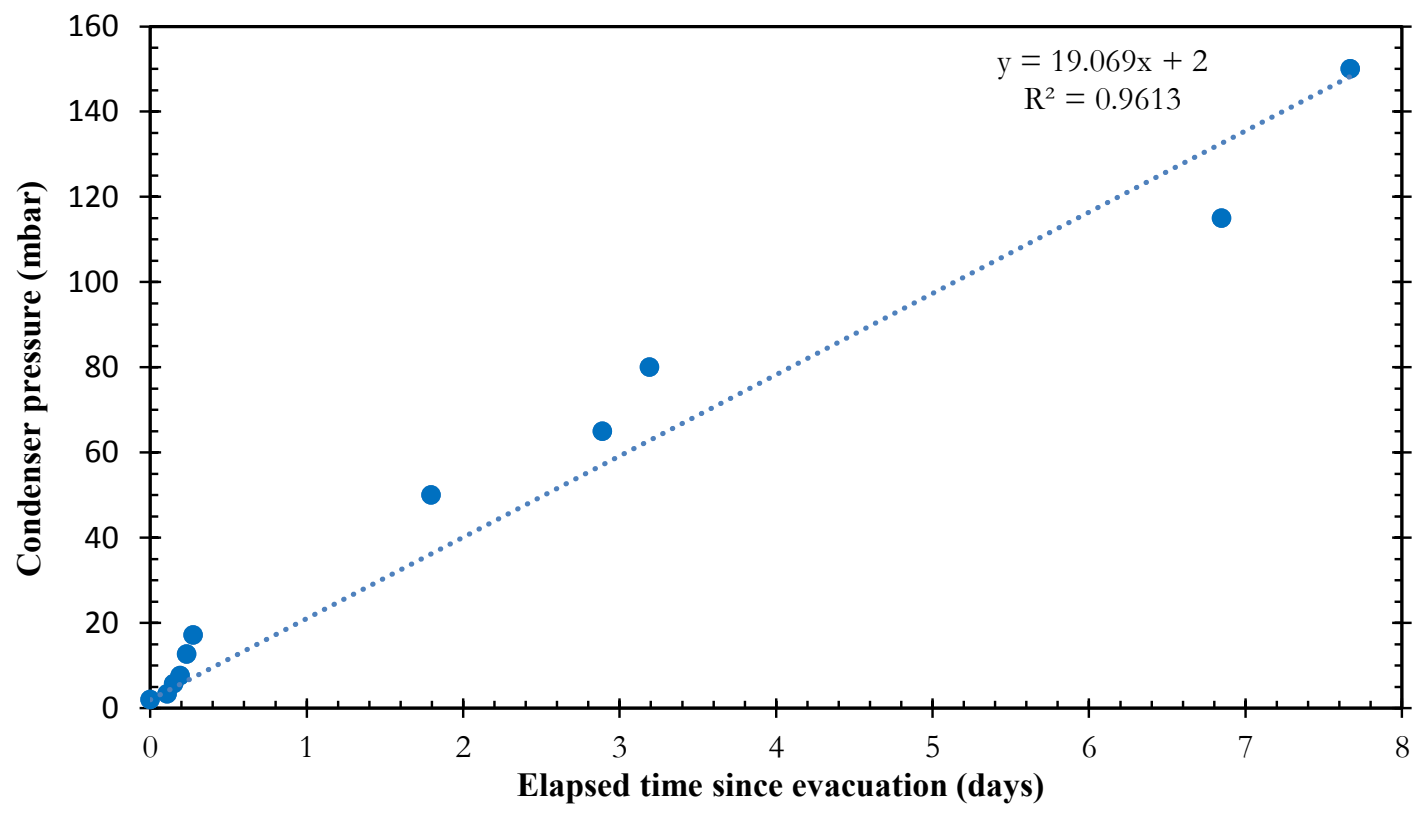

Figure 3-7: Post-evacuation vacuum retention (Barrel A)

\subsection{Development of Experimental Procedure}

The objective of the experimental procedure was to characterize the charging and discharging rates of the chiller for a given set of controlled boundary conditions (i.e., inlet temperatures and flow rates). In doing so, a comprehensive set of charge and discharge curves can be established to predict the charge or discharge rate of the chiller as a function of the inlet temperatures and SOC. However, having ascertained that the chiller was unable to retain its vacuum, it was first necessary to investigate how a loss of vacuum affected its performance.

Two tests were conducted on Barrel B to compare the effects of the initial condenser pressure on the charging cycle. Each test began at a fully discharged state and lasted 18 hours. The inlet temperatures of the driving circuit and heat rejection circuit were set to $93^{\circ} \mathrm{C}$ and $20^{\circ} \mathrm{C}$, respectively, while each circuit was set to have a flow rate of $25 \mathrm{~L} / \mathrm{min}$ for 
the duration of the test. The only difference between the two tests was that the first test began with a condenser pressure of $5 \mathrm{mbar}$, while the second test had an initial condenser pressure of 150 mbar. As shown in Figure 3-8, the test with the higher initial condenser pressure resulted in both a slower charging rate and a significantly lower maximum SOC $\left(\mathrm{SOC}_{\max }\right)$ of $55 \%$ compared to $92 \%$ for the 5 mbar test. This procedure was then repeated to determine the chiller's sensitivity to small changes in the initial condenser pressure. Specifically, initial condenser pressures of $2 \mathrm{mbar}, 10 \mathrm{mbar}$, and $20 \mathrm{mbar}$ were tested. Figure 3-9 shows that while there was minimal difference in the charging profile for the tests with initial condenser pressures of $10 \mathrm{mbar}$ and $20 \mathrm{mbar}$, the chiller charged more quickly and achieved a higher final SOC when the initial condenser pressure was 2 mbar. Therefore, to minimize the influence of the initial condenser pressure on the results of future tests, the chiller was evacuated to 10 mbar prior to each test.

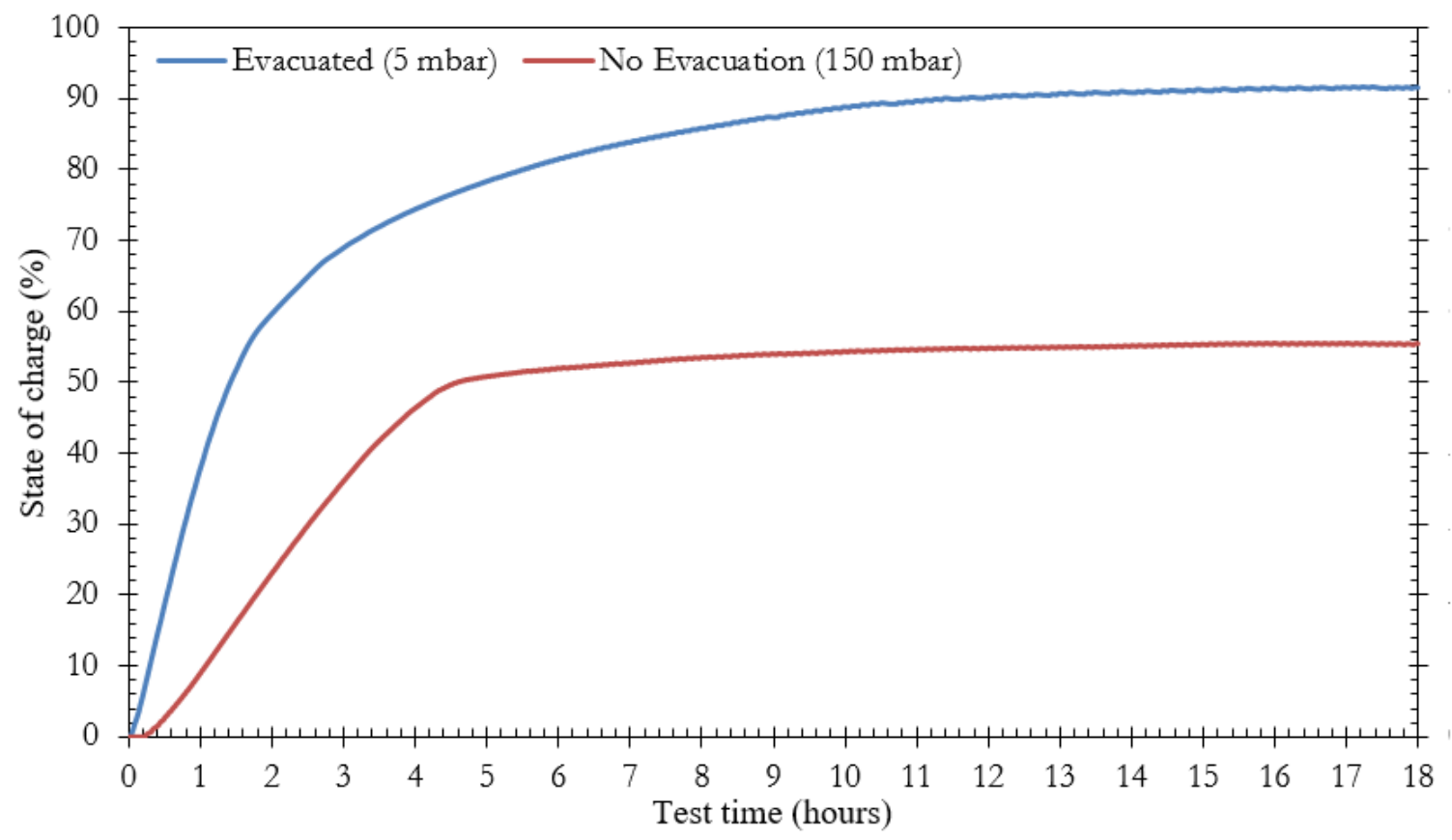

Figure 3-8: Comparison of charge cycle for evacuated and non-evacuated starting condition 


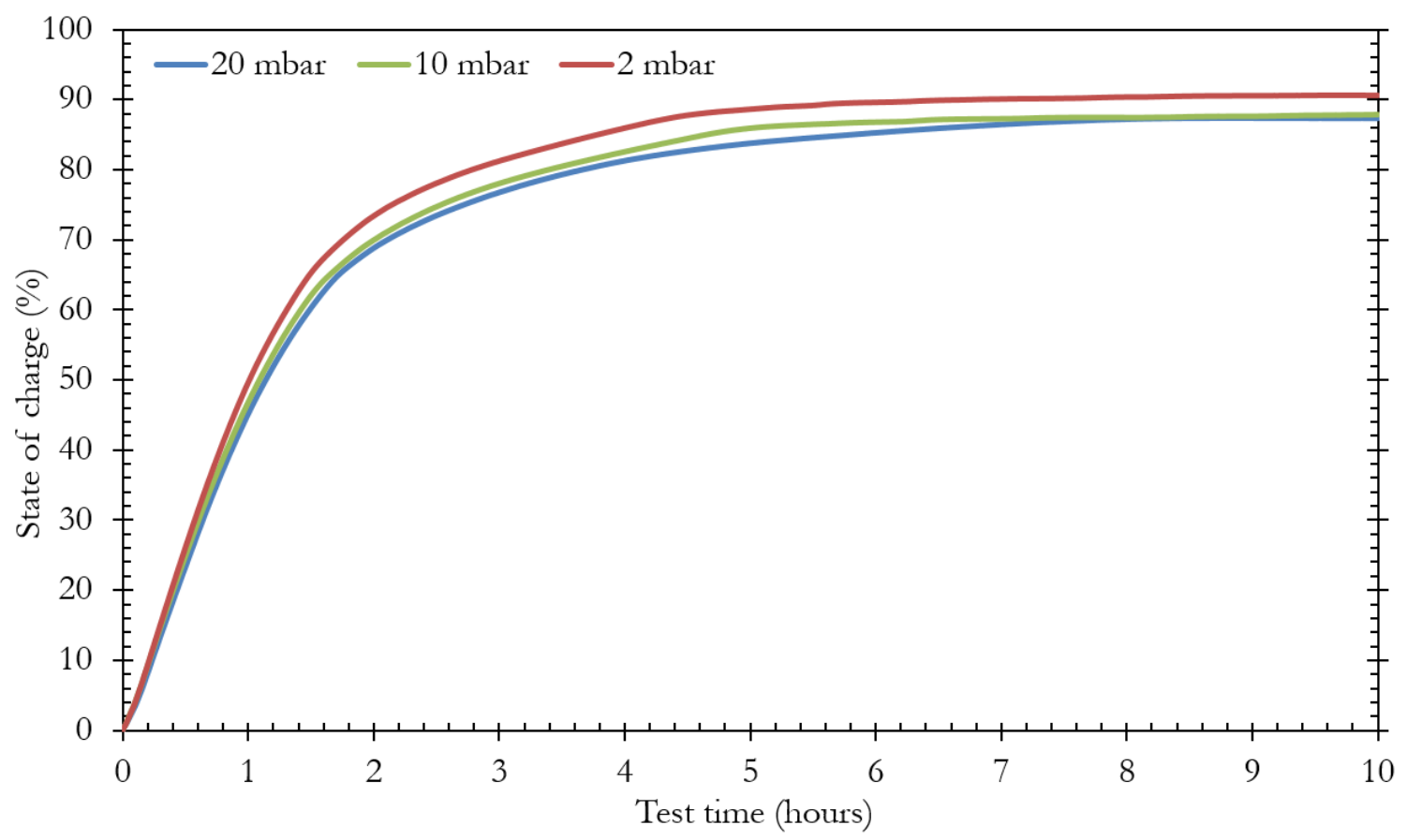

Figure 3-9: Sensitivity of charging rate for different initial condenser pressures

Each charge test was to be conducted over the full range of the cycle (i.e., from an initial SOC of $0 \%$ to the maximum attainable state of charge for the given boundary conditions). A charging test was said to have reached its $\mathrm{SOC}_{\max }$ when the hourly average temperature difference across the inlet and outlet of the heat rejection circuit changed by less than $\pm 0.15^{\circ} \mathrm{C}$ for three consecutive hours. Since the SOC $\max$ will be less than $100 \%$ for most boundary conditions, at the end of a given charge test the driving temperature was set to $95^{\circ} \mathrm{C}$ and the heat rejection temperature was set to $15^{\circ} \mathrm{C}$ to ensure that a SOC of $100 \%$ is reached prior to the start of a discharge test. Similarly, at the end of a discharge test, the chilled water inlet temperature was increased to $55^{\circ} \mathrm{C}$ while the heat rejection temperature was set to $15^{\circ} \mathrm{C}$ to ensure that a SOC of $0 \%$ was reached before beginning the next charge test.

Due to the high volume of refrigerant employed by the ClimateWell, the time required to complete an experimental characterization test for one full charge/discharge 
cycle ranged from 30 to 50 hours, depending on the boundary conditions. This lengthy test time, along with the knowledge that the evacuation of the chiller prior to each test would alter its physical properties by removing some of the refrigerant water, were important factors in determining the number of tests that should be conducted to develop the performance map. Therefore, a temperature resolution of $10^{\circ} \mathrm{C}$ was initially chosen for the performance map, with the knowledge that supplemental tests could be performed at a later time if it was deemed that the $10^{\circ} \mathrm{C}$ resolution was insufficient. The charge cycle was characterized for 12 different combinations of constant heat input and heat rejection temperatures. More specifically, heat input temperatures of $65^{\circ} \mathrm{C}, 75^{\circ} \mathrm{C}, 85^{\circ} \mathrm{C}$, and $95^{\circ} \mathrm{C}$ were investigated while the heat rejection temperatures were varied between $15^{\circ} \mathrm{C}, 25^{\circ} \mathrm{C}$, and $35^{\circ} \mathrm{C}$. Similarly, the discharge cycle was characterized for heat rejection inlet temperatures of $15^{\circ} \mathrm{C}, 25^{\circ} \mathrm{C}$, and $35^{\circ} \mathrm{C}$ and chilled water inlet temperatures of $15^{\circ} \mathrm{C}, 25^{\circ} \mathrm{C}$, and $35^{\circ} \mathrm{C}$. 


\section{Chapter 4}

\section{System Modelling}

\subsection{Introduction}

To simulate the performance of the triple-state sorption chiller, a Microsoft Excel-based model was developed for use in TRNSYS [45]. TRNSYS is a "flexible graphically based software environment used to simulate the behaviour of transient systems" [46]. The program contains extensive libraries of different solar and HVAC components which can be

linked together to represent a physical system. Each component is referred to as a Type and consists of a Fortran subroutine which executes a series of mathematical operations for a given set of inputs and passes the generated outputs to each linked Type. The modular nature of TRNSYS allows new configurations of components and control systems to be easily implemented, making the program a very powerful and versatile tool for parametric sensitivity analyses and optimization. For these reasons, TRNSYS was selected as the most appropriate simulation tool for the triple-state sorption chiller.

\subsection{Existing TRNSYS Sorption Chiller Models}

While two sorption chiller Types are available in the TRNSYS component libraries, neither Type is appropriate for modelling the performance of a triple-state sorption chiller. Type 107 models the continuous cycle of a single-effect absorption chiller, while Type 909 is intended to model the performance of an adsorption chiller. This section describes the mathematical basis of these Types as well as the limitations of their applicability. 


\subsubsection{Single-effect absorption chiller - Type 107}

The standard component library in TRNSYS contains Type 107, which models the performance of a single-effect absorption chiller based on a set of user specified performance data. For each combination of driving, heat rejection, and chilled water temperatures, the user is asked to specify cooling capacity and $\mathrm{COP}_{\text {th }}$ as a fraction of the nominal cooling capacity and nominal $\mathrm{COP}_{\text {th }}$.

The first calculation performed by Type 107 is to determine the cooling power required to meet the chilled water set-point temperature,

$$
\dot{\mathrm{Q}}_{\mathrm{cw}, \mathrm{req}}=\dot{\mathrm{m}}_{\mathrm{cw}} \mathrm{c}_{\mathrm{p}, \mathrm{cw}}\left(\mathrm{T}_{\mathrm{cw}, \mathrm{in}}-\mathrm{T}_{\mathrm{cw}, \mathrm{set}}\right)
$$

where $\dot{\mathrm{m}}_{\mathrm{cw}}$ is the mass flow rate of the chilled water, $\mathrm{c}_{\mathrm{p}, \mathrm{cw}}$ is the specific heat of the chilled water, $\mathrm{T}_{\mathrm{cw} \text {,in }}$ is the inlet temperature of the chilled water, and $\mathrm{T}_{\mathrm{cw} \text {,set }}$ is the chilled water setpoint temperature. After determining the required cooling power, the load fraction of the chiller is then calculated according to Equation 4.2,

$$
\mathrm{f}_{\text {load }}=\frac{\dot{\mathrm{Q}}_{\mathrm{cw}, \mathrm{req}}}{\operatorname{cap}_{\text {nom }} \mathrm{f}_{\text {cap }}}
$$

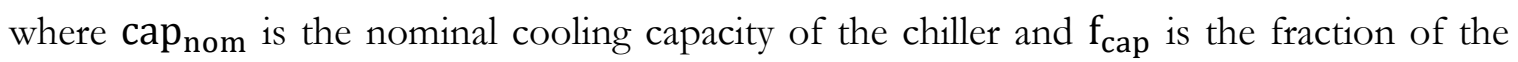
nominal cooling capacity that can be produced at the given boundary conditions. Because it is only practical for the user to provide performance data for a finite number of boundary conditions, $\mathrm{f}_{\text {cap }}$ must be determined through linear interpolation of the user-provided data. The outlet temperature of the chilled water circuit is then calculated according to Equation 4.3.

$$
\mathrm{T}_{\mathrm{cw}, \mathrm{out}}=\mathrm{T}_{\mathrm{cw}, \mathrm{in}}-\frac{\operatorname{Min}\left\{\dot{\mathrm{Q}}_{\mathrm{cw}, \mathrm{req}}, \mathrm{cap}_{\text {nom }} \mathrm{f}_{\mathrm{cap}}\right\}}{\dot{\mathrm{m}}_{\mathrm{cw}} \mathrm{c}_{\mathrm{p}, \mathrm{cw}}}
$$


The chilled water outlet temperature is calculated based on the minimum value between the required cooling power and available cooling power to ensure that the chilled water is not cooled beyond the capability of the chiller. The driving power is then calculated according to Equation 4.4.

$$
\dot{\mathrm{Q}}_{\mathrm{dr}}=\frac{\operatorname{cap}_{\text {nom }} \mathrm{f}_{\text {cap }} \mathrm{f}_{\text {load }}}{\operatorname{COP}_{\text {nom }} \mathrm{f}_{\text {COP }}}
$$

where $\mathrm{f}_{\mathrm{COP}}$ is the fraction of the nominal $\mathrm{COP}_{\text {nom }}$ at the given boundary conditions. The outlet temperature of the driving circuit is then calculated according to Equation 4.5.

$$
\mathrm{T}_{\mathrm{dr}, \text { out }}=\mathrm{T}_{\mathrm{dr}, \text { in }}-\frac{\dot{\mathrm{Q}}_{\mathrm{dr}}}{\dot{\mathrm{m}}_{\mathrm{dr}} \mathrm{c}_{\mathrm{p}, \mathrm{dr}}}
$$

By performing an energy balance on the system, the heat rejection power can be calculated according to Equation 4.6.

$$
\dot{\mathrm{Q}}_{\mathrm{hr}}=\dot{\mathrm{Q}}_{\mathrm{dr}}+\dot{\mathrm{Q}}_{\mathrm{cw}}
$$

Finally the outlet temperature of the heat rejection circuit is calculated according to Equation 4.7.

$$
\mathrm{T}_{\mathrm{hr}, \text { out }}=\mathrm{T}_{\mathrm{hr}, \mathrm{in}}-\frac{\dot{\mathrm{Q}}_{\mathrm{hr}}}{\dot{\mathrm{m}}_{\mathrm{hr}} \mathrm{c}_{\mathrm{p}, \mathrm{hr}}}
$$

\subsubsection{Adsorption chiller - Type 909}

In addition to Type 107 found in the standard TRNSYS library, the extended library produced by the Thermal Energy System Specialists (TESS) contains Type 909, which models the performance of an adsorption chiller. The mathematical model of Type 909 is identical to that of Type 107 with the exception that it does not allow the chiller to modulate its cooling power in order to meet the set temperature for the chilled water circuit (i.e., the load fraction is always equal to one). 


\subsubsection{Limitations of existing TRNSYS Types}

The performance data used by Type 107 and Type 909 are obtained from steady-state operation and therefore do not account for transient effects such as the significant amount of heat transfer that occurs between the external fluids and internal heat exchangers of the chiller during start-up. In the case of absorption chillers, where the start-up phase typically represents only a small fraction of total operation time, this use of steady-state performance data may be justified. However, this modelling technique is not appropriate for sorption chillers employing an intermittent cycle, since the sorbent-filled compartment is sequentially heated and cooled as the unit alternates between charging and discharging cycles. The large thermal mass of the internal heat exchangers significantly affects the outlet temperatures of the external fluids at the beginning of each cycle. The energy required to cool or heat the sorbent heat exchanger at the beginning of the cycle is effectively wasted energy and has a detrimental effect on the thermal coefficient of performance of the chiller, particularly for short charge/discharge cycles. Furthermore, a large temperature drop in the driving circuit at the beginning of a charging cycle will affect the performance of connected system components (e.g., solar collector, storage tank). Similarly, a steep temperature rise in the heat rejection circuit at the beginning of the discharge cycle will affect the performance of the fluid cooler.

Although the above mentioned TRNSYS Types account for the variations in cooling capacity and $\mathrm{COP}_{\text {th }}$ that result from changing boundary conditions, these Types do not account for the fact that the cooling capacity of an intermittent sorption chiller is also highly dependent on the state of charge of the system. For a given set of boundary conditions, the existing Types use the average cooling capacity throughout an entire discharge cycle to 
characterize the performance of the chiller at any point during the cycle. In reality, for a given set of constant boundary conditions, the instantaneous cooling capacity is highest at the beginning of a discharge cycle and decreases continuously throughout the remainder of the cycle. Figure 4-1 shows the fractional cooling power as a function of the SOC for a discharge test with the constant boundary conditions of chilled water inlet temperature of $35^{\circ} \mathrm{C}$ and heat rejection inlet temperature of $20^{\circ} \mathrm{C}$. As shown Figure 4-1, the instantaneous cooling power is within $\pm 25 \%$ of the cycle's average cooling power for only $30 \%$ of the discharge cycle. Therefore, Type 107 and Type 909 will significantly underestimate the cooling power at the beginning of a discharge cycle and overestimate the cooling power at the end of the discharge cycle.

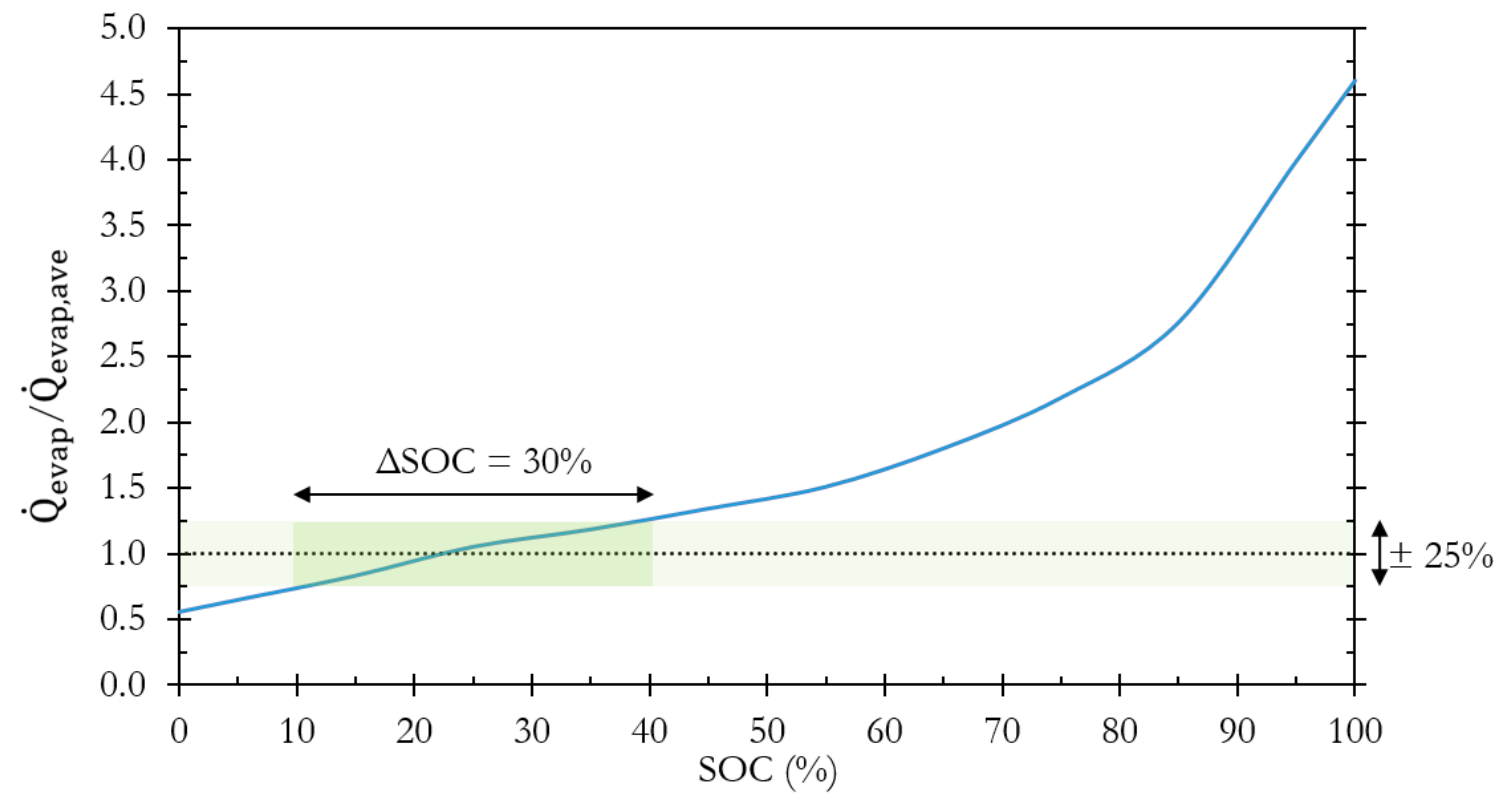

Figure 4-1: Fractional cooling capacity throughout the discharge cycle of a triple-state sorption chiller with constant boundary conditions

For these reasons, it was necessary to develop a new TRNSYS model to characterize the performance of the triple-state sorption chiller. The new model must account for transient heat transfer with the internal heat exchangers as well as the influence of the SOC on the performance of the chiller. 


\subsection{Modelling Approach}

The development of the new TRNSYS model set out to achieve the following goals:

i. the model should accurately predict the outlet temperatures of the external heat transfer fluids throughout the entire operating range of the chiller, including transitions between charging and discharging cycles;

ii. the model should be based solely on experimental data rather than explicitly modelling the physical properties of the chiller (which may require access to proprietary information);

iii. the techniques used to develop the model should be applicable to other sorption chillers employing an intermittent cycle;

To achieve theses goals, a "grey-box" modelling approach was used wherein the physical processes of the chiller are greatly simplified in favour of input-output relationships derived from experimental results. The following sections detail the steps to taken to develop the empirical model for the charging cycle. The modelling of the discharging cycle is not presented due to the poor cooling output of the sorption chiller, which is discussed in further detail in Chapter 5.

\subsubsection{Charging - Condenser}

During the charging cycle, the rate of heat transfer to the fluid in the heat rejection circuit can be described by the following equation,

$$
\dot{\mathrm{Q}}_{\mathrm{hr}}=\dot{\mathrm{Q}}_{\text {sens,ref }}+\dot{\mathrm{Q}}_{\mathrm{cond}}+\dot{\mathrm{Q}}_{\text {sens,HX}}-\dot{\mathrm{Q}}_{\text {loss }}
$$

where $\dot{\mathrm{Q}}_{\text {sens,ref }}$ is the thermal power gained through sensible heat transfer with the vapour refrigerant, $\dot{Q}_{\text {cond }}$ is the thermal power gained from the condensation of the refrigerant, 
$\dot{\mathrm{Q}}_{\text {sens,HX}}$ is the thermal power gained through sensible heat transfer with the condenser heat exchanger, and $\dot{Q}_{\text {loss }}$ is the rate of heat loss to the environment. ${ }^{2}$

The power gained by the heat rejection circuit at time, $t$, can also be expressed in terms of the mass flow rate and the temperature change of the fluid through the condenser heat exchanger,

$$
\dot{\mathrm{Q}}_{\mathrm{hr}, \mathrm{t}}=\left[\dot{\mathrm{m}}_{\mathrm{p}}\left(\mathrm{T}_{\text {out }}-\mathrm{T}_{\mathrm{in}}\right)\right]_{\mathrm{hr}, \mathrm{t}}
$$

Furthermore, the total temperature change can be subdivided into the various components described in Equation 4.8a,

$$
\dot{\mathrm{Q}}_{\mathrm{hr}, \mathrm{t}}=\left[\dot{\mathrm{mc}}_{\mathrm{p}}\left(\Delta \mathrm{T}_{\mathrm{sens,ref}}+\Delta \mathrm{T}_{\text {cond }}+\Delta \mathrm{T}_{\mathrm{sens}, \mathrm{HX}}-\Delta \mathrm{T}_{\text {loss }}\right)\right]_{\mathrm{hr}, \mathrm{t}}
$$

where $\Delta \mathrm{T}_{\text {sens,ref }}$ is the temperature increase resulting from sensible heat transfer with the vapour refrigerant, $\Delta \mathrm{T}_{\text {cond }}$ is the temperature increase due to the condensation of the refrigerant, $\Delta \mathrm{T}_{\text {sens, } \mathrm{HX}}$ is the temperature increase due to sensible heat transfer with the condenser heat exchanger, and $\Delta \mathrm{T}_{\text {loss }}$ is the temperature decrease due to heat loss to the environment.

In order to determine the contribution of each individual component of Equation $4.8 \mathrm{c}$, it was first necessary to conduct a test that would characterize the thermal response of the condenser heat exchanger in isolation. This test consisted of heating the condenser heat exchanger from $25^{\circ} \mathrm{C}$ to $58^{\circ} \mathrm{C}$ while the chiller was in a fully discharged state (i.e., $\Delta \mathrm{T}_{\text {sens,ref }}$ and $\Delta \mathrm{T}_{\text {cond }}$ are equal to zero). Figure $4-2$ shows the inlet and outlet temperatures of the heat rejection circuit during the first 30 minutes of the test, where it can be observed that a constant temperature difference of $0.63^{\circ} \mathrm{C}$ persists across the inlet and

2 Often, the heat loss to the environment will be negative due to the high temperature of the adjacent generator. 
outlet once steady-state conditions are reached. This constant temperature difference is indicative of the heat loss from the condenser heat exchanger to the environment, while the remaining temperature differences observed throughout the test can be attributed to the sensible heat transfer from the heat rejection fluid to the condenser heat exchanger.

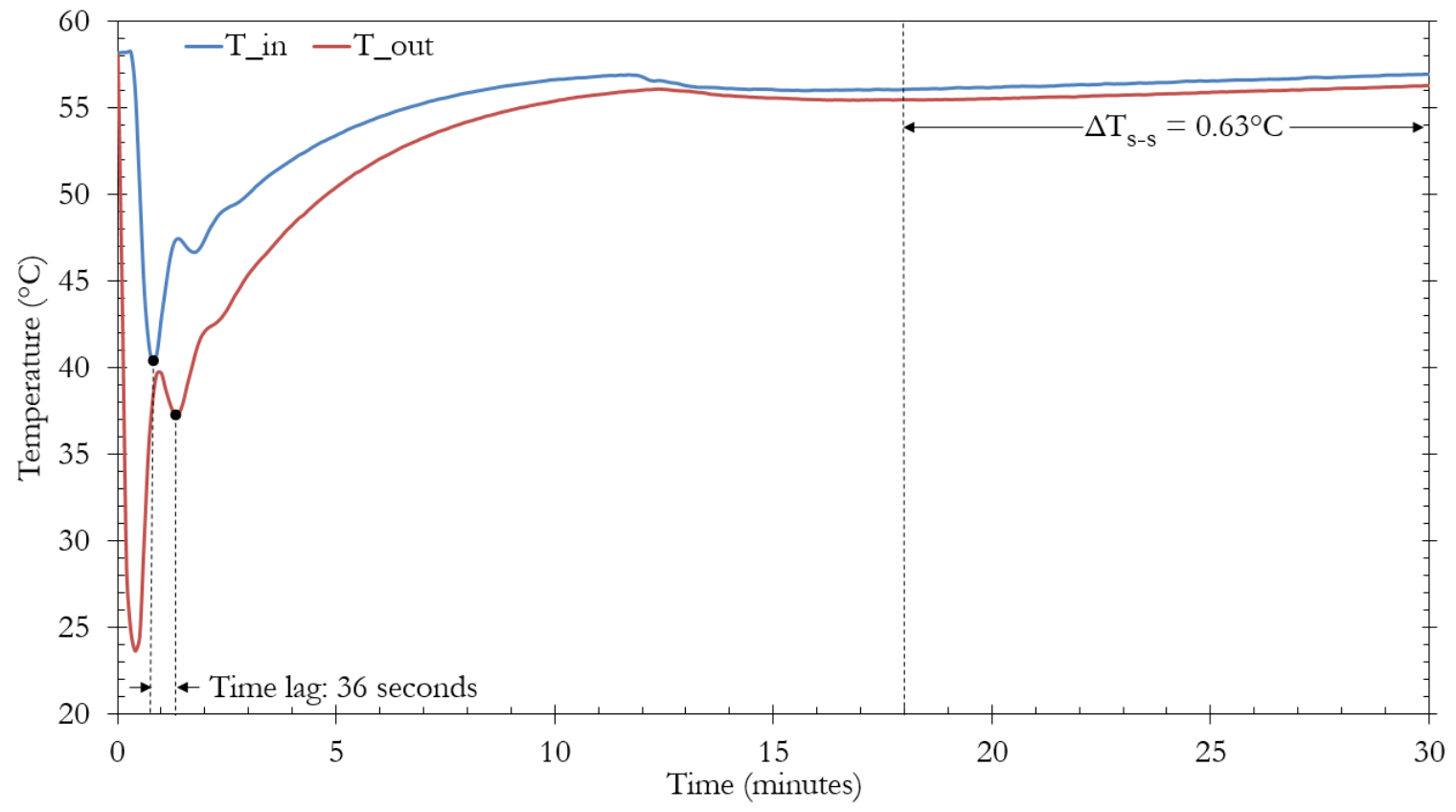

Figure 4-2: Sensible heat test

As indicated in Figure 4-2, it is also apparent that for the design flow rate of $25 \mathrm{~L} / \mathrm{s}$, the heat rejection fluid takes approximately 36 seconds to pass through the condenser heat exchanger. Therefore, if the condenser heat exchanger is assumed to have an initial temperature equal to the ambient temperature $\left(25^{\circ} \mathrm{C}\right)$, then its temperature 36 seconds later (i.e., after the first pass of the heat rejection fluid) can be expressed according to the following equation,

$$
\mathrm{T}_{\mathrm{HX}, \mathrm{t}=36 \mathrm{~s}}=\mathrm{T}_{\mathrm{HX}, \mathrm{t}=0}+\mathrm{A}\left(\mathrm{T}_{\mathrm{hr}, \mathrm{in}, \mathrm{t}=0}-\mathrm{T}_{\mathrm{HX}, \mathrm{t}=0}-\Delta \mathrm{T}_{\mathrm{s}-\mathrm{s}}\right)
$$

where $\mathrm{T}_{\mathrm{HX}}$ is the temperature of the condenser heat exchanger, $\Delta \mathrm{T}_{\mathrm{s}-\mathrm{s}}$ is the steady-state temperature difference across the inlet and outlet of the heat rejection circuit, and $\mathrm{A}$ is a 
dimensionless heat transfer coefficient. As a simplification, the temperature of the condenser heat exchanger can be assumed to be equal to the outlet temperature of the heat rejection circuit. Therefore, if a 36 second time step is used (i.e., $\Delta \mathrm{t}=36 \mathrm{~s}$ ), Equation 4.9 a can be expressed as,

$$
\mathrm{T}_{\text {hr,out,t }}=\mathrm{T}_{\mathrm{hr}, \text { out }, \mathrm{t}-\Delta \mathrm{t}}+\mathrm{A}\left(\mathrm{T}_{\mathrm{hr}, \mathrm{in}, \mathrm{t}-\Delta \mathrm{t}}-\mathrm{T}_{\mathrm{hr}, \text { out }, \mathrm{t}-\Delta \mathrm{t}}-\Delta \mathrm{T}_{\mathrm{s}-\mathrm{s}}\right)
$$

where $\mathrm{T}_{\mathrm{hr} \text { out,t }-\Delta \mathrm{t}}$ represents the temperature of the condenser heat exchanger when the exiting fluid first entered the heat exchanger and $\mathrm{T}_{\mathrm{in}, \mathrm{t}-\Delta \mathrm{t}}$ represents the temperature of fluid when it first entered the heat exchanger. Equation $4.9 \mathrm{~b}$ can be rearranged to form a linear equation passing through the origin,

$$
\left(T_{h r, o u t, t}-T_{h r, o u t, t-\Delta t}\right)=A\left(T_{h r, i n, t-\Delta t}-T_{h r, o u t, t-\Delta t}-\Delta T_{s-s}\right)
$$

Equation 4.9c is plotted in Figure 4-3 and a linear fit was used to determine the dimensionless heat transfer coefficient A.

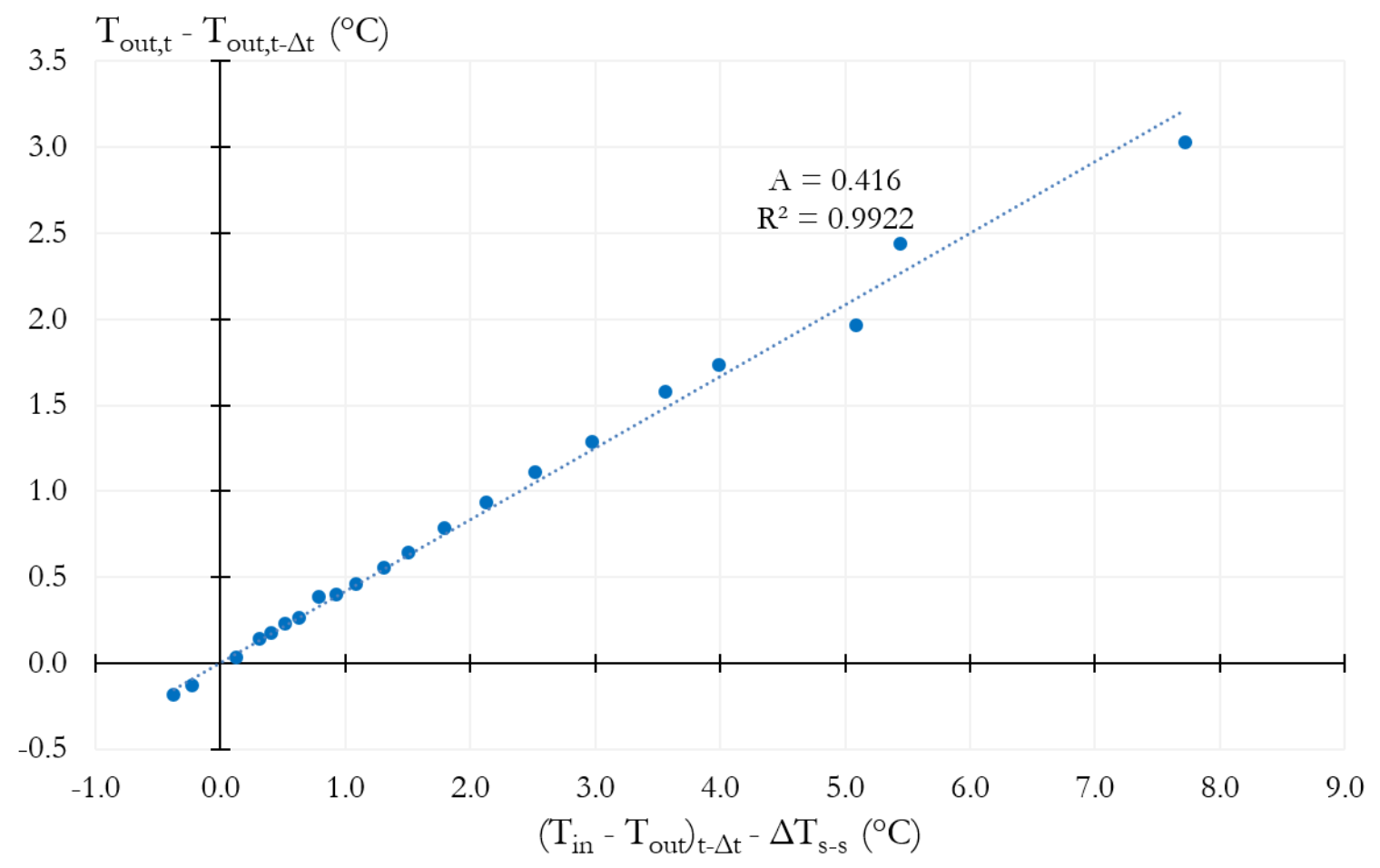

Figure 4-3: Determining the dimensionless heat transfer coefficient A 
After solving for the dimensionless heat transfer coefficient, Equations 4.8b, 4.8c, and 4.9b can be combined to form the following expressions,

$$
\begin{gathered}
\left(\Delta \mathrm{T}_{\text {sens, } \mathrm{HX}}-\Delta \mathrm{T}_{\text {loss }}\right)_{\mathrm{t}}=\left(\mathrm{T}_{\text {out }}-\mathrm{T}_{\mathrm{in}}\right)_{\mathrm{hr}, \mathrm{t}} \\
\left(\Delta \mathrm{T}_{\text {sens }, \mathrm{HX}}-\Delta \mathrm{T}_{\text {loss }}\right)_{\mathrm{t}}=\mathrm{T}_{\mathrm{HX}, \mathrm{t}-\Delta \mathrm{t}}+0.416\left(\mathrm{~T}_{\mathrm{hr}, \text { in }, \mathrm{t}-\Delta \mathrm{t}}-\mathrm{T}_{\mathrm{HX}, \mathrm{t}-\Delta \mathrm{t}}-\Delta \mathrm{T}_{\mathrm{s}-\mathrm{s}}\right)-\mathrm{T}_{\mathrm{hr}, \mathrm{in}, \mathrm{t}}
\end{gathered}
$$

Furthermore, from Equations $4.8 \mathrm{~b}$ and $4.9 \mathrm{~b}$ it is known that,

$$
\left(\Delta \mathrm{T}_{\text {sens,ref }}+\Delta \mathrm{T}_{\text {cond }}\right)=\left(\mathrm{T}_{\text {out }}-\mathrm{T}_{\text {in }}\right)_{\mathrm{hr}}-\left(\Delta \mathrm{T}_{\text {sens, } \mathrm{HX}}-\Delta \mathrm{T}_{\text {loss }}\right)
$$

By substituting Equation 4.10b into Equation 4.10c, an expression can be formed to determine the temperature increase due to the sensible cooling and subsequent condensation of the refrigerant:

$$
\begin{gathered}
\left(\Delta \mathrm{T}_{\text {sens,ref }}+\Delta \mathrm{T}_{\text {cond }}\right)_{\mathrm{t}}=\left(\mathrm{T}_{\text {out }}-\mathrm{T}_{\mathrm{in}}\right)_{\mathrm{hr}, \mathrm{t}}-\left[\mathrm{T}_{\mathrm{HX}, \mathrm{t}-\Delta \mathrm{t}}+0.416\left(\mathrm{~T}_{\mathrm{in}, \mathrm{t}-\Delta \mathrm{t}}-\mathrm{T}_{\mathrm{HX}, \mathrm{t}-\Delta \mathrm{t}}-\Delta \mathrm{T}_{\mathrm{s}-\mathrm{s}}\right)-\mathrm{T}_{\mathrm{in}, \mathrm{hr}, \mathrm{t}}\right] \\
\left(\Delta \mathrm{T}_{\text {sens,ref }}+\Delta \mathrm{T}_{\text {cond }}\right)_{\mathrm{t}}=\mathrm{T}_{\mathrm{hr}, \text { out }, \mathrm{t}}-\mathrm{T}_{\mathrm{HX}, \mathrm{t}-\Delta \mathrm{t}}-0.416\left(\mathrm{~T}_{\mathrm{hr}, \mathrm{in}, \mathrm{t}-\Delta \mathrm{t}}-\mathrm{T}_{\mathrm{HX}, \mathrm{t}-\Delta \mathrm{t}}-\Delta \mathrm{T}_{\mathrm{s}-\mathrm{s}}\right)
\end{gathered}
$$

As a simplification, it can be assumed that only enough refrigerant enters the condenser during a given time-step to satisfy the temperature rise calculated in Equation 4.10, and that the refrigerant vapour is immediately cooled and condensed. If the vapour refrigerant is assumed to enter the condenser at the same temperature as the outlet temperature of the driving circuit, then the energy gained by the heat rejection circuit per time-step due to sensible heat transfer with the vapour refrigerant can be calculated according to Equation 4.11,

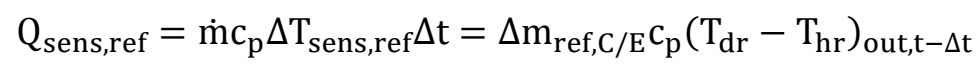

where $\Delta \mathrm{m}_{\text {ref }}$ is the change in the mass of the refrigerant in the condenser. The energy gained by the heat rejection circuit per time-step due to the condensation of the vapour refrigerant can be calculated according to Equation 4.12,

$$
\mathrm{Q}_{\text {cond }}=\dot{\mathrm{m}} \mathrm{c}_{\mathrm{p}} \Delta \mathrm{T}_{\text {cond }} \Delta \mathrm{t}=\Delta \mathrm{m}_{\mathrm{ref}, \mathrm{C} / \mathrm{E}} \Delta \mathrm{H}_{\text {cond }}
$$


where $\Delta \mathrm{H}_{\text {cond }}$ is the enthalpy of condensation of the refrigerant. Equations 4.11 and 4.12 can be combined to form an expression for the mass of refrigerant that is cooled and condensed per time-step.

$$
\Delta \mathrm{m}_{\mathrm{ref}, \mathrm{C} / \mathrm{E}, \mathrm{t}}=\frac{\dot{\mathrm{m}}_{\mathrm{hr}} \mathrm{c}_{\mathrm{p}, \mathrm{hr}}\left(\Delta \mathrm{T}_{\text {sens,ref }}+\Delta \mathrm{T}_{\text {cond }}\right)_{\mathrm{t}} \Delta \mathrm{t}}{\mathrm{c}_{\mathrm{p}}\left(\mathrm{T}_{\mathrm{dr}}-\mathrm{T}_{\mathrm{hr}}\right)_{\text {out }, \mathrm{t}-\Delta \mathrm{t}}+\Delta \mathrm{H}_{\text {cond }}}
$$

Equation 4.10e can be substituted into Equation 4.13a to form a final expression for $\Delta \mathrm{m}_{\mathrm{ref}}$ that can be solved with known variables, as shown in Equation 4.13b.

$$
\Delta \mathrm{m}_{\text {ref,t }}=\frac{\dot{\mathrm{m}}_{\mathrm{hr}} \mathrm{c}_{\mathrm{p}, \mathrm{hr}}\left(\mathrm{T}_{\mathrm{hr}, \text { out }, \mathrm{t}}-\mathrm{T}_{\mathrm{HX}, \mathrm{t}-\Delta \mathrm{t}}-0.416\left(\mathrm{~T}_{\mathrm{hr}, \mathrm{in}, \mathrm{t}-\Delta \mathrm{t}}-\mathrm{T}_{\mathrm{HX}, \mathrm{t}-\Delta \mathrm{t}}-\Delta \mathrm{T}_{\mathrm{s}-\mathrm{s}}\right)\right) \Delta \mathrm{t}}{\mathrm{c}_{\mathrm{p}}\left(\mathrm{T}_{\mathrm{dr}}-\mathrm{T}_{\mathrm{hr}}\right)_{\text {out }, \mathrm{t}-\Delta \mathrm{t}}+\Delta \mathrm{H}_{\text {cond }}}
$$

Since the mass of the refrigerant in the condenser represents the state of charge of the system, the SOC at time t can be determined using Equation 4.14.

$$
\mathrm{SOC}_{\mathrm{t}}=\mathrm{SOC}_{\mathrm{t}=0}+\frac{\sum_{\mathrm{i}=1}^{\mathrm{i}=\mathrm{t} / \Delta \mathrm{t}} \Delta \mathrm{m}_{\mathrm{ref}, \mathrm{t}=36 \mathrm{i}}}{\mathrm{m}_{\mathrm{ref}, \max }}
$$

where $\mathrm{m}_{\mathrm{ref} \text {,max }}$ is the total mass of refrigerant contained within the condenser/evaporatorgenerator/adsorber pair. For the purpose of this research, $\mathrm{m}_{\text {ref,total }}$ is equal to the mass of the refrigerant that can be stored in the condenser during a charging cycle having a driving temperature of $95^{\circ} \mathrm{C}$ and heat rejection temperature of $15^{\circ} \mathrm{C}$.

The SOC, as calculated according to Equation 4.14, was compared to the SOC measured by the load cell of the sorption chiller for a charge test having a driving temperature of $80^{\circ} \mathrm{C}$ and heat rejection temperature of $30^{\circ} \mathrm{C}$. As shown in Figure 4-4, the numerical solution closely matches the SOC measured by the load cell. 


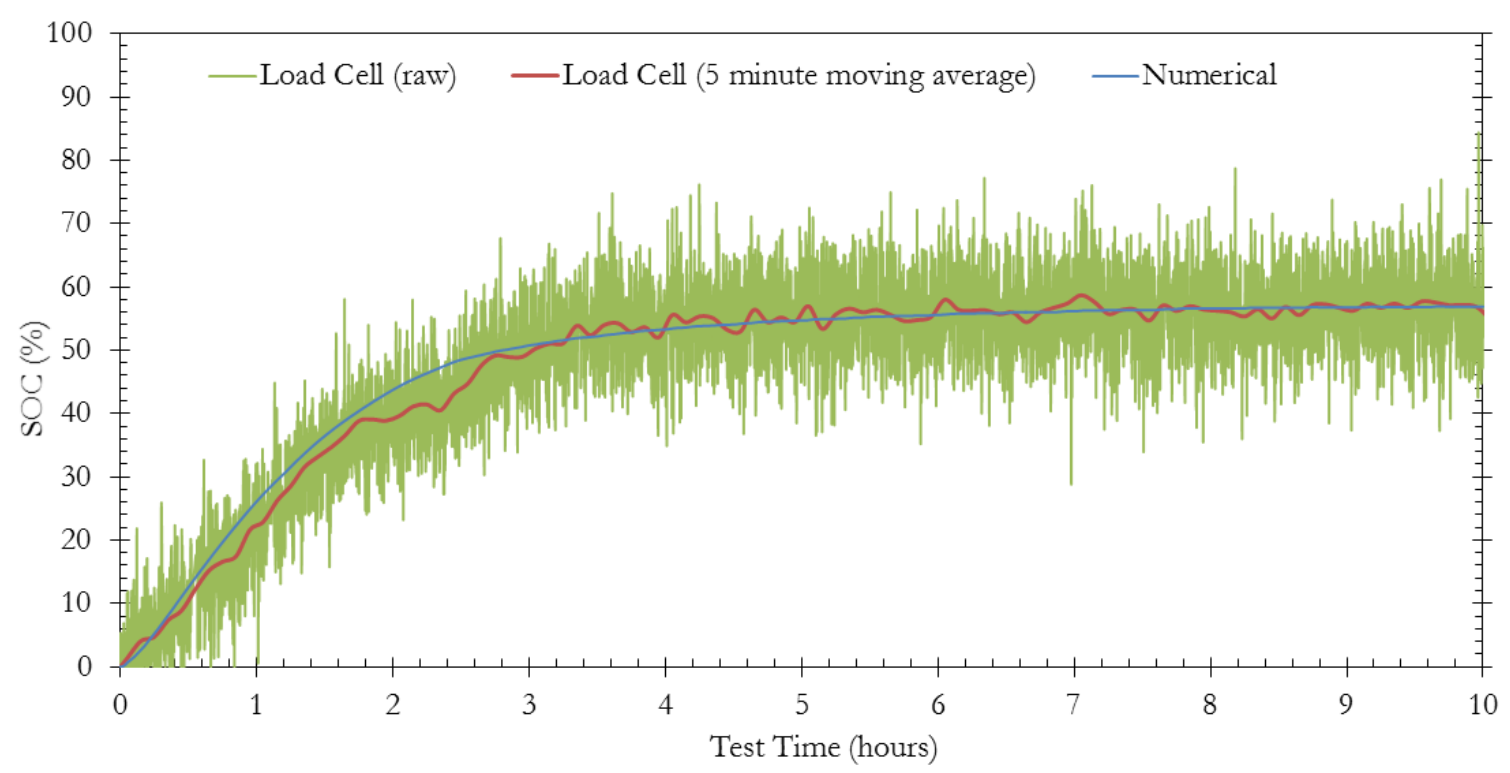

Figure 4-4: Comparison of methodologies for determining SOC

Once the charging curve has been established for a given set of boundary conditions, the change in the SOC during one time step can be expressed as a function of the SOC from the previous time-step, as shown in Figure 4-5. Although the charging rate is expected to be highest at the beginning of the charge cycle, it is visible from Figure 4-5 that this is not the case. The slow charging rate at the beginning of the charge cycle suggests that the majority of the energy supplied to the generator at this time is being transferred to the refrigerant in the form of sensible heat, while a small amount of refrigerant is simultaneously being desorbed. Therefore, the piecewise linear fit shown in Figure 4-5 is only applicable for a charge cycle beginning at an initial SOC equal to zero. To accommodate all possible charging cycles, the piecewise linear fit of Figure 4-5 can be adapted by extending the first negative linear slope to the y-axis and multiplying by a time-dependent decay function, as shown in Figure 4-6. The adapted charging rate function is described by Equation 4.15.

$$
\Delta \mathrm{SOC}=\left(1-\mathrm{e}^{-7.5 t_{\text {cycle }}}\right)\left\{\begin{array}{cc}
-0.00385 \mathrm{SOC}_{\mathrm{t}-\Delta \mathrm{t}}+0.360, & \mathrm{SOC}_{\mathrm{t}-\Delta \mathrm{t}} \leq 25.5 \\
-0.00675 \mathrm{SOC}_{\mathrm{t}-\Delta \mathrm{t}}+0.432, & 25.5<\mathrm{SOC}_{\mathrm{t}-\Delta \mathrm{t}} \leq 45.5 \\
-0.01231 \mathrm{SOC}_{\mathrm{t}-\Delta \mathrm{t}}+0.685, & 45.5<\mathrm{SOC}_{\mathrm{t}-\Delta \mathrm{t}} \leq 52.0 \\
-0.00643 \mathrm{SOC}_{\mathrm{t}-\Delta \mathrm{t}}+0.379, & \mathrm{SOC}_{\mathrm{t}-\Delta \mathrm{t}}>52.0
\end{array}\right.
$$


where $t_{\text {cycle }}$ is the elapsed time (hours) since the beginning of the charging cycle. After this mathematical relation is established, the change in the SOC can be calculated at any point during the charging cycle, regardless of the initial SOC. Figure 4-6 also shows how the decay function can be employed to predict the charging rate for a charge cycle beginning with a SOC of $30 \%$.

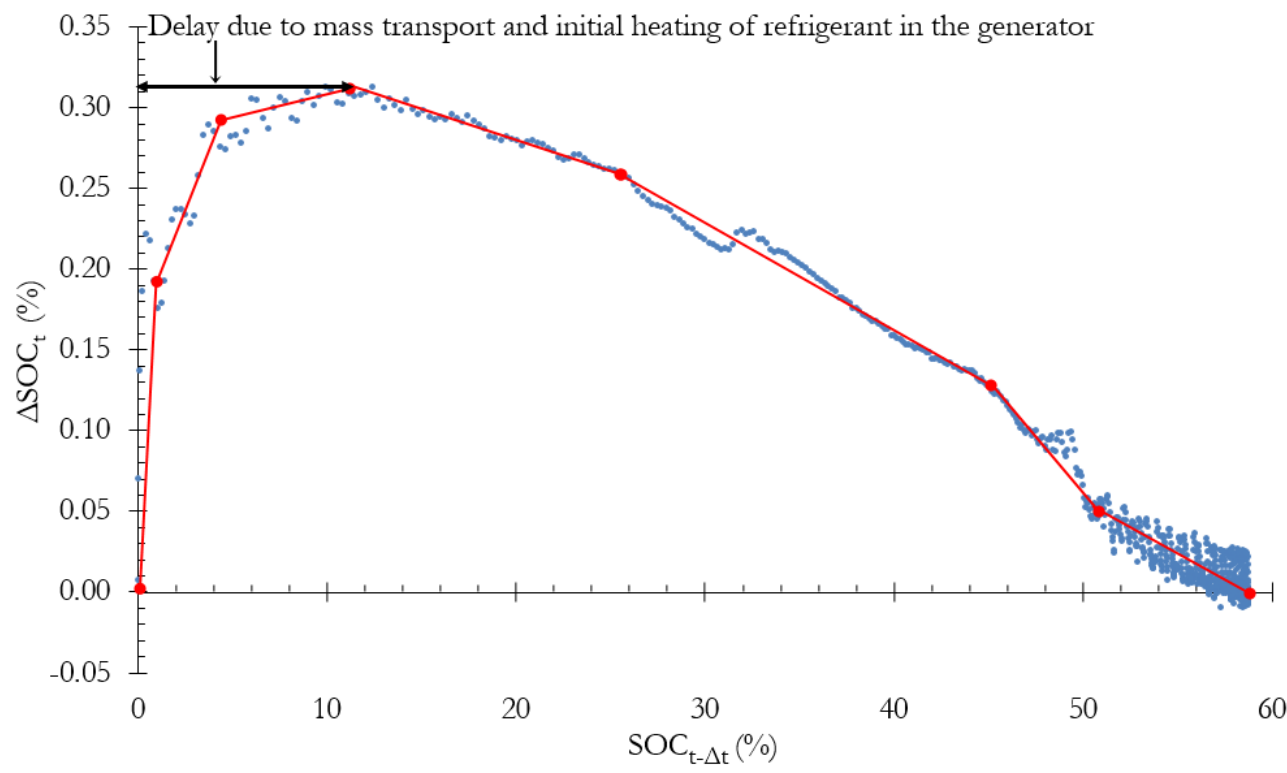

Figure 4-5: Charging rate vs. state of charge $\left(\mathrm{T}_{\mathrm{dr}}=80^{\circ} \mathrm{C}, \mathrm{T}_{\mathrm{hr}}=30^{\circ} \mathrm{C}\right)$

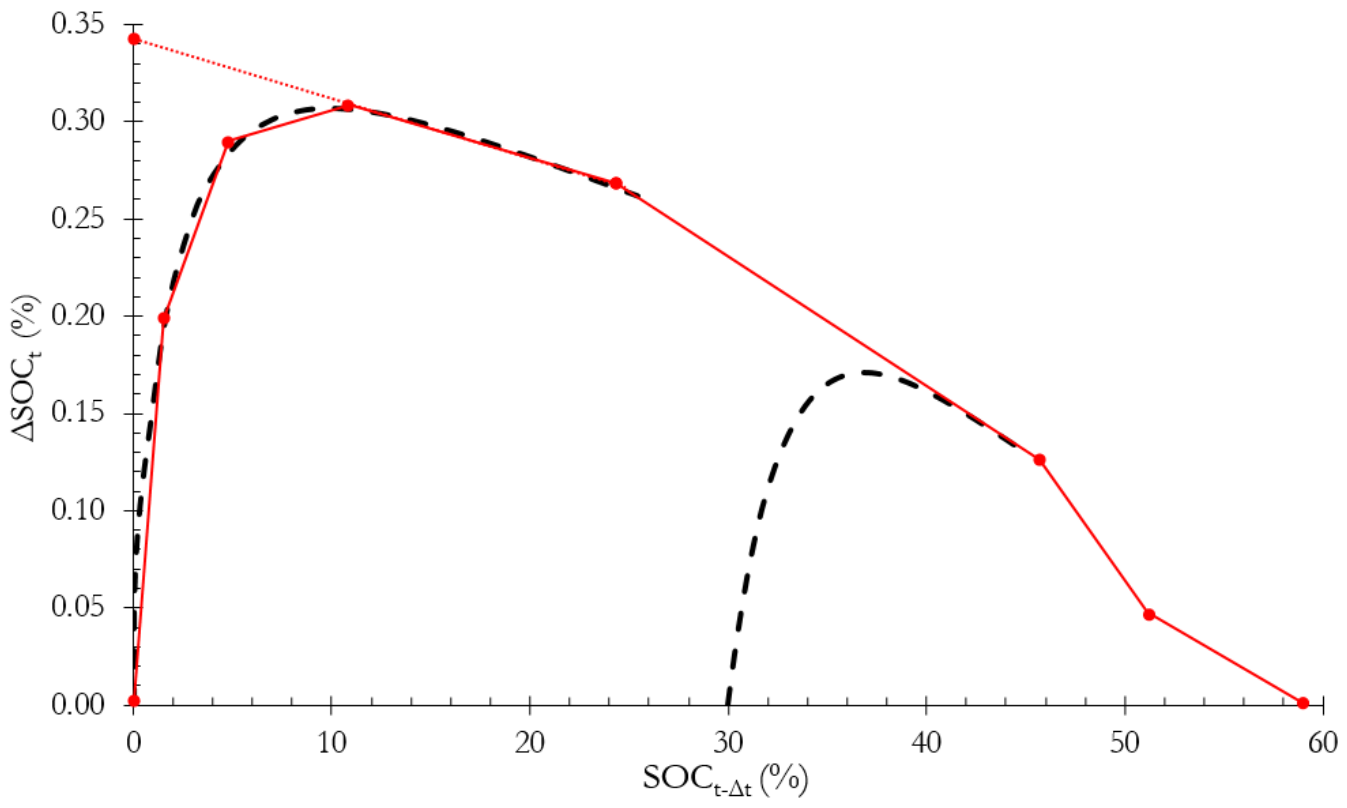

Figure 4-6: Charging rate vs. state of charge, with decay function $\left(\mathrm{T}_{\mathrm{dr}}=80^{\circ} \mathrm{C}, \mathrm{T}_{\mathrm{hr}}=30^{\circ} \mathrm{C}\right)$ 
Finally, the change in the SOC during a single time-step can be related back to the temperature increase in the heat rejection circuit due to the cooling and condensing of the refrigerant in the condenser. This relationship, which is shown in Figure 4-7, can then be used to establish a final equation for determining the outlet temperature in the heat rejection circuit,

$$
\mathrm{T}_{\mathrm{hr}, \text { out }, \mathrm{t}}=\mathrm{T}_{\mathrm{HX}, \mathrm{t}-\Delta \mathrm{t}}+0.416\left(\mathrm{~T}_{\mathrm{hr}, \mathrm{in}, \mathrm{t}-\Delta \mathrm{t}}-\mathrm{T}_{\mathrm{HX}, \mathrm{t}-\Delta \mathrm{t}}-\Delta \mathrm{T}_{\mathrm{s}-\mathrm{s}}\right)+19.34 \Delta \mathrm{SOC}_{\mathrm{t}}
$$

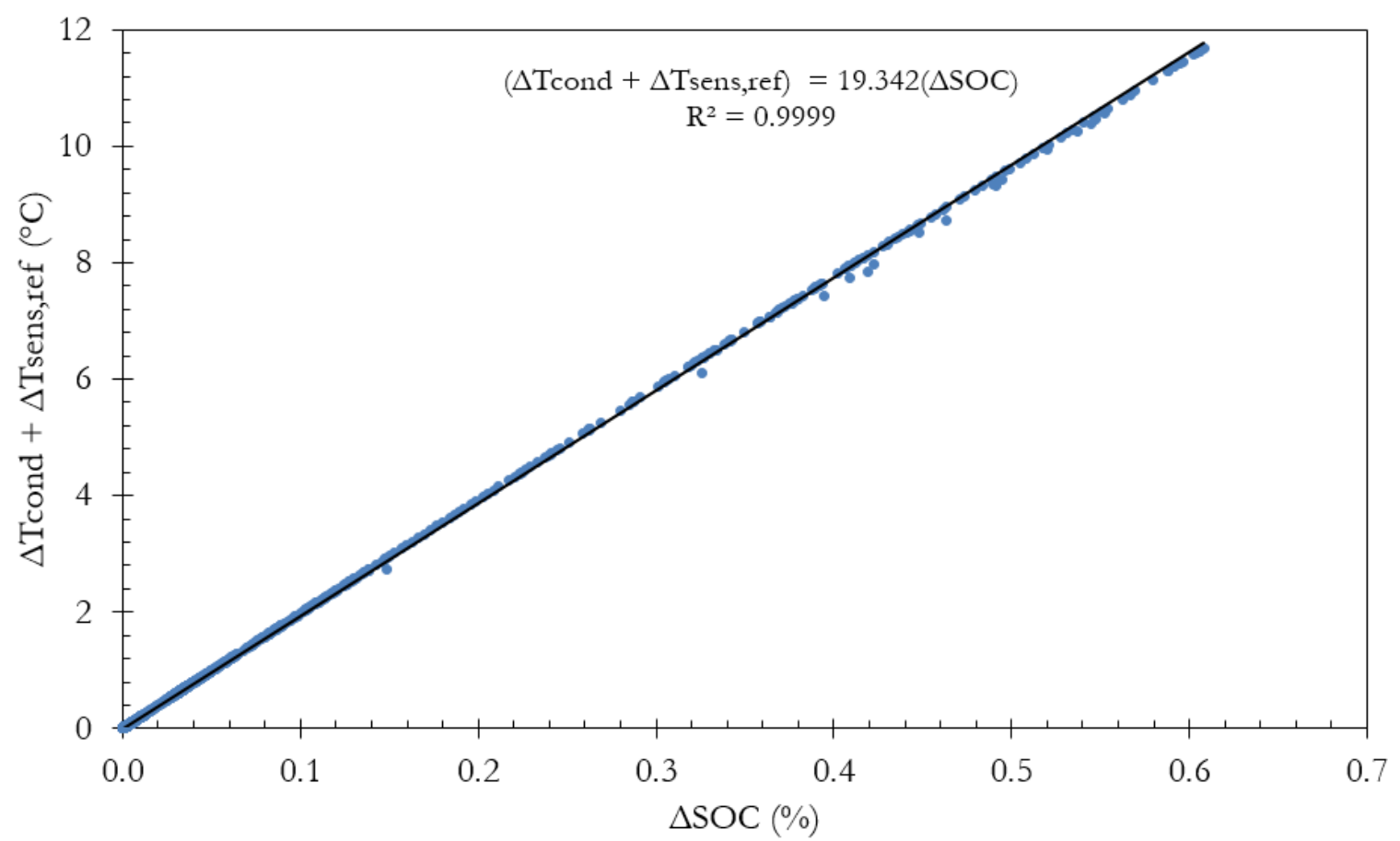

Figure 4-7: Relationship between charging rate and temperature increase in the heat rejection circuit due to the cooling and condensing of the refrigerant in the condenser

\subsubsection{Charging - Generator}

During the charging cycle, the rate of heat transfer to the generator from the fluid in the driving circuit can be described by the following equation,

$$
\dot{\mathrm{Q}}_{\mathrm{dr}}=\dot{\mathrm{Q}}_{\mathrm{sens,ref}}+\dot{\mathrm{Q}}_{\mathrm{des}}+\dot{\mathrm{Q}}_{\mathrm{sens}, \mathrm{HX}}+\dot{\mathrm{Q}}_{\text {loss }}
$$

where $\dot{Q}_{\text {sens,ref }}$ is the rate of sensible heat transfer to the refrigerant, $\dot{Q}_{\text {des }}$ is the thermal power consumed from the desorption of the refrigerant, $\dot{\mathrm{Q}}_{\mathrm{sens}, \mathrm{HX}}$ is the thermal power 
consumed through sensible heat transfer with the generator heat exchanger, and $\dot{\mathrm{Q}}_{\text {loss }}$ is the rate of heat loss to the environment.

The power delivered to the generator at time, $\mathrm{t}$, can also be expressed in terms of the mass flow rate and temperature change of the fluid through the generator heat exchanger,

$$
\begin{gathered}
\dot{\mathrm{Q}}_{\mathrm{dr}, \mathrm{t}}=\left[\dot{\mathrm{m}} \mathrm{p}_{\mathrm{p}}\left(\mathrm{T}_{\text {out }}-\mathrm{T}_{\mathrm{in}}\right)\right]_{\mathrm{dr}, \mathrm{t}} \\
\dot{\mathrm{Q}}_{\mathrm{dr}, \mathrm{t}}=\left[\dot{\mathrm{m}} \mathrm{c}_{\mathrm{p}}\left(\Delta \mathrm{T}_{\text {sens,ref }}+\Delta \mathrm{T}_{\text {des }}+\Delta \mathrm{T}_{\text {sens } \mathrm{HX}}-\Delta \mathrm{T}_{\text {loss }}\right)\right]_{\mathrm{dr}, \mathrm{t}}
\end{gathered}
$$

Similar to Equation 4.10b developed in Section 4.3.1, Equation 4.18a describes the temperature change that occurs in the driving circuit due to sensible heat transfer with the generator heat exchanger, sensible heat transfer with the refrigerant in the generator, and heat loss to the environment,

$$
\left(\Delta \mathrm{T}_{\text {sens,HX}}+\Delta \mathrm{T}_{\text {sens,ref }}-\Delta \mathrm{T}_{\text {loss }}\right)_{\mathrm{t}}=\mathrm{T}_{\mathrm{HX}, \mathrm{t}-\Delta \mathrm{t}}+\mathrm{B}\left(\mathrm{T}_{\mathrm{dr}, \mathrm{in}, \mathrm{t}-\Delta \mathrm{t}}-\mathrm{T}_{\mathrm{HX}, \mathrm{t}-\Delta \mathrm{t}}-\Delta \mathrm{T}_{\mathrm{s}-\mathrm{s}}\right)-\mathrm{T}_{\mathrm{dr}, \mathrm{in}, \mathrm{t}}
$$

where $\mathrm{B}$ is a dimensionless heat transfer coefficient that is dependent on the mass of refrigerant contained within the generator, and is described by Equation 4.18b,

$$
B=b_{1}+b_{2}\left(100-S C_{t-\Delta t}\right)
$$

where $\mathrm{b}_{1}$ and $\mathrm{b}_{2}$ are numerically derived constants.

The temperature change in the driving circuit that results due to the endothermic desorption of the refrigerant can be described by Equation 4.19a,

$$
\Delta \mathrm{T}_{\mathrm{des}}=\frac{\Delta \mathrm{m}_{\mathrm{ref}, \mathrm{G} / \mathrm{A}} \Delta \mathrm{H}_{\mathrm{des}}}{\dot{\mathrm{m}}_{\mathrm{dr}} \mathrm{c}_{\mathrm{p}, \mathrm{dr}} \Delta \mathrm{t}}
$$

where $\Delta \mathrm{m}_{\mathrm{ref}, \mathrm{G} / \mathrm{A}}$ is the change in mass of the refrigerant within the generator, and $\Delta \mathrm{H}_{\mathrm{des}}$ is the enthalpy of desorption. The continuity equation states that the mass of refrigerant added to the condenser must equal the mass of refrigerant removed from the generator,

$$
\Delta \mathrm{m}_{\mathrm{ref}, \mathrm{C} / \mathrm{E}}=-\Delta \mathrm{m}_{\mathrm{ref}, \mathrm{G} / \mathrm{A}}
$$


Equations 4.17-4.19 can be combined to form an objective function that can be minimized to solve for variables $\mathrm{b}_{1}, \mathrm{~b}_{2}$, and $\Delta \mathrm{H}_{\text {des. }}$. The objective function is described by Equation 4.20.

$\mathrm{f}_{\min }=\sum_{i=1}^{i=t_{\text {final }} / \Delta t}\left[\left(\mathrm{~T}_{\text {out }}-\mathrm{T}_{\text {in }}\right)_{d r, t=i \Delta t}-\left(\Delta \mathrm{T}_{\text {sens,ref }}+\Delta \mathrm{T}_{\text {des }}+\Delta \mathrm{T}_{\text {sens }, \mathrm{HX}_{G / A}}-\Delta \mathrm{T}_{\text {loss }}\right)_{d r, t=i \Delta t}\right]^{2}$

The solution to Equation 4.20 yielded the following values:

$$
\mathrm{b}_{1}=0.507, \mathrm{~b}_{2}=-0.00236, \Delta \mathrm{H}_{\mathrm{des}}=2280 \mathrm{~kJ} / \mathrm{kg}
$$

Finally, the change in the SOC during a single time-step can be related back to the temperature increase in the driving circuit due to the desorption of the refrigerant in the generator. This relationship, which is shown in Figure 4-8, can then be used to establish a final equation for determining the outlet temperature in the driving circuit,

$$
\mathrm{T}_{\mathrm{dr}, \text { out }, \mathrm{t}}=\mathrm{T}_{\mathrm{HX}, \mathrm{t}-\Delta \mathrm{t}}+\mathrm{B}\left(\mathrm{T}_{\mathrm{dr}, \text { in }, \mathrm{t}-\Delta \mathrm{t}}-\mathrm{T}_{\mathrm{HX}, \mathrm{t}-\Delta \mathrm{t}}-\Delta \mathrm{T}_{\mathrm{s}-\mathrm{s}}\right)+15.40 \Delta \mathrm{SOC}_{\mathrm{t}}
$$

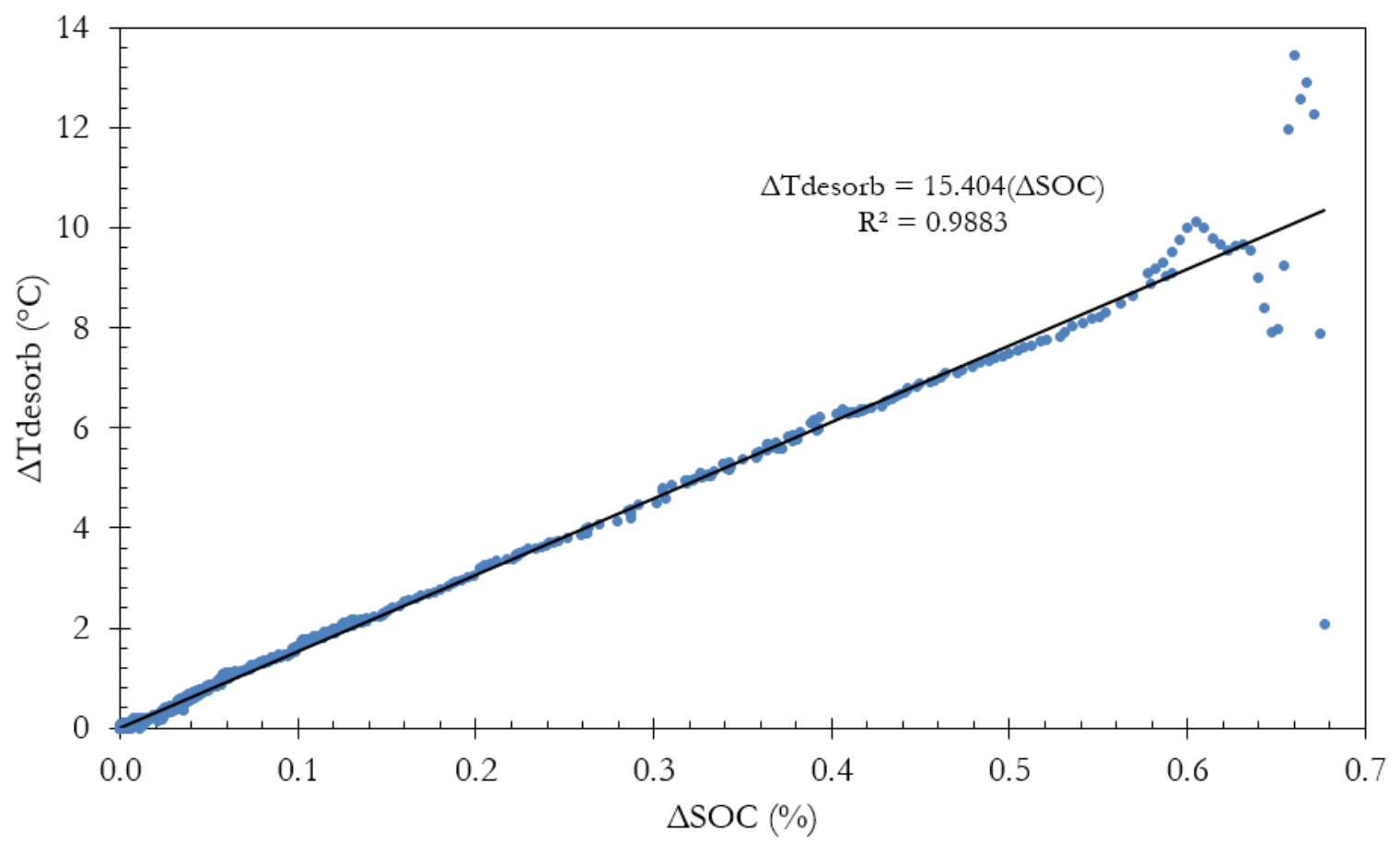

Figure 4-8: Relationship between charging rate and temperature increase in the driving circuit due to the desorption of the refrigerant in the generator 
Figure 4-8 shows that a strong linear relationship exists between the charging rate and the temperature change due to desorption. However, this model is imperfect as there are some notable discrepancies in the linear relationship at higher charging rates due to the transience at the beginning of the cycle.

\subsubsection{Description of TRNSYS validation model}

A simple TRNSYS model, shown in Figure 4-9, was created to validate the mathematical model developed for the charging cycle. A single barrel of the triple-state sorption chiller is represented by Type 62, which allows TRNSYS to communicate with a user-specified Microsoft Excel program. The inputs and outputs of the Type 62 component are detailed below in Table 4-1. The validation model also consists of a Type 93 component to temporarily store the outputs from the previous time-step, and a Type 65 component to plot the simulation outputs and save the results in a separate Microsoft Excel file for further analysis. The full input file for the validation model can be found in Appendix B.

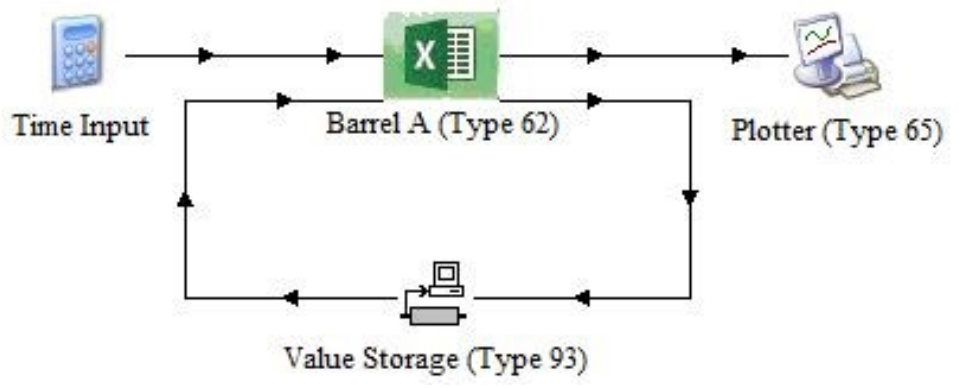

Figure 4-9: TRNSYS validation model 
Table 4-1: Inputs and outputs for the Type 62 triple-state sorption chiller model

\begin{tabular}{|c|c|c|c|}
\hline \multicolumn{2}{|r|}{ Inputs } & \multicolumn{2}{|r|}{ Outputs } \\
\hline Name & Description & Name & Description \\
\hline $\mathrm{SOC}_{\mathrm{t}-\Delta \mathrm{t}}$ & State of charge at previous time-step & $\mathrm{SOC}_{\mathrm{t}}$ & State of charge at current time-step \\
\hline $\mathrm{T}_{H X}(\mathrm{C} / \mathrm{E}), \mathrm{t}-\Delta \mathrm{t}$ & $\begin{array}{l}\text { Temperature of the } \\
\text { condenser/evaporator heat } \\
\text { exchanger at the previous time-step }\end{array}$ & $\mathrm{T}_{\mathrm{HX}(\mathrm{C} / \mathrm{E}), \mathrm{t}}$ & $\begin{array}{c}\text { Temperature of the } \\
\text { condenser/evaporator heat } \\
\text { exchanger at current time-step }\end{array}$ \\
\hline $\mathrm{T}_{\mathrm{HX}}(\mathrm{G} / \mathrm{A}), \mathrm{t}-\Delta \mathrm{t}$ & $\begin{array}{l}\text { Temperature of the generator heat } \\
\text { exchanger at the previous time-step }\end{array}$ & $\mathrm{T}_{\mathrm{HX}(\mathrm{G} / \mathrm{A}), \mathrm{t}}$ & $\begin{array}{l}\text { Temperature of the generator heat } \\
\text { exchanger at current time-step }\end{array}$ \\
\hline $\mathrm{T}_{\mathrm{in}, \mathrm{dr}, \mathrm{t}-\Delta \mathrm{t}}$ & $\begin{array}{l}\text { Inlet temperature of the driving } \\
\text { circuit at the previous time-step }\end{array}$ & $\mathrm{T}_{\text {out,dr,t- }-\Delta \mathrm{t}}$ & $\begin{array}{l}\text { Outlet temperature of the driving } \\
\text { circuit at current time-step }\end{array}$ \\
\hline $\mathrm{T}_{\text {in,hr,t- }-\Delta \mathrm{t}}$ & $\begin{array}{l}\text { Inlet temperature of the heat } \\
\text { rejection circuit at the previous } \\
\text { time-step }\end{array}$ & $\mathrm{T}_{\text {out }, h r, t-\Delta \mathrm{t}}$ & $\begin{array}{l}\text { Outlet temperature of the heat } \\
\text { rejection circuit at current time- } \\
\text { step }\end{array}$ \\
\hline$t_{\text {cycle }}$ & $\begin{array}{l}\text { Elapsed time since beginning of } \\
\text { charge cycle }\end{array}$ & & \\
\hline
\end{tabular}




\section{Chapter 5}

\section{Results and Discussion}

This chapter begins by summarizing the results of the experimental tests conducted to characterize the charge and discharge cycles. Next, the results of a validation test are used to compare the model output to the experimentally measured values. The chapter concludes with an investigation into the effects of different boundary conditions on the optimal length of the charge cycle.

\subsection{Experimental Results}

\subsubsection{Charge Cycle}

The charge cycle of the triple-state sorption chiller was characterized for driving temperatures of $65^{\circ} \mathrm{C}, 75^{\circ} \mathrm{C}, 85^{\circ} \mathrm{C}$, and $95^{\circ} \mathrm{C}$ and heat rejection temperatures of $15^{\circ} \mathrm{C}, 25^{\circ} \mathrm{C}$, and $35^{\circ} \mathrm{C}$, resulting in a total of 12 test conditions. The experimental test procedure outlined in Section 3.6 was followed for each experimental test, while the modelling methodology described in Section 4.3 was used to develop the characteristic charging curves.

The characteristic charging curves for the triple-state sorption chiller are shown in Figure 5-1, where each plot displays the charging curves for a specific driving temperature. In Figure 5-1 (a) it is shown that, for a driving temperature of $65^{\circ} \mathrm{C}$, a lower heat rejection temperature leads to a moderately increased charging rate during the first three hours of the charge cycle, but only results in a slightly higher $\mathrm{SOC}_{\max }\left(56 \% \mathrm{SOC}_{\max }\right.$ for a heat rejection temperature of $15^{\circ} \mathrm{C}$ versus $53 \%$ for a heat rejection temperature of $35^{\circ} \mathrm{C}$ ). Similarly, for driving temperatures of $75^{\circ} \mathrm{C}, 85^{\circ} \mathrm{C}$, and $95^{\circ} \mathrm{C}$, it can be observed that reducing the heat rejection temperature only marginally increases the charging rate during the first three hours 
of the charge cycle. However, as the driving temperature increases, the heat rejection temperature becomes more influential in determining the $\mathrm{SOC}_{\max }$. For example, when the driving temeprature is $95^{\circ} \mathrm{C}$, a heat rejection temperature of $15^{\circ} \mathrm{C}$ results in a $\mathrm{SOC}_{\max }$ of $100 \%$, whereas a heat rejection temperature of $35^{\circ} \mathrm{C}$ only achieves a $\mathrm{SOC}_{\max }$ of $83 \%$.

Figure 5-2 also displays the characteristic charging curves of the triple-state sorption chiller, however in this case the charging curves are organized into three separate plots with each plot representing tests conducted at a specific heat rejection temperature. From these plots it is evident that, regardless of the heat rejection temperature, it is the driving temperature that largely influences the charging rate during the beginning of the charge cycle. In addition to increasing the charging rate at the beginning of the charge cycle, higher driving temperaturtes also lead to higher values of $\mathrm{SOC}_{\max }$

The full set of equations describing the characteristic charging curves can be found in Appendix C, along with the steady-state temperature values used by the model.

\subsubsection{Discharge Cycle}

It was initially planned to characterize the performance of the discharge cycle of the triplestate sorption chiller for chilled water temperatures of $15^{\circ} \mathrm{C}, 20^{\circ} \mathrm{C}$, and $25^{\circ} \mathrm{C}$ and heat rejection temperatures of $15^{\circ} \mathrm{C}, 25^{\circ} \mathrm{C}$, and $35^{\circ} \mathrm{C}$. However, it quickly became apparent that the discharge rate (and therefore cooling capacity) was significantly slower than expected. For example, a discharge test was conducted with a chilled water inlet temperature of $20^{\circ} \mathrm{C}$ and heat rejection temperature of $25^{\circ} \mathrm{C}$, yielding an average cooling power of only $0.25 \mathrm{~kW}$ during the first hour of the test. By comparison, according to the performance curves supplied by ClimateWell, discharge under these conditions should produce a cooling power of approximately $7.5 \mathrm{~kW}$ [47]. 


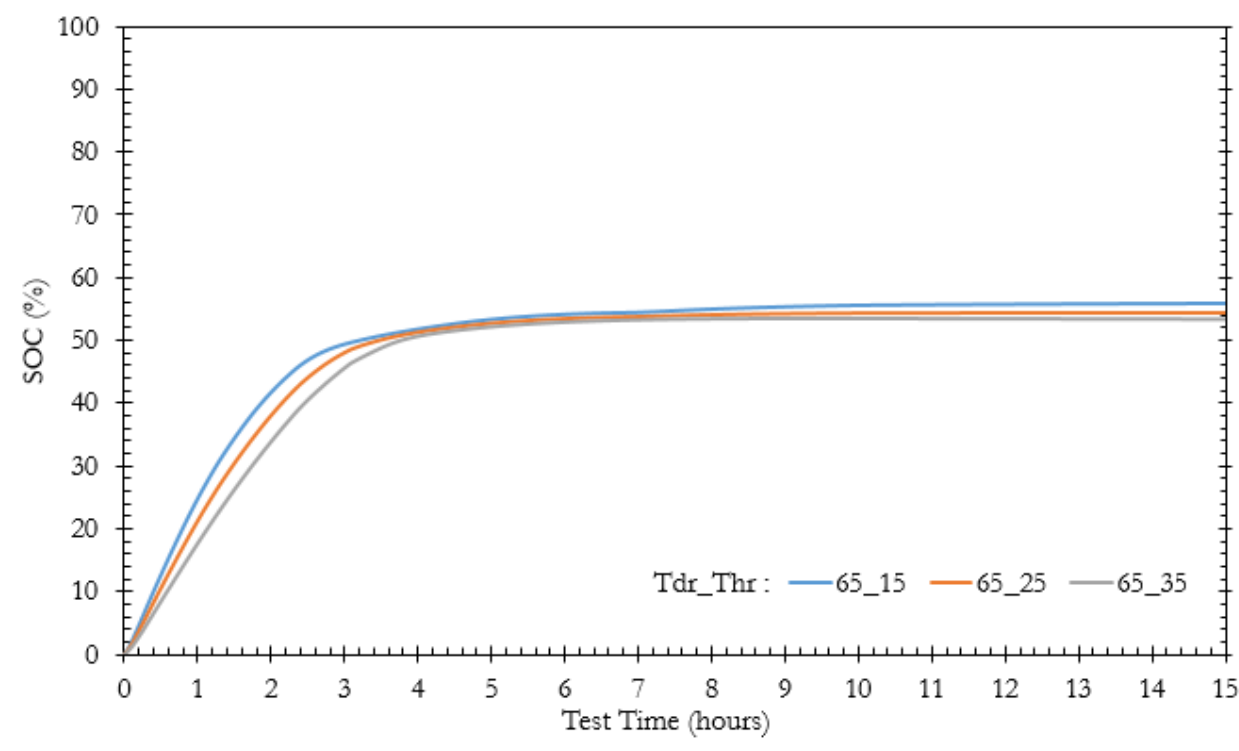

(a)

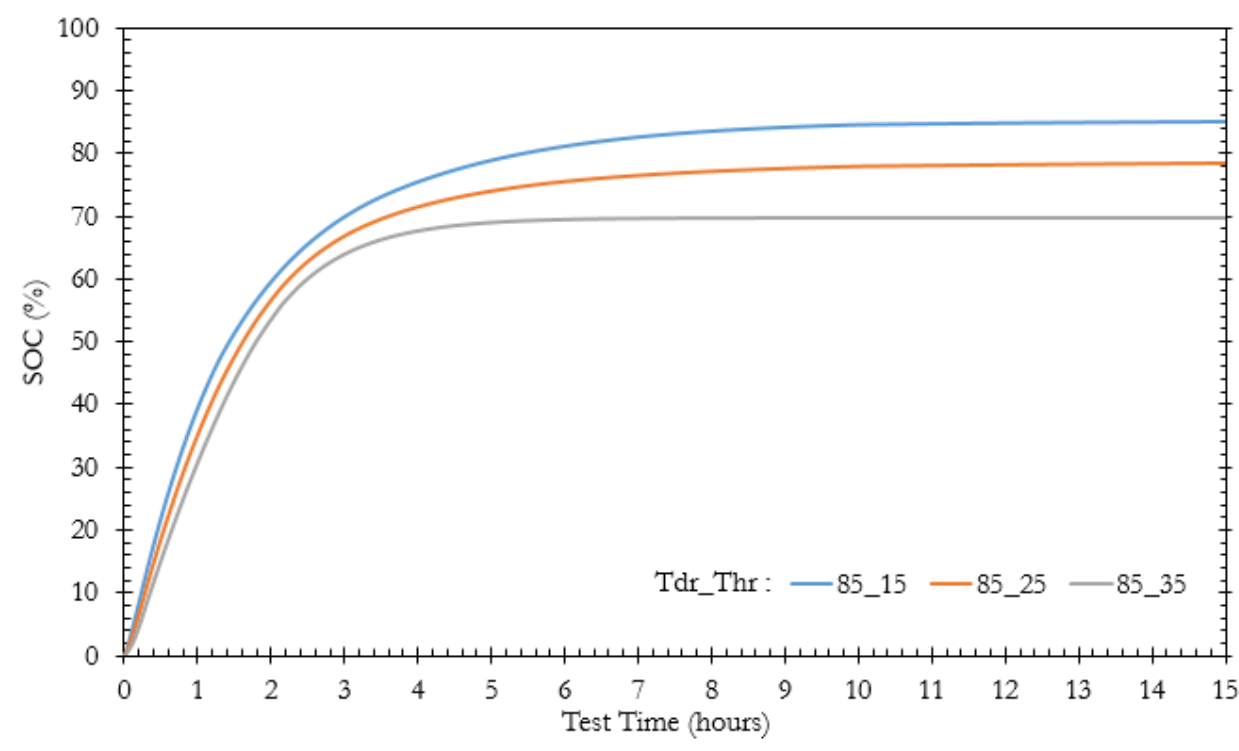

(c)

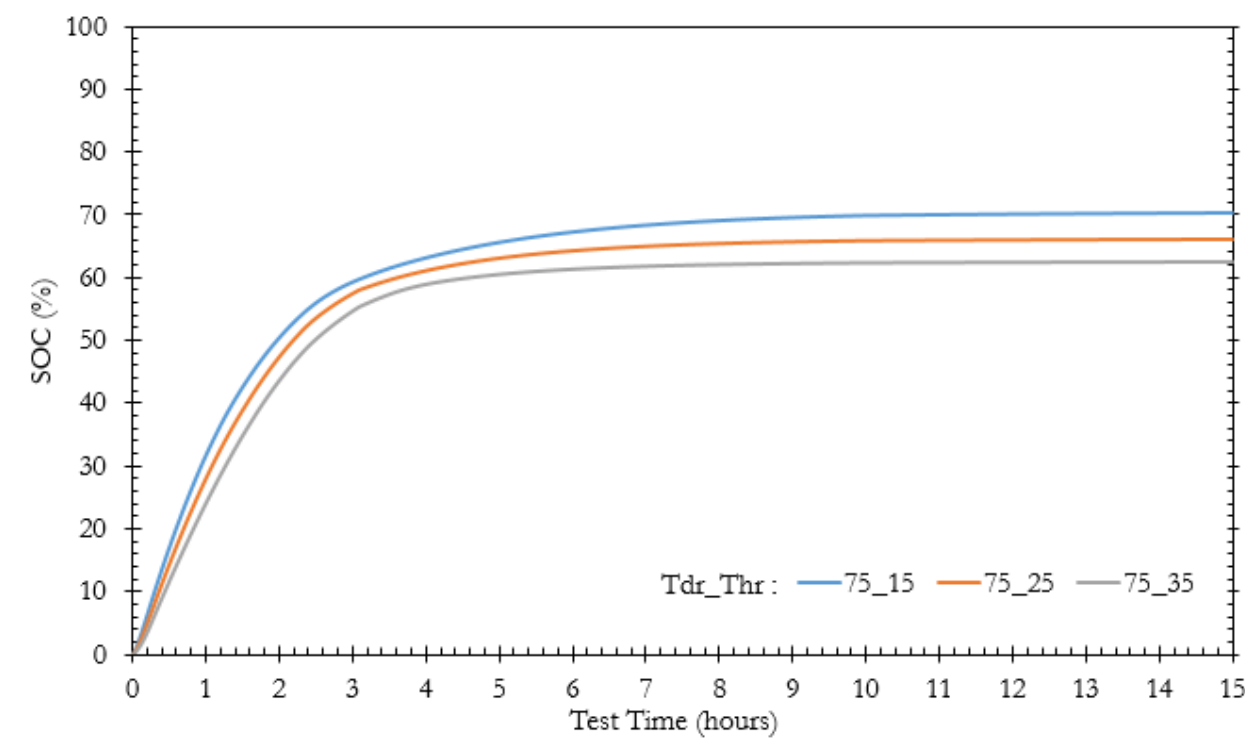

(b)

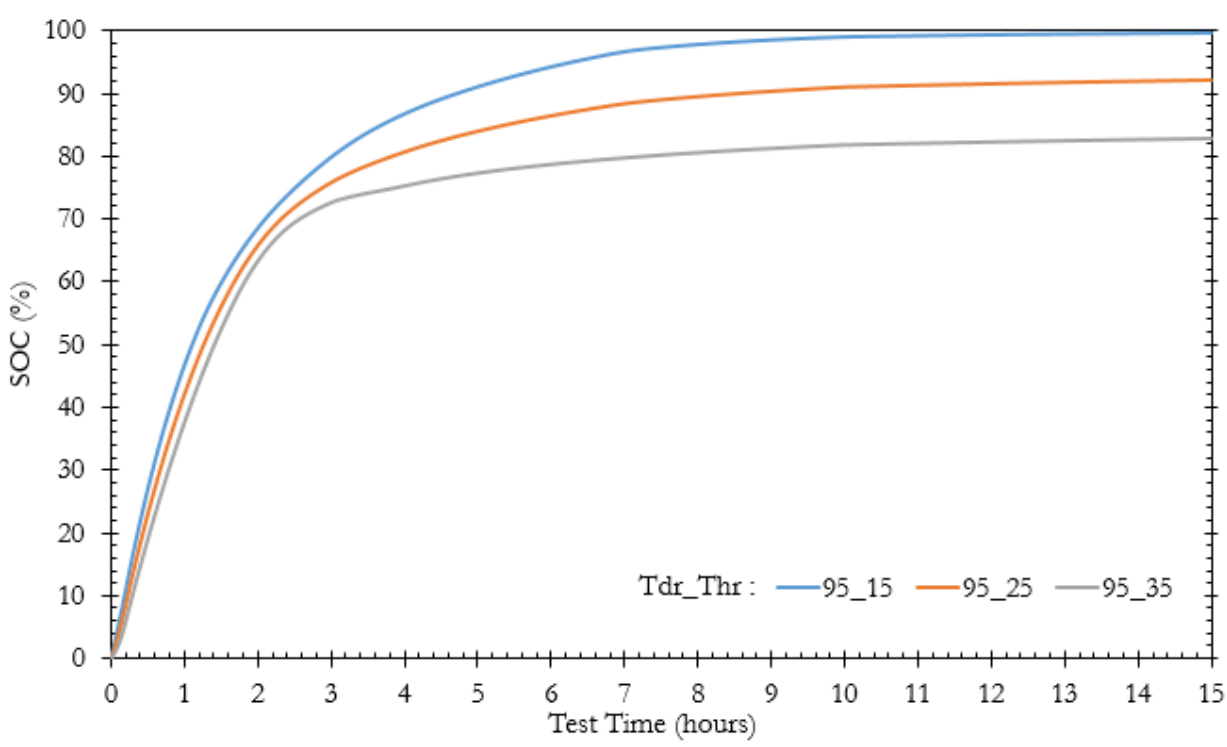

(d)

Figure 5-1: Characteristic charge curves for varying heat rejection temperatures and constant driving temperatures of (a) $65^{\circ} \mathrm{C}$, (b) $75^{\circ} \mathrm{C}$, (c) $85^{\circ} \mathrm{C}$, and (d) $95^{\circ} \mathrm{C}$ 


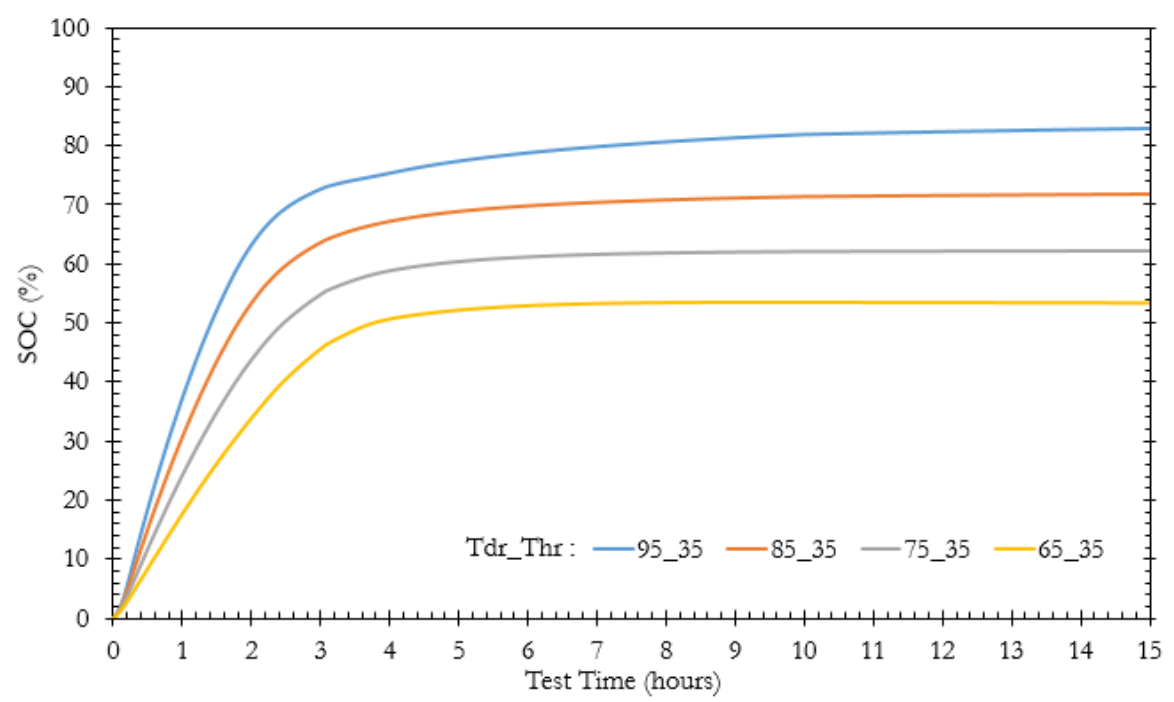

(a)

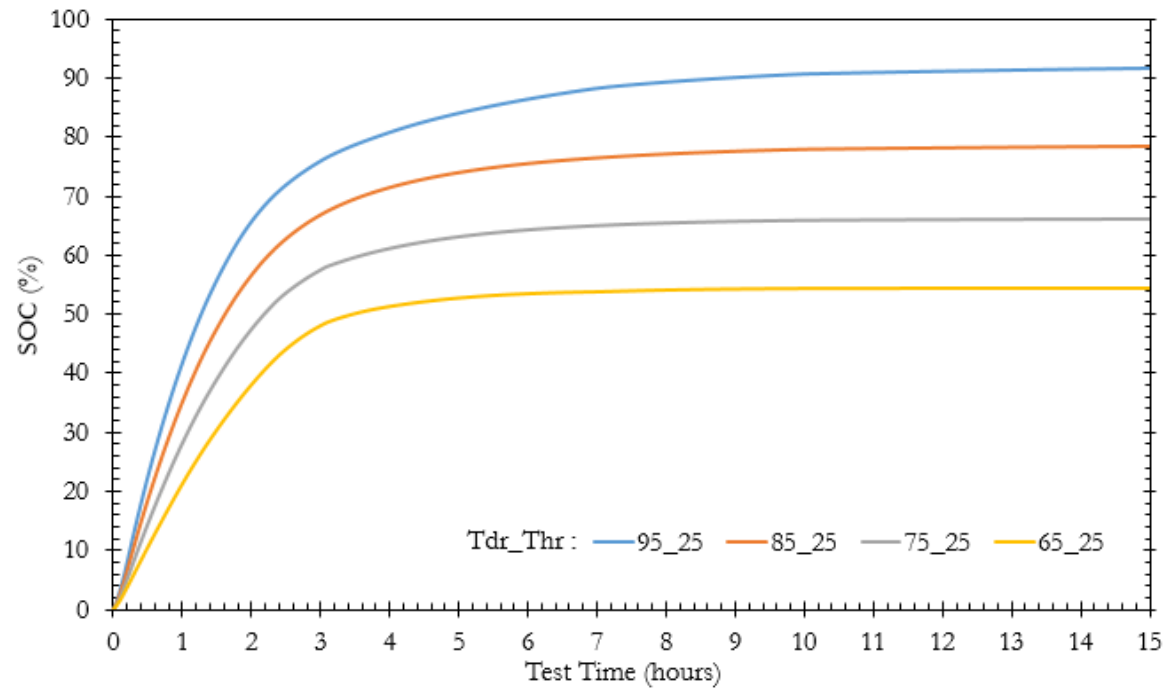

(b)

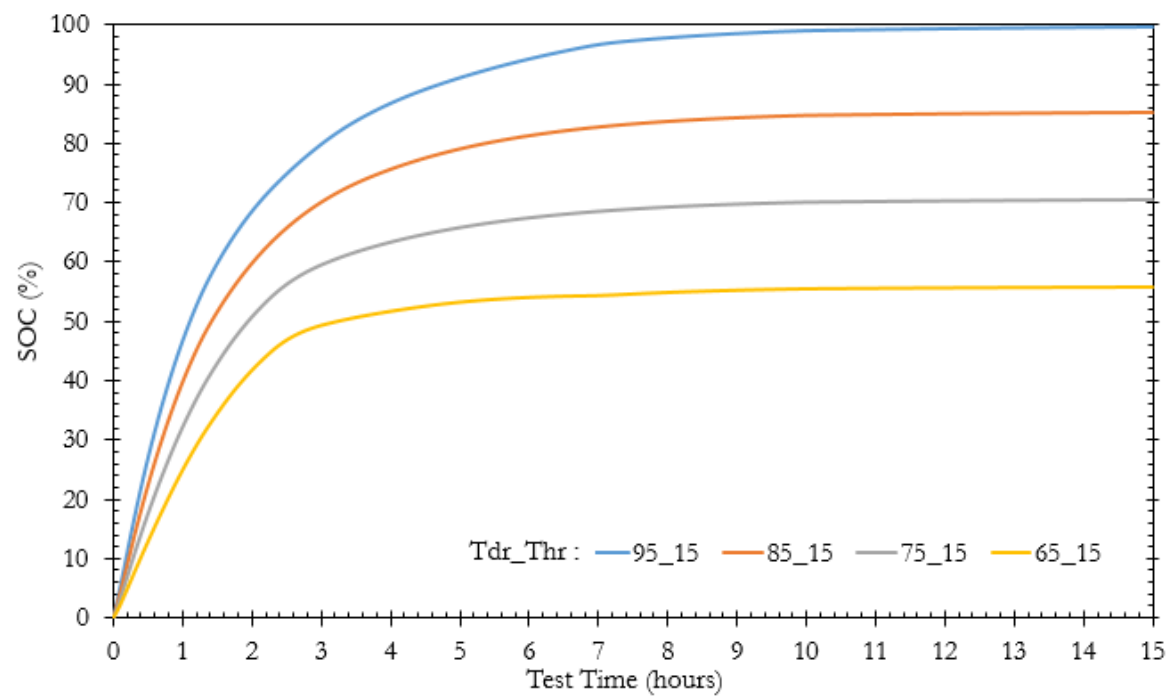

(c)

Figure 5-2: Characteristic charge curves for varying driving temperatures and constant heat rejection temperatures of (a) $35^{\circ} \mathrm{C}$, (b) $25^{\circ} \mathrm{C}$, and (c) $15^{\circ} \mathrm{C}$ 
Because the discharge process requires the pressure in the evaporator to be less than the vapour pressure of the refrigerant water, it was important to investigate the possibility that the poor cooling output observed in the above mentioned test was due to a gradual pressure buildup within the system during the charge cycle. Therefore, a second discharge test was performed with the same chilled water and heat rejection temperatures and flow rates, with the only difference being that the unit was evacuated to a pressure of $10 \mathrm{mbar}$ prior to the beginning of the discharge cycle. An evaporator pressure of 10 mbar should be capable of producing chilled water at temperatures as low as $8^{\circ} \mathrm{C}$, however it was found that evacuating the system prior to the discharge cycle had no measureable effect on the cooling output. This may be due to the extreme sensitivity to any pressure increase during the discharge cycle (e.g., for a chilled water temperature of $20^{\circ} \mathrm{C}$, the evaporator pressure must not exceed 23 mbar).

There are two possible mechanisms that could lead to undesired pressure increases in the evaporator during the discharge cycle. First, it is possible that the hermetic seal is broken and small air leak is gradually allowing ambient air to enter the system. Sapienza et al. [48] experimentally determined that even small increases in air pressure $(0.04-0.06 \mathrm{mbar})$ due to air leaks increased adsorption time by a factor of $1.5-2$, hence reducing cooling power by as much as $50 \%$. Furthermore, it was observed that if an air leak resulted in an additional 1 mbar of pressure within the unit, the adsorption time would increase by a factor of 10 (i.e., $90 \%$ reduction in average cooling power).

A pressure increase in the evaporator could also result from the production of noncondensable gases such as hydrogen due to corrosion reactions. Although the negative effects of hydrogen gas are not as severe as those of air, Sapienza et al. [48] found that a 
partial pressure of hydrogen of 1.65 mbar increased the adsorption time by a factor of approximately five compared to the adsorption time in the absence of hydrogen. A 2012 patent filed by ClimateWell $\mathrm{AB}$ aknowledged that "a drawback relating to the use of salt solutions in absorption processes is that corrosion easily occurs" and that "corrosion typically results in the formation of non-condensable gases, mainly hydrogen gas, or even rupture of the building material in a machine working according to the absorption process" [49]. The patent also discloses that "the effects of corrosion gases decrease or stop the absorption process". It is likely that corrosion on the inner surfaces of the tested chiller was largely responsible for the poor cooling power observed during discharge tests. This is supported by the fact that in July 2015, Barrel A experienced a rupture due to corrosion, rendering one half of the sorption chiller inoperable. In September 2015, Barrel B also ruptured due to corrosion.

In addition to the performance degradation imparted by the presence of unwanted gases, the performance may be further hindered by the migration of the $\mathrm{LiCl}$ salt within host matrix of the adsorber [49]. Such migration can lead to an uneven salt concentration within the matrix, which reduces the total surface area of exposed adsorbent, thereby reducing the cooling power of the unit. Furthermore, it is also possible for the $\mathrm{LiCl}$ salt to gradually migrate to the condenser/evaporator in the form of liquid droplets carried by the vapour refrigerant [49]. The presence of $\mathrm{LiCl}$ in the evaporator would lower the vapour pressure of the liquid refrigerant, thus reducing the pressure gradient between the evaporator and adsorber, and consequently reduce the cooling power.

\subsection{Model Validation}

After implementing the charge rate equations and steady state heat loss values into the TRNSYS model, a separate experimental test was performed with the intention of validating 
the model. Because the previously conducted discharge tests revealed that the cooling power produced by the unit was inadequate for its intended use, only the charging component of the model was validated. As shown in Figure 5-3, the inlet temperatures of the heat rejection and driving circuits were consistently varied during the five hour validation test to ensure that the entire performance map was utilized. The measured inlet temperatures were then input into the TRNSYS model and the outlet temperatures of the simulation were compared to those of the experimental test. The deviations between the experimental and simulation results are summarized in Table 5-1, including the maximum temperature deviation for each circuit, the root-mean-square deviation (RMSD) for the 500 time steps, and the deviation in cumulative energy transfer for each hydraulic circuit.

Table 5-1: Comparison of model and experimental results

\begin{tabular}{c|ccccc}
\hline $\begin{array}{c}\text { Hydraulic } \\
\text { Circuit }\end{array}$ & $\begin{array}{c}\text { Maximum } \\
\text { Deviation }\left({ }^{\circ} \mathrm{C}\right)\end{array}$ & $\begin{array}{c}\text { RMSD } \\
\left({ }^{\circ} \mathrm{C}\right)\end{array}$ & $\begin{array}{c}\text { Actual Energy } \\
\text { Transfer }(\mathrm{kWh})\end{array}$ & $\begin{array}{c}\text { Model Energy } \\
\text { Transfer }(\mathrm{kWh})\end{array}$ & $\begin{array}{c}\text { Energy Transfer } \\
\text { Deviation }\end{array}$ \\
\hline Driving & 3.17 & 0.64 & 29.87 & 30.09 & $+0.7 \%$ \\
Heat rejection & 3.06 & 1.02 & 29.87 & 29.48 & $-1.3 \%$ \\
\hline
\end{tabular}

While Figure 5-3 shows good agreement between the simulation and experimental results, more work is necessary to sufficiently validate the model. Due to the unexpected failure of the system, only a single validation test could be completed for the charge cycle. Furthermore, the model is currently incomplete without the incorporation of the discharge cycle. Once a complete model is constructed, additional validation tests should be conducted to assess its ability to predict the performance of the chiller under a variety of conditions. One such test would consist of cycling the sorption chiller through multiple charge/discharge cycles over the course of a day to evaluate the model's ability to accurately predict the outlet temperatures during the transition periods. This test would also be valuable 
in determining whether the model's predictive output becomes less accurate as the test progresses due to drifting between the actual SOC and that determined by the model. The model should also be tested for conditions in which the operation of the chiller itself is intermittent, whether for a few hours during the day or from one day to the next. This test would ensure that the model treats such periods of inactivity properly, both in terms of the gradual loss of SOC and the slow return of the condenser and generator heat exchangers back to room temperature.

\subsection{Optimal Cycle Time}

One of the benefits to the modelling methodology employed is that the total heat input provided by the driving circuit can be separated into its various components, namely the heat loss to the environment, the sensible heat required to heat the liquid refrigerant and generator heat exchanger, and the heat required for the desorption of the refrigerant. Figure 5-4 shows that sensible heat accounts for a high percentage of the total energy input during the beginning of a charge cycle, while the heat lost to the environment becomes more prominent as the cycle time increases. Both the heat loss and sensible heat components can be regarded as "waste heat" inputs as they are not directly responsible for transporting the refrigerant to the condenser/evaportor. Therefore, to maximize the $\mathrm{COP}_{\text {th }}$ of the unit it is desirable to maximize the allocation of energy directed towards desorption. Figure 5-4 shows that for a charge cycle having a driving temperature of $90^{\circ} \mathrm{C}$ and a heat rejection temperature of $20^{\circ} \mathrm{C}$, a cycle time of 1.25 hours maximizes the percentage of total heat input that can be attributed to the desorption of the refrigerant and therefore should also maximize the $\mathrm{COP}_{\mathrm{th}}$. It is important to note that since the charging rate varies throughout the charging cycle, the optimal charging cycle time will vary depending on the SOC at the beginning of the cycle. 


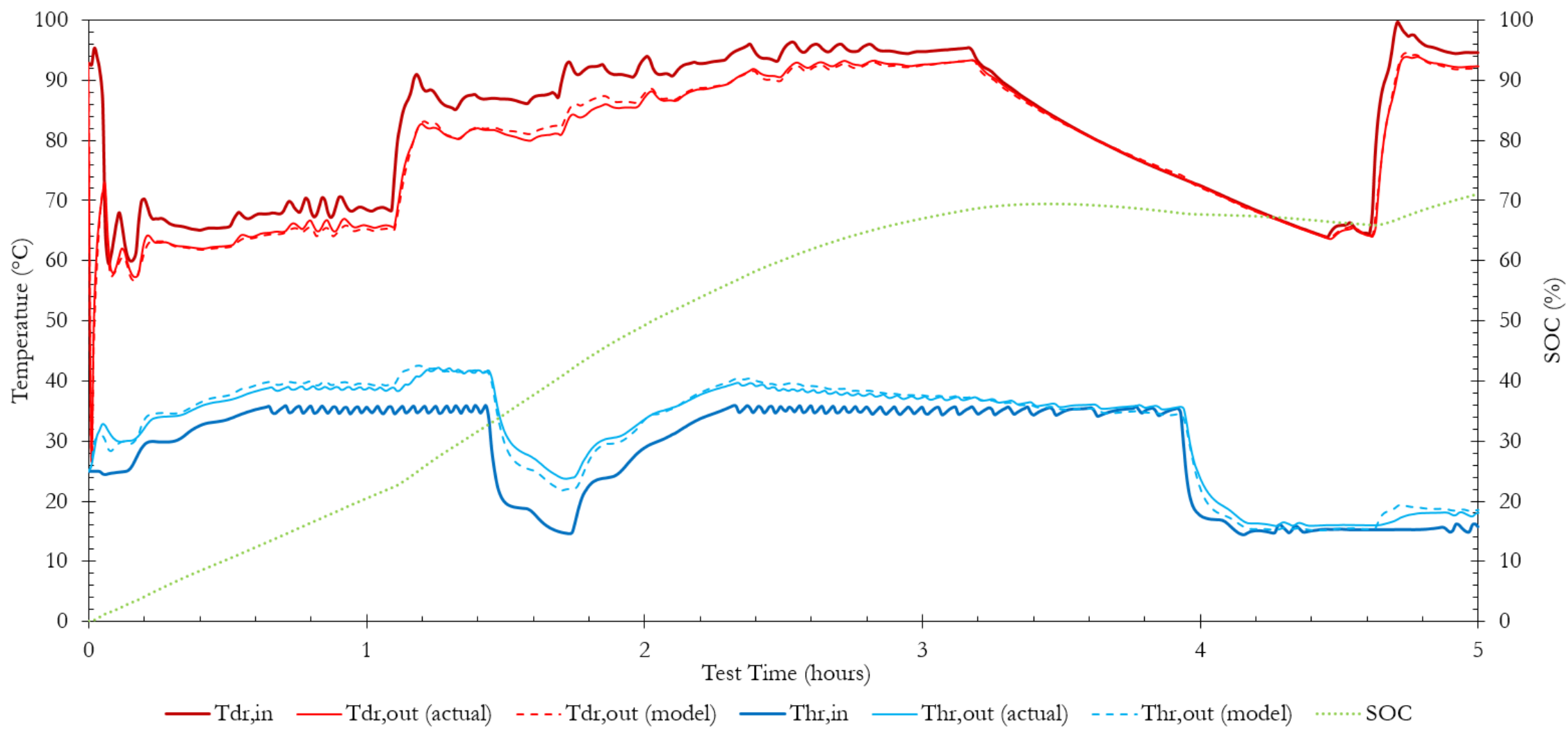

Figure 5-3: Comparison of experimental and simulated outlet temperatures for validation test 
This concept is explored in further detail in Figure 5-5, which shows the optimal charging time for cycles having an initial SOC of $0 \%, 25 \%$, and $50 \%$. One notable trend that may be observed from Figure 5-5 is that the optimal cycle time generally decreases as the initial SOC increases. However, this trend does not persist evenly throughout the performance map, which suggests that choosing an appropriate charging cycle time could have major implications on improving the $\mathrm{COP}_{\text {th }}$ of the chiller. It is also important to note that while this analysis offers some insight into the optimal cycle length, a full analysis would give equal consideration to the effects of cycle length on the performance of the discharge cycle. Furthermore, the focus of this analysis is to optimize the $\mathrm{COP}_{\text {th }}$ of the chiller and therefore prioritizes cooling energy rather than cooling power. When optimizing the operation of a sorption chiller as part of residential cooling system, it will be important to maximize the $\mathrm{COP}_{\text {th }}$ while ensuring that the cooling power is sufficient to meet the cooling load.

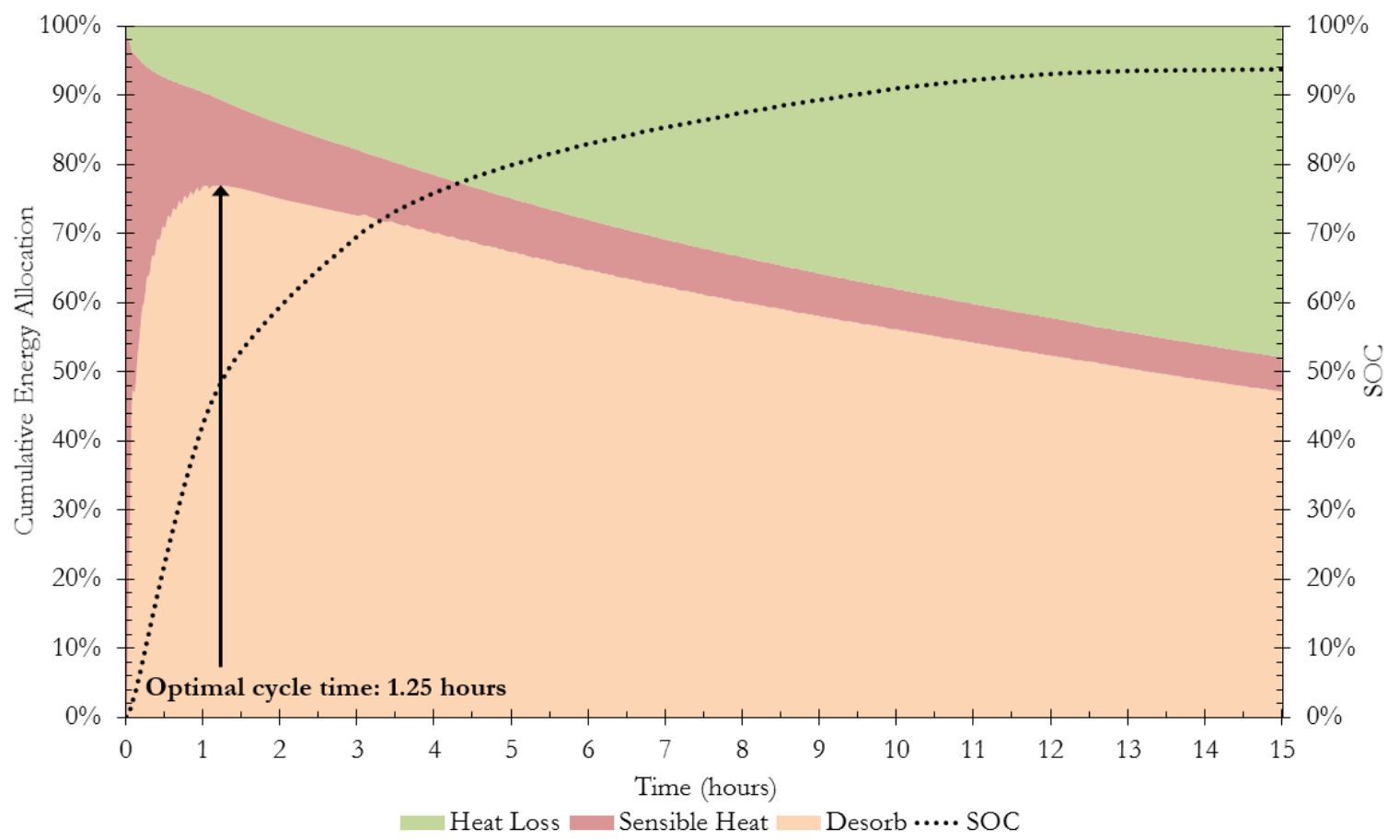

Figure 5-4: Cumulative energy allocation for driving circuit during charging cycle 


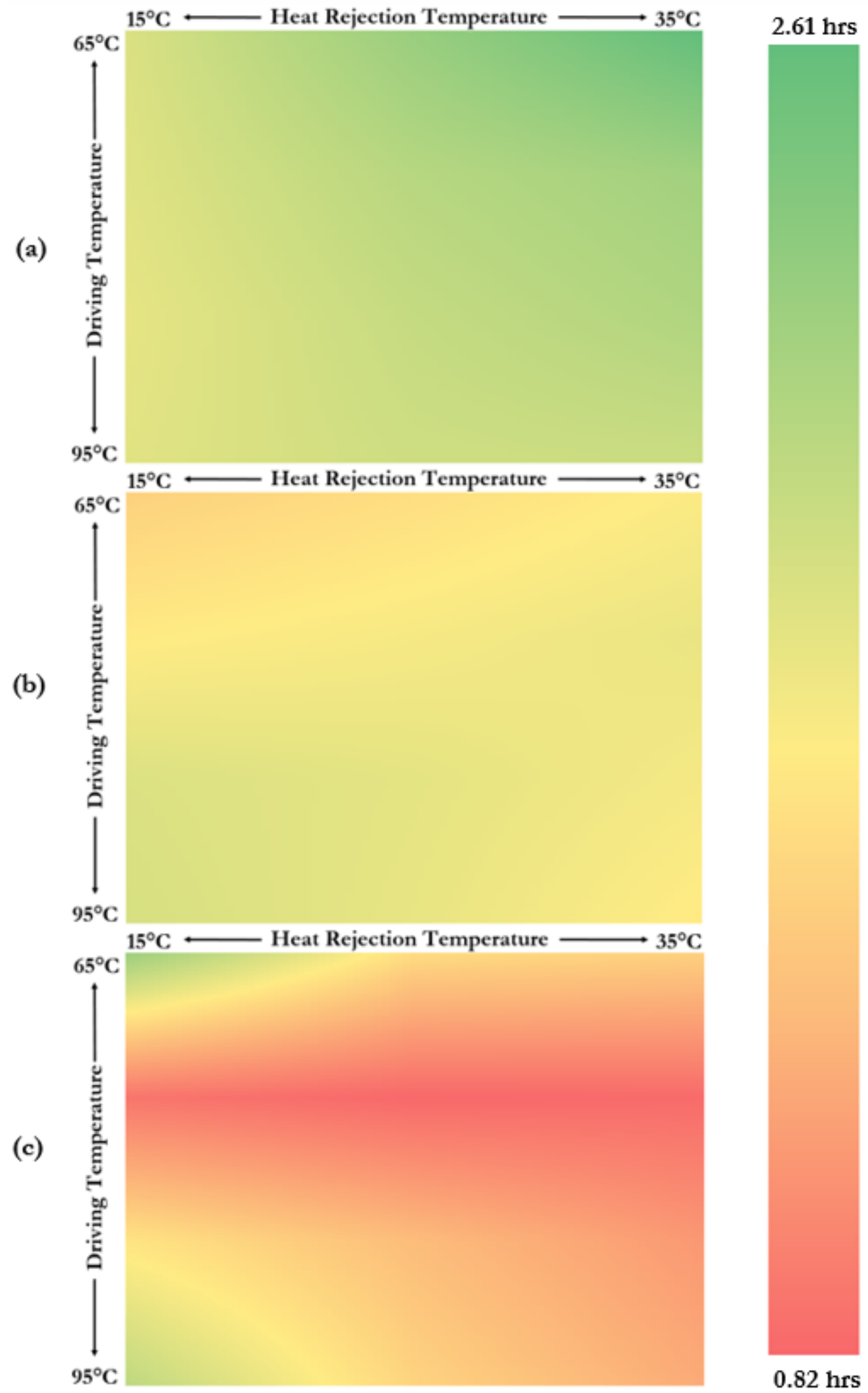

Figure 5-5: Optimal charging cycle time for an initial SOC of (a) $0 \%$, (b) $25 \%$, and (c) $50 \%$ 


\section{Chapter 6}

\section{Conclusions and Future Work}

\subsection{Conclusions}

Solar-driven sorption chillers have the potential to reduce the peak load placed on the electrical grid during Canada's warm summer months. However, in order to accurately assess the feasibility of this technology in the Canadian climate, more work is needed to create robust simulation models that accurately characterize the performance of commercially available sorption chillers. This thesis represents the second phase of a project which aims to experimentally evaluate and model the performance of a novel triple-state sorption chiller.

Although experimental testing of the ClimateWell sorption chiller revealed that the cooling power was inadequate for practical applications within the Canadian residential sector, this thesis was able to lay the groundwork for the testing and modelling methodologies required to assess the performance of sorption chillers employing an intermittent cycle. The goal of the modelling methodology was to allow the transient heat transfer effects of the chiller to be captured while relying only on measured performance data (i.e., without access to proprietary information about the size/configuration of the internal heat exchangers, mass of refrigerant/adsorbent, etc.). In this respect, the developed model was able to predict the heat input and heat rejected during a five hour charging cycle to within $0.7 \%$ and $1.3 \%$ of the experimentally measured values, respectively. 


\subsection{Future Work}

The next stage of this project will consist of the commissioning and experimental testing of a recently acquired $16 \mathrm{~kW}$ SorTech eCoo 2.0 adsorption chiller, shown in Figure 6-1. This adsorption chiller was chosen to serve as the replacement for the ClimateWell because SorTech has been one of the leading manufacturers of residential scale sorption chillers since 2002. Their newest product, the eCoo 2.0 silica gel-water adsorption chiller, represents the current state-of-the-art for this technology.

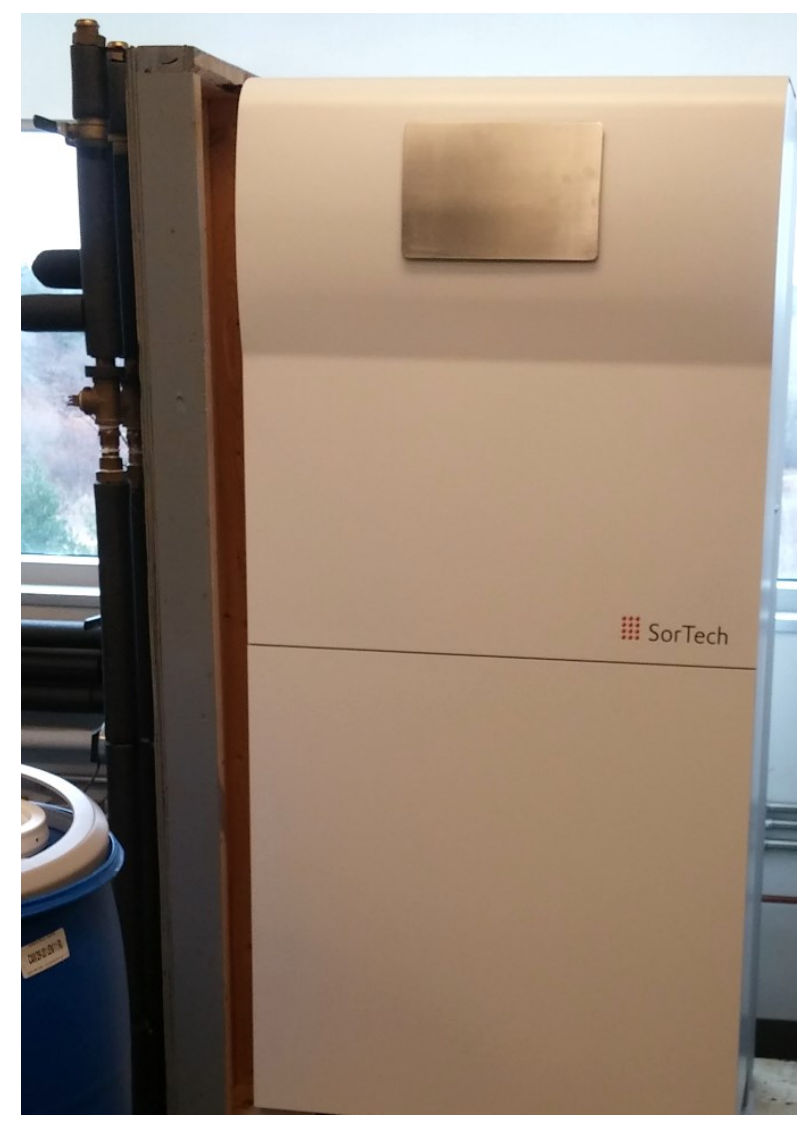

Figure 6-1: Recently acquired SorTech eCoo 2.0 adsorption chiller

The existing experimental set-up will be used to conduct the experimental tests, allowing the performance of the eCoo 2.0 chiller to be compared to that of the ClimateWell. However, some modifications may be made to the experimental set-up to provide greater control of the desired boundary conditions. For example, an investigation should be carried 
out to determine whether the addition of a buffer tank to the driving circuit could help reduce the large fluctuations in temperature experienced during the start-up phase of a charging test. Furthermore, the experimental set-up may require modifications to the controls system to ensure that an adequate cooling load can be supplied for the chiller's $16 \mathrm{~kW}$ cooling capacity.

The testing and modelling techniques developed in this thesis may be used to accelerate the initial research on the eCoo 2.0 chiller, allowing a greater concentration to be placed on optimizing the operation of the chiller for Canadian residential applications. Additionally, since the eCoo 2.0 employs the conventional intermittent adsorption cycle as opposed to the triple-state cycle of the ClimateWell, the time required to conduct experimental charge and discharge tests is expected to be reduced to only a few hours. The reduction in individual test time may allow for more tests to be conducted, resulting in a more refined performance map. Furthermore, multiple flow rates may be investigated to extend the breadth of operational conditions included in the model. 


\section{References}

[1] L. W. Davis and P. J. Gertler, "Contribution of air conditioning adoption to future energy use under global warming," Proceedings of the National Academy of Sciences, vol. 112, no. 19 , pp. 5962-5967, 2015.

[2] M. Sivak, "Will AC put a chill on the global energy supply?," American Scientist, p. 330, September-October 2013.

[3] M. Isaac and D. P. van Vuuren, "Modeling global residential sector energy demand for heating and air conditioning in the context of global warming," Energy Policy, vol. 37, pp. 507-521, 2009.

[4] The World Bank, "World Development Indicators: Electricity production, sources, and access,” 2015. [Online]. Available: http://wdi.worldbank.org/table/3.7\#. [Accessed 6 November 2015].

[5] Independent Electricity System Operator, “Generator Output Capacity,” 2015.

[6] M. Zamora, M. Bourouis, A. Coronas and M. Valles, "Pre-industrial development and experimental characterization of new air-cooled and water-cooled ammonia/lithium nitrate absorption chillers," International Journal of Refrigeration, vol. 45, pp. 189-197, 2014.

[7] D. Mugnier and U. Jakob, "Status of solar cooling in the World: markets and available products," Wiley Interdisciplinary Reviews: Energy and Environment, vol. 4, no. 3, pp. 229-234, 2015.

[8] C. Baldwin and C. A. Cruickshank, "A review of solar cooling technologies for 
residential applications in Canada," Energy Procedia, vol. 30, pp. 495-504, 2012.

[9] K. Stephan, "History of absorption heat pumps and working pair development in Europe," International Journal of Refrigeration, vol. 6, no. 3, pp. 160-166, 1983.

[10] C. A. Balaras, G. Grossman, H.-M. Henning, C. A. Infante Ferreira, E. Podesser, L. Wang and E. Wiemken, "Solar air conditioning in Europe - an overview," Reneweable and Sustainable Energy Reviews, vol. 11, pp. 299-314, 2007.

[11] H. Henning, "Solar assisted air conditioning of buildings - an overview," Aplied Thermal Enegineering, 2006.

[12] K. Wang, O. Abdelaziz, P. Kisari and E. A. Vineyard, "State-of-the-art review on crystallization control technolgies for water/LiBr absorption heat pumps," International Journal of Refrigeration, vol. 34, pp. 1325-1337, 2011.

[13] M. R. Conde-Petit, "Aqueous solutions of lithium and calcium chlorides: Property formulations for use in air conditioning equipment design," M. Conde Engineering, Zurich, 2014.

[14] S. Udomsri, C. Bales, A. Martin and V. Martin, "Decentralized cooling in district heating network: System simulation and parametric study," Applied Energy, vol. 92, pp. 175-184, 2012.

[15] R. Olsson and G. Bolin, "Chemical heat pump working with a hybrid substance”. Patent US 2009029825 A1, 8 October 2009.

[16] H. Hassan, A. Mohamed and R. Bennacer, "Simulation of an adsorption solar cooling system,” Energy, vol. 36, pp. 530-537, 2011.

[17] M. Helm, K. Hagel, W. Pfeffer, S. Hiebler and C. Schweigler, "Solar heating and cooling 
system with absorption chiller and latent heat storage - A research project summary," Energy Procedia, vol. 48, pp. 837-849, 2014.

[18] C. A. Balaras, G. Grossman, H.-M. Henning, C. A. I. Ferreira, E. Podesser, L. Wang and E. Wiemken, "Solar air conditioning in Europe - an overview," Renewable and Sustainable Energy Reviews, vol. 11, pp. 299-314, 2007.

[19] L. Yang, K. Du, X. F. Niu, B. Cheng and Y. F. Jiang, "Experimental study on enhancement of ammonia-water falling film absorption by adding nano-particles," International Journal of Refrigeration, vol. 34, pp. 640-647, 2011.

[20] F. Cabrera, A. Fernandez-Garcia, R. Silva and M. Perez-Garcia, "Use of parabolic trough solar collectors for solar refrigeraion and air-conditioning applicatioins," Renewable and Sustainable Energy Reviews, vol. 20, pp. 103-118, 2013.

[21] G. Mittelman, A. Kribus and A. Dayan, "Solar cooling with concentrating photovoltaic/thermal (CPVT) systems," Energy Conversion and Management, vol. 48, pp. 2481-2490, 2007.

[22] Z. Lu, R. Wang, Z. Xia, X. Lu, C. Yang, Y. Ma and G. Ma, "Study of a novel solar adsorption cooling system and a solar absorption cooling system with new CPC collectors," Renewable Energy, vol. 50, pp. 299-306, 2013.

[23] A. Gonzalez-Gil, M. Izquierdo, J. Marcos and E. Palacios, "New flat-fan sheets adiabatic absorber for direct air-cooled $\mathrm{LiBr} / \mathrm{H} 2 \mathrm{O}$ absorption machines: Simulation, parametric study and experimental results," Applied Energy, vol. 98, pp. 162-173, 2012.

[24] D. Borge-Diaz, A. Colmenar-Santos, C. Perez-Molina and M. Castro-Gil, "Experimental validation of a fully solar-driven triple-state absorption system in small residential 
buildings," Energy and Buildings, vol. 55, pp. 227-237, 2012.

[25] J. Deng, R. Wang and G. Han, “A review of thermally activated cooling technologies for combined cooling, heating and power systems," Progress in Energy and Combustion Science, vol. 37, pp. 172-203, 2011.

[26] SorTech, "The energy efficient, heat-driven chillers aggregate eCoo \& eCoo-POWER," [Online]. Available: http://www.sortech.de/en/products/adsorption-chillers/. [Accessed December 2014].

[27] InvenSor, "InvenSor Adsorption Technology: No Superficial Matter," [Online]. Available: http://www.invensor.com/en/technology/adsorption-technology.htm. [Accessed December 2014].

[28] S. K. Henninger, H. A. Habib and C. Janiak, "MOFs as Adsorbents for Low Temperature Heating and Cooling Applications," Journal of the American Chemical Society, vol. 131, pp. 2776-2777, 2009.

[29] R. Wang and R. Oliveira, "Adsorption refrigeration-An efficient way to make good use of waste heat and solar energy," Progress in Energy and Combustion Science, vol. 32, pp. 424458, 2006.

[30] C. Monné, S. Alonso, F. Palacin and L. Serra, "Monitoring and simulation of an existing solar powered absorption cooling system in Zaragoza (Spain)," Applied Thermal Engineering, vol. 31, pp. 28-35, 2011.

[31] M. Izquierdo, A. Gonzalez-Gil and E. Palacios, "Solar-powered single-and double-effect directly air-cooled $\mathrm{LiBr}-\mathrm{H} 2 \mathrm{O}$ absorption prototype built as a single unit," Applied Energy, vol. 130, pp. 7-19, 2014. 
[32] A. Sapienza, S. Santamaria, A. Frazzica and A. Freni, "Influence of the management strategy and operating conditions on the performance of an adsorption chiller," Energy, vol. 36, pp. 5532-5538, 2011.

[33] Z. Lu, R. Wang, Z. Xia and L. Gong, "Experimental investigation adsorption chillers using micro-porous silica gel-water and compound adsorbent-methanol," Energy Conversion and Management, vol. 65, pp. 43-437, 2013.

[34] A. Li, A. B. Ismail, K. Thu, K. C. Ng and W. S. Loh, "Performance evaluation of a zeolite-water adsorption chiller with entropy analysis of thermodynamic insight," Applied Energy, vol. 130, pp. 702-711, 2014.

[35] G. Angrisani, A. Rosato, C. Roselli, M. Sasso and S. S, "Experimental results of a microtrigeneration installation," Applied Thermal Engineering, vol. 38, pp. 78-90, 2012.

[36] C. Sanjuan, S. Soutullo and H. M.R., "Optimization of a solar cooling system with interior energy storage," Solar Energy, vol. 84, pp. 1244-1254, 2010.

[37] C. Bales and A. O, "Modelling of Commercial Absorption Heat Pump With Integral Storage," in Effstock 2009, Stockholm, 2009.

[38] S. Udomsri, C. Bales, A. R. Martin and V. Martin, "Decentralised cooling in district heating network: Monitoring results and calibration of simulation model," Energy and Buildings, vol. 43, pp. 3311-3321, 2011.

[39] U. Eicker, A. Comenar-Santos, L. Teran, M. Cotrado and D. Borge-Diaz, "Economic evaluation of solar thermal and photovoltaic cooling systems through simulation in different climatic conditions: An analysis in three different European cities," Energy and Buildings, vol. 70, pp. 207-223, 2014. 
[40] R. M. Lazzarin, "Solar cooling: PV or thermal? A thermodynamic and economic analysis," International Journal of Refrigeration, vol. 39, pp. 38-47, 2014.

[41] C. Baldwin, "Design and Construction of an Experimental Apparatus to Assess the Performance of a Solar Absorption Chiller with Integrated Thermal Storage," Master's Thesis, Carleton University, Ottawa, 2013.

[42] Brooks Instrument, Data Sheet: BM Oval Series, 2008.

[43] ClimateWell, "Installation Manual," ClimateWell AB, 2010.

[44] ClimateWell, "Design Guidelines for Solar Cooling," ClimateWell AB, 2010.

[45] S. Klein and et.al., TRNSYS 17 - A TRaNsient SYstem Simulation Program - User Manual, Madison, WI.: Solar Energy Laboratory, University of Wisconsin - Madison, 2010.

[46] Solar Energy Laboratory, University of Wisconsin-Madison, “TRNSYS: Transient System Simulation Tool,” 2015. [Online]. Available: http://www.trnsys.com/. [Accessed 25 November 2015].

[47] ClimatWell AB, "Design Guidelines for Solar Cooling," 2010.

[48] A. Sapienza, A. Frazzica, A. Freni and Y. Aristov, "Dramatic effect of residual gas on dynamics of isobaric adsorption stage of an adsorptive chiller," Applied Thermal Engineering, vol. 96, pp. 385-390, 2016.

[49] G. Bolin and D. Glebov, "Salt coated with nanoparticles". Patent EP 2681501 A1, 8 January 2014. 


\section{Appendix A Detailed System Schematic}

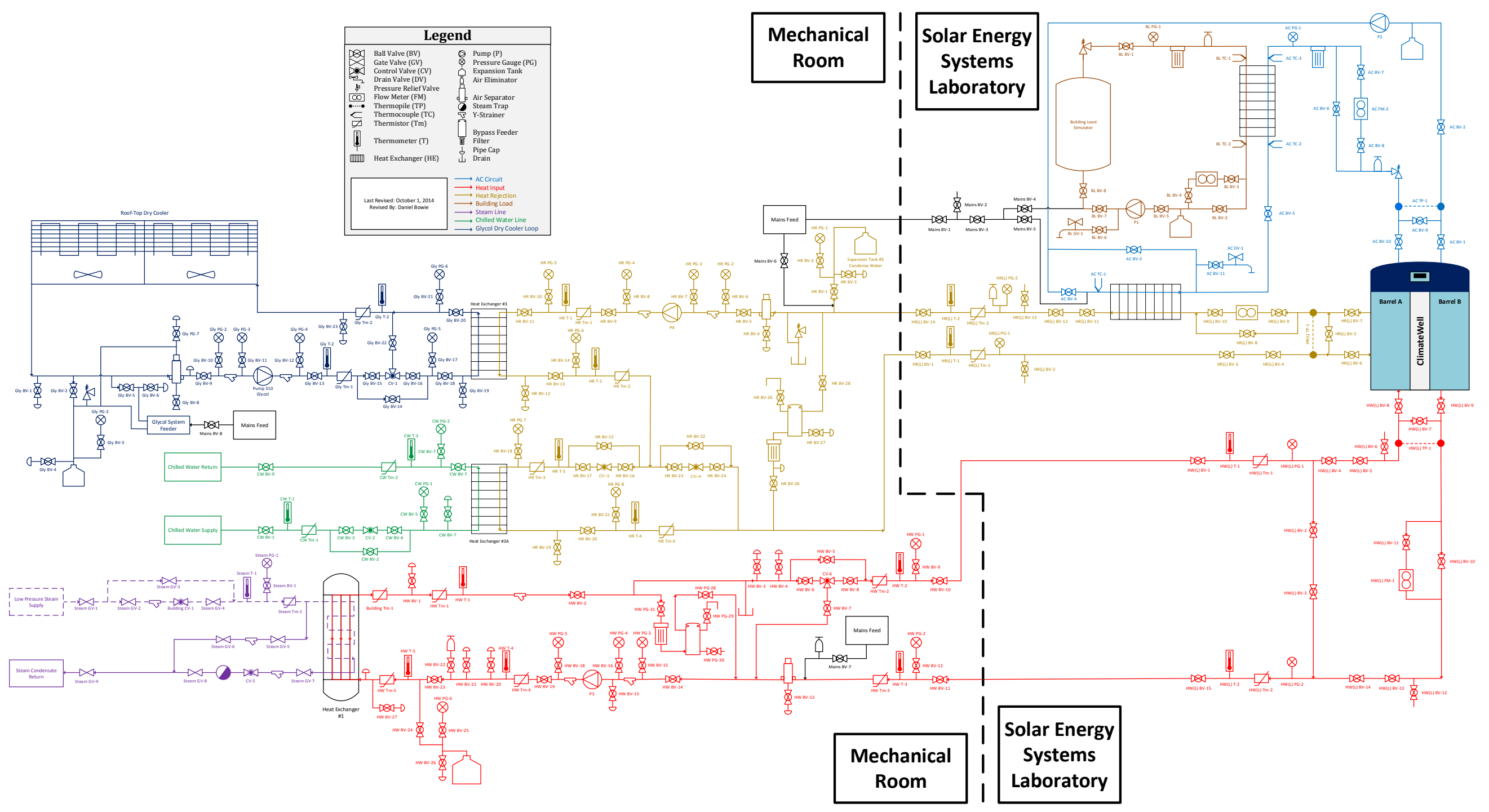




\section{Appendix B TRNSYS Deck File}

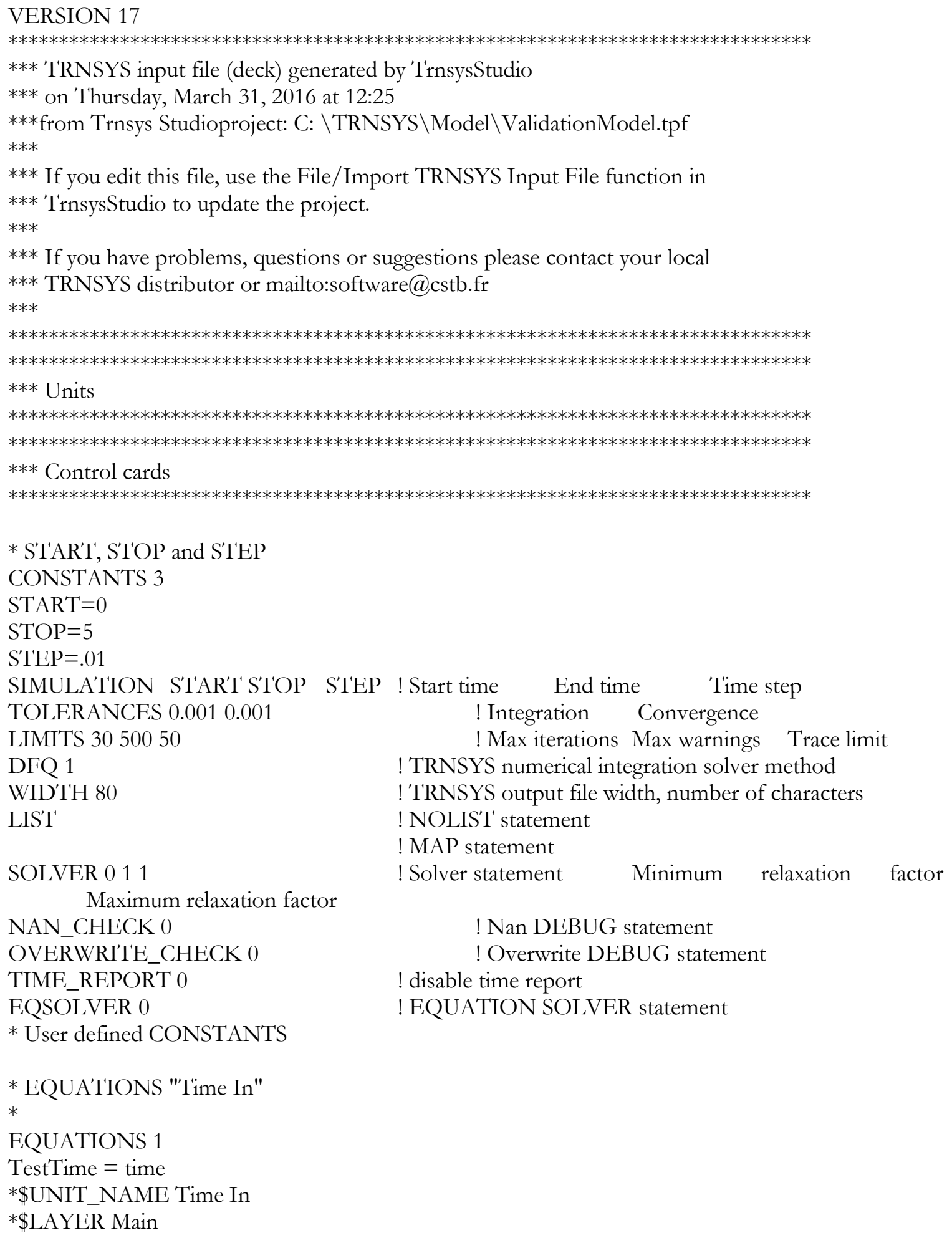




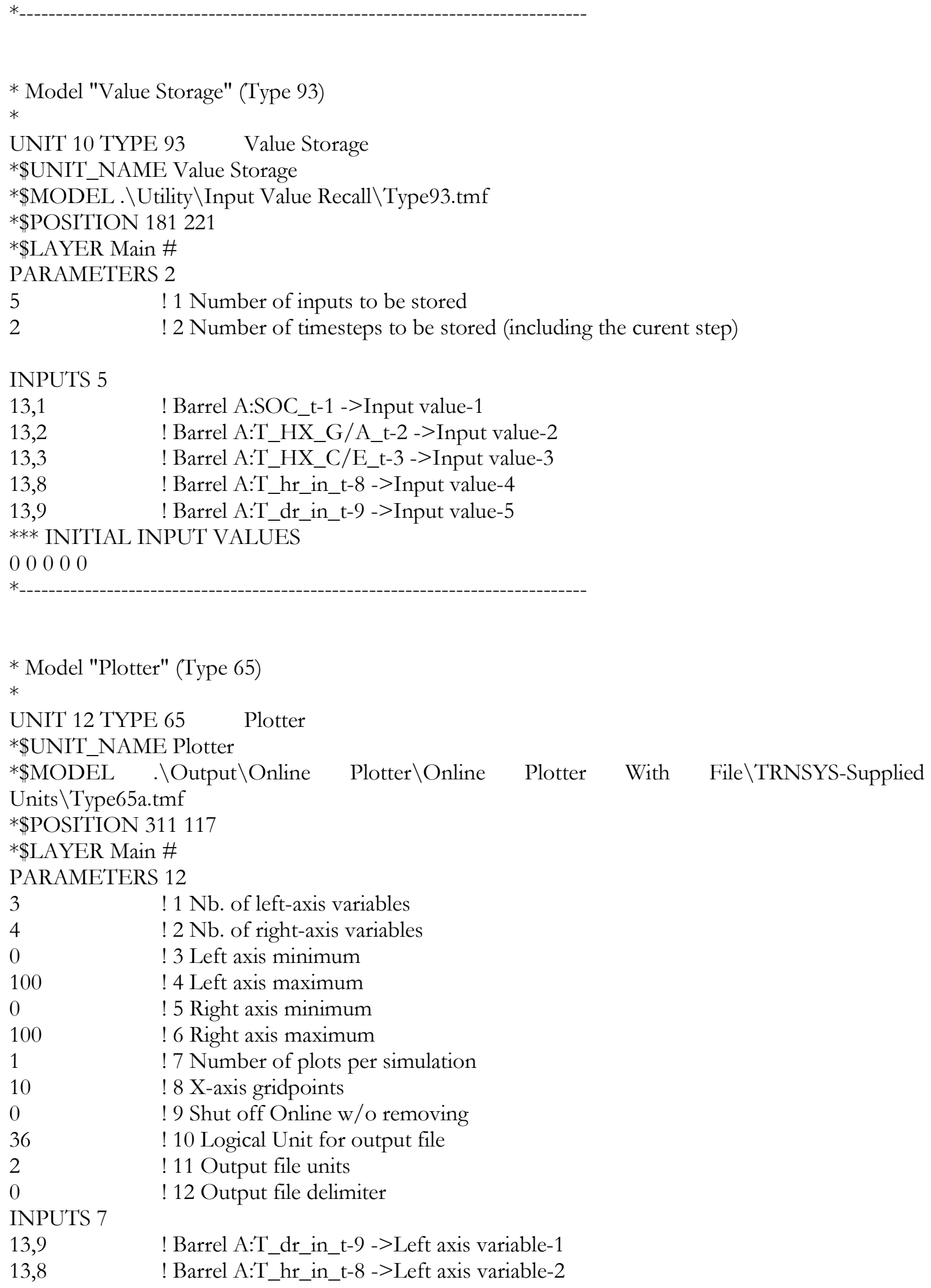




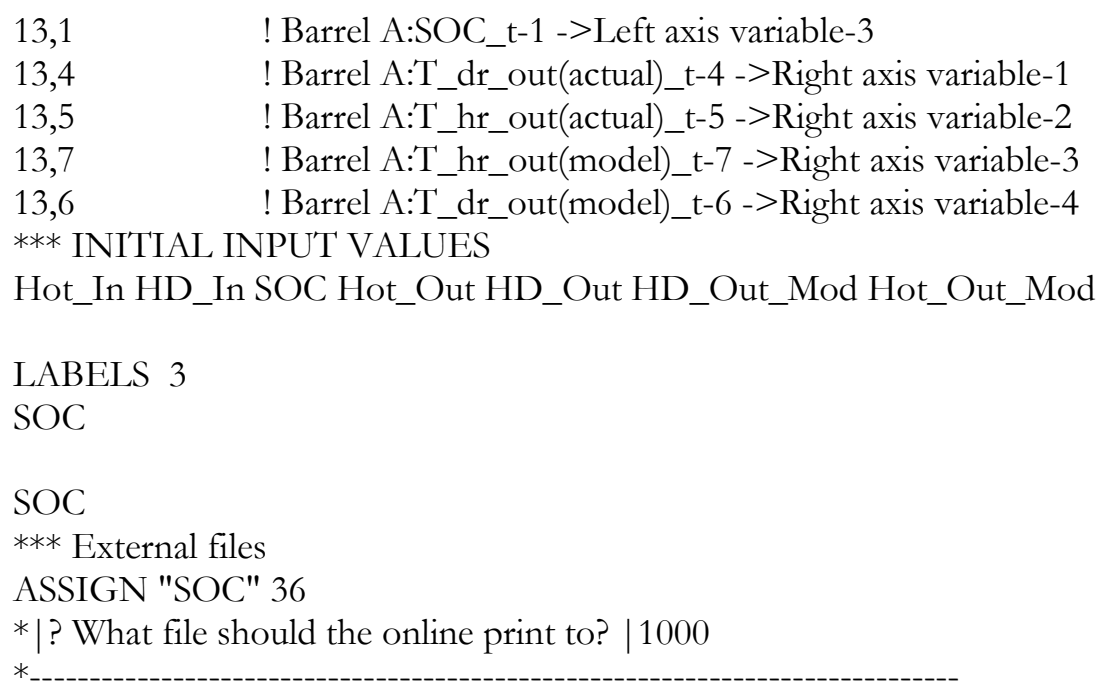




\section{Appendix C Charge Curve Equations}

$\left.\Delta \mathrm{SOC}\right|_{\mathrm{T}_{\mathrm{dr}}=65^{\circ} \mathrm{C}, \mathrm{T}_{\mathrm{hr}}=35^{\circ} \mathrm{C}}$

$$
=\left(1-\mathrm{e}^{-7.5 \mathrm{t}_{\text {cycle }}}\right)\left\{\begin{array}{lc}
-0.00090 \mathrm{SOC}_{\mathrm{t}-\Delta \mathrm{t}}+0.194, & \mathrm{SOC}_{\mathrm{t}-\Delta \mathrm{t}} \leq 19.3 \\
-0.00212 \mathrm{SOC}_{\mathrm{t}-\Delta \mathrm{t}}+0.218, & 19.3<\mathrm{SOC}_{\mathrm{t}-\Delta \mathrm{t}} \leq 38.6 \\
-0.00724 \mathrm{SOC}_{\mathrm{t}-\Delta \mathrm{t}}+0.415, & 38.6<\mathrm{SOC}_{\mathrm{t}-\Delta \mathrm{t}} \leq 46.2 \\
-0.01141 \mathrm{SOC}_{\mathrm{t}-\Delta \mathrm{t}}+0.608, & \mathrm{SOC}_{\mathrm{t}-\Delta \mathrm{t}}>46.2
\end{array}\right.
$$

$\left.\Delta \mathrm{SOC}\right|_{\mathrm{T}_{\mathrm{dr}}=75^{\circ} \mathrm{C}, \mathrm{T}_{\mathrm{hr}}=35^{\circ} \mathrm{C}}$

$$
=\left(1-\mathrm{e}^{-7.5 t_{\text {cycle }}}\right)\left\{\begin{array}{cc}
-0.00246 \mathrm{SOC}_{\mathrm{t}-\Delta \mathrm{t}}+0.291, & \mathrm{SOC}_{\mathrm{t}-\Delta \mathrm{t}} \leq 27.2 \\
-0.00416 \mathrm{SOC}_{\mathrm{t}-\Delta \mathrm{t}}+0.337, & 27.2<\mathrm{SOC}_{\mathrm{t}-\Delta \mathrm{t}} \leq 42.6 \\
-0.00735 \mathrm{SOC}_{\mathrm{t}-\Delta \mathrm{t}}+0.473, & 42.6<\mathrm{SOC}_{\mathrm{t}-\Delta \mathrm{t}} \leq 55.8 \\
-0.00940 \mathrm{SOC}_{\mathrm{t}-\Delta \mathrm{t}}+0.588, & \mathrm{SOC}_{\mathrm{t}-\Delta \mathrm{t}}>55.8
\end{array}\right.
$$

$\left.\Delta \mathrm{SOC}\right|_{\mathrm{T}_{\mathrm{dr}}=85^{\circ} \mathrm{C}, \mathrm{T}_{\mathrm{hr}}=35^{\circ} \mathrm{C}}$

$$
=\left(1-\mathrm{e}^{-7.5 \mathrm{t}_{\text {cycle }}}\right)\left\{\begin{array}{lc}
-0.00333 \mathrm{SOC}_{\mathrm{t}-\Delta \mathrm{t}}+0.388, & \mathrm{SOC}_{\mathrm{t}-\Delta \mathrm{t}} \leq 32.8 \\
-0.00474 \mathrm{SOC}_{\mathrm{t}-\Delta \mathrm{t}}+0.435, & 32.8<\mathrm{SOC}_{\mathrm{t}-\Delta \mathrm{t}} \leq 48.4 \\
-0.00684 \mathrm{SOC}_{\mathrm{t}-\Delta \mathrm{t}}+0.536, & 48.4<\mathrm{SOC}_{\mathrm{t}-\Delta \mathrm{t}} \leq 56.0 \\
-0.01109 \mathrm{SOC}_{\mathrm{t}-\Delta \mathrm{t}}+0.774, & \mathrm{SOC}_{\mathrm{t}-\Delta \mathrm{t}}>56.0
\end{array}\right.
$$

$\left.\Delta \mathrm{SOC}\right|_{\mathrm{T}_{\mathrm{dr}}=95^{\circ} \mathrm{C}, \mathrm{T}_{\mathrm{hr}}=35^{\circ} \mathrm{C}}$

$$
=\left(1-\mathrm{e}^{-7.5 t_{\text {cycle }}}\right)\left\{\begin{array}{lc}
-0.00381 \mathrm{SOC}_{\mathrm{t}-\Delta \mathrm{t}}+0.480, & \mathrm{SOC}_{\mathrm{t}-\Delta \mathrm{t}} \leq 35.9 \\
-0.00525 \mathrm{SOC}_{\mathrm{t}-\Delta \mathrm{t}}+0.531, & 35.9<\mathrm{SOC}_{\mathrm{t}-\Delta \mathrm{t}} \leq 58.0 \\
-0.01250 \mathrm{SOC}_{\mathrm{t}-\Delta \mathrm{t}}+0.952, & 58.0<\mathrm{SOC}_{\mathrm{t}-\Delta \mathrm{t}} \leq 74.4 \\
-0.00262 \mathrm{SOC}_{\mathrm{t}-\Delta \mathrm{t}}+0.217, & \mathrm{SOC}_{\mathrm{t}-\Delta \mathrm{t}}>74.4
\end{array}\right.
$$

$\left.\Delta \mathrm{SOC}\right|_{\mathrm{T}_{\mathrm{dr}}=65^{\circ} \mathrm{C}, \mathrm{T}_{\mathrm{hr}}=25^{\circ} \mathrm{C}}$

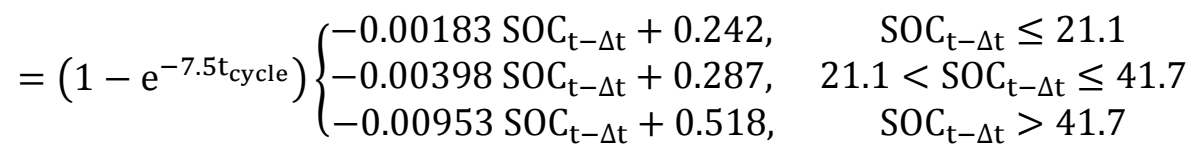

$\left.\Delta \mathrm{SOC}\right|_{\mathrm{T}_{\mathrm{dr}}=75^{\circ} \mathrm{C}, \mathrm{T}_{\mathrm{hr}}=25^{\circ} \mathrm{C}}$

$$
=\left(1-\mathrm{e}^{-7.5 t_{\text {cycle }}}\right)\left\{\begin{array}{cc}
-0.00378 \mathrm{SOC}_{\mathrm{t}-\Delta \mathrm{t}}+0.352, & \mathrm{SOC}_{\mathrm{t}-\Delta \mathrm{t}} \leq 27.6 \\
-0.00537 \mathrm{SOC}_{\mathrm{t}-\Delta \mathrm{t}}+0.396, & 27.6<\mathrm{SOC}_{\mathrm{t}-\Delta \mathrm{t}} \leq 51.8 \\
-0.01115 \mathrm{SOC}_{\mathrm{t}-\Delta \mathrm{t}}+0.695, & 51.8<\mathrm{SOC}_{\mathrm{t}-\Delta \mathrm{t}} \leq 57.9 \\
-0.00617 \mathrm{SOC}_{\mathrm{t}-\Delta \mathrm{t}}+0.407, & \mathrm{SOC}_{\mathrm{t}-\Delta \mathrm{t}}>57.9
\end{array}\right.
$$


$\left.\Delta \mathrm{SOC}\right|_{\mathrm{T}_{\mathrm{dr}}=85^{\circ} \mathrm{C}, \mathrm{T}_{\mathrm{hr}}=25^{\circ} \mathrm{C}}$

$$
=\left(1-\mathrm{e}^{-7.5 t_{\text {cycle }}}\right)\left\{\begin{array}{lc}
-0.00496 \mathrm{SOC}_{\mathrm{t}-\Delta \mathrm{t}}+0.422, & \mathrm{SOC}_{\mathrm{t}-\Delta \mathrm{t}} \leq 34.3 \\
-0.00648 \mathrm{SOC}_{\mathrm{t}-\Delta \mathrm{t}}+0.295, & 34.3<\mathrm{SOC}_{\mathrm{t}-\Delta \mathrm{t}} \leq 58.7 \\
-0.00842 \mathrm{SOC}_{\mathrm{t}-\Delta \mathrm{t}}+0.137, & 58.7<\mathrm{SOC}_{\mathrm{t}-\Delta \mathrm{t}} \leq 70.1 \\
-0.00500 \mathrm{SOC}_{\mathrm{t}-\Delta \mathrm{t}}+0.041, & \mathrm{SOC}_{\mathrm{t}-\Delta \mathrm{t}}>70.1
\end{array}\right.
$$

$\left.\Delta \mathrm{SOC}\right|_{\mathrm{T}_{\mathrm{dr}}=95^{\circ} \mathrm{C}, \mathrm{T}_{\mathrm{hr}}=25^{\circ} \mathrm{C}}$

$$
=\left(1-\mathrm{e}^{-7.5 t_{\text {cycle }}}\right)\left\{\begin{array}{lc}
-0.00589 \mathrm{SOC}_{\mathrm{t}-\Delta \mathrm{t}}+0.574, & \mathrm{SOC}_{\mathrm{t}-\Delta \mathrm{t}} \leq 48.0 \\
-0.00702 \mathrm{SOC}_{\mathrm{t}-\Delta \mathrm{t}}+0.628, & 48.0<\mathrm{SOC}_{\mathrm{t}-\Delta \mathrm{t}} \leq 62.1 \\
-0.00923 \mathrm{SOC}_{\mathrm{t}-\Delta \mathrm{t}}+0.765, & 62.1<\mathrm{SOC}_{\mathrm{t}-\Delta \mathrm{t}} \leq 76.4 \\
-0.00380 \mathrm{SOC}_{\mathrm{t}-\Delta \mathrm{t}}+0.350, & \text { SOC }_{\mathrm{t}-\Delta \mathrm{t}}>76.4
\end{array}\right.
$$

$\left.\Delta \mathrm{SOC}\right|_{\mathrm{T}_{\mathrm{dr}}=65^{\circ} \mathrm{C}, \mathrm{T}_{\mathrm{hr}}=15^{\circ} \mathrm{C}}$

$$
=\left(1-\mathrm{e}^{-7.5 t_{\text {cycle }}}\right)\left\{\begin{array}{cc}
-0.00278 \mathrm{SOC}_{\mathrm{t}-\Delta \mathrm{t}}+0.293, & \mathrm{SOC}_{\mathrm{t}-\Delta \mathrm{t}} \leq 23.0 \\
-0.00578 \mathrm{SOC}_{\mathrm{t}-\Delta \mathrm{t}}+0.362, & 23.0<\mathrm{SOC}_{\mathrm{t}-\Delta \mathrm{t}} \leq 45.3 \\
-0.01438 \mathrm{SOC}_{\mathrm{t}-\Delta \mathrm{t}}+0.751, & 45.3<\mathrm{SOC}_{\mathrm{t}-\Delta \mathrm{t}} \leq 50.1 \\
-0.00534 \mathrm{SOC}_{\mathrm{t}-\Delta \mathrm{t}}+0.299, & \mathrm{SOC}_{\mathrm{t}-\Delta \mathrm{t}}>50.1
\end{array}\right.
$$

$\left.\Delta \mathrm{SOC}\right|_{\mathrm{T}_{\mathrm{dr}}=75^{\circ} \mathrm{C}, \mathrm{T}_{\mathrm{hr}}=15^{\circ} \mathrm{C}}$

$$
=\left(1-\mathrm{e}^{-7.5 t_{\text {cycle }}}\right)\left\{\begin{array}{lc}
-0.00496 \mathrm{SOC}_{\mathrm{t}-\Delta \mathrm{t}}+0.415, & \mathrm{SOC}_{\mathrm{t}-\Delta \mathrm{t}} \leq 30.9 \\
-0.00658 \mathrm{SOC}_{\mathrm{t}-\Delta \mathrm{t}}+0.465, & 30.9<\mathrm{SOC}_{\mathrm{t}-\Delta \mathrm{t}} \leq 54.0 \\
-0.01115 \mathrm{SOC}_{\mathrm{t}-\Delta \mathrm{t}}+0.712, & 54.0<\mathrm{SOC}_{\mathrm{t}-\Delta \mathrm{t}} \leq 59.2 \\
-0.00617 \mathrm{SOC}_{\mathrm{t}-\Delta \mathrm{t}}+0.327, & \mathrm{SOC}_{\mathrm{t}-\Delta \mathrm{t}}>59.2
\end{array}\right.
$$

$\left.\Delta \mathrm{SOC}\right|_{\mathrm{T}_{\mathrm{dr}}=85^{\circ} \mathrm{C}, \mathrm{T}_{\mathrm{hr}}=15^{\circ} \mathrm{C}}$

$$
=\left(1-\mathrm{e}^{-7.5 \mathrm{t}_{\text {cycle }}}\right)\left\{\begin{array}{lc}
-0.00641 \mathrm{SOC}_{\mathrm{t}-\Delta \mathrm{t}}+0.548, & \mathrm{SOC}_{\mathrm{t}-\Delta \mathrm{t}} \leq 38.9 \\
-0.00899 \mathrm{SOC}_{\mathrm{t}-\Delta \mathrm{t}}+0.649, & 38.9<\mathrm{SOC}_{\mathrm{t}-\Delta \mathrm{t}} \leq 49.8 \\
-0.00628 \mathrm{SOC}_{\mathrm{t}-\Delta \mathrm{t}}+0.514, & 49.8<\mathrm{SOC}_{\mathrm{t}-\Delta \mathrm{t}} \leq 73.2 \\
-0.00454 \mathrm{SOC}_{\mathrm{t}-\Delta \mathrm{t}}+0.386, & \mathrm{SOC}_{\mathrm{t}-\Delta \mathrm{t}}>73.2
\end{array}\right.
$$

$\left.\Delta \mathrm{SOC}\right|_{\mathrm{T}_{\mathrm{dr}}=95^{\circ} \mathrm{C}, \mathrm{T}_{\mathrm{hr}}=15^{\circ} \mathrm{C}}$

$$
=\left(1-\mathrm{e}^{\left.-7.5 t_{\text {cycle }}\right)}\left\{\begin{array}{cc}
-0.00763 \mathrm{SOC}_{\mathrm{t}-\Delta \mathrm{t}}+0.678, & \mathrm{SOC}_{\mathrm{t}-\Delta \mathrm{t}} \leq 53.3 \\
-0.01065 \mathrm{SOC}_{\mathrm{t}-\Delta \mathrm{t}}+0.839, & 53.3<\mathrm{SOC}_{\mathrm{t}-\Delta \mathrm{t}} \leq 57.9 \\
-0.00675 \mathrm{SOC}_{\mathrm{t}-\Delta \mathrm{t}}+0.613, & 57.9<\mathrm{SOC}_{\mathrm{t}-\Delta \mathrm{t}} \leq 73.6 \\
-0.00446 \mathrm{SOC}_{\mathrm{t}-\Delta \mathrm{t}}+0.444, & \mathrm{SOC}_{\mathrm{t}-\Delta \mathrm{t}}>73.6
\end{array}\right.\right.
$$


Table C-1: Steady state temperature differences for generator during charge cycle

\begin{tabular}{|c|c|c|c|c|}
\hline & \multicolumn{3}{|c|}{ Heat Rejection Temperature $\left({ }^{\circ} \mathrm{C}\right)$} \\
\hline & & 15 & 25 & 35 \\
\hline \multirow{4}{*}{.0 } & 65 & 0.81 & 0.64 & 0.49 \\
\hline & 75 & 0.83 & 0.73 & 0.68 \\
\hline & 85 & 0.83 & 0.80 & 0.78 \\
\hline & 95 & 0.84 & 0.81 & 0.80 \\
\hline
\end{tabular}

Table C-2: Steady state temperature differences for condenser during charge cycle

\begin{tabular}{|c|c|c|c|c|}
\hline & & \multicolumn{3}{|c|}{ Heat Rejection Temperature $\left({ }^{\circ} \mathrm{C}\right)$} \\
\hline & & 15 & 25 & 35 \\
\hline \multirow{4}{*}{ 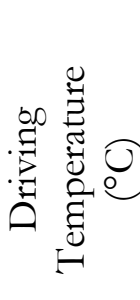 } & 65 & 0.44 & 0.40 & 0.37 \\
\hline & 75 & 0.59 & 0.53 & 0.47 \\
\hline & 85 & 0.66 & 0.64 & 0.57 \\
\hline & 95 & 0.76 & 0.66 & 0.59 \\
\hline
\end{tabular}

